Uti. isso

UCRL--21137

DE89 004708

\title{
STANDARD REVIEW PLAN FOR REVIEWING \\ SAFETY ANALYSIS REPORTS FOR DRY \\ METALLIC SPENT FUEL STORAGE CASKS
}

\author{
Prepared by \\ NUCLEAR SAFETY ENGINEERING \\ 2500 Marconi Ave., Suite 316 \\ Sucramento, CA 95825 \\ Project Manager \\ Dr. Martin W. Schwartz \\ Prepared for

\section{LAWRENCE LIVERMORE NATIONAL LABORATORY \\ 7000 East Avenue Livermore, CA 94550} \\ Technical Representative \\ Jack M. Johnson

\section{NUCLEAR SYSTEM SAFETY PROGRAM} \\ DISCLAIMER
}

\begin{abstract}
This report was prepared as an account of work sponsoted by an agency of the United States Government. Neither the United Slates Government hur any agency thereof, nor any of their employees, makes any warranty, express or implied, or assumes any legal liability of responsi. bility for the accuracy, completeness, or usefulness of any information, anparatus, product, or process disclosed, or reptesents that ils use would nat infringe privately owned rights. Reference hercin to any specific comrnercial product, process, or service by trade name, teadernark, manufaclurer, or otherwise does not necessarily constitule ar imply its endorsement, recom. mendation, or favoring by the United Stales Governmenl of any agency thereol. The views and opinions of authars expressed herein do nol necessurily state or reflect those of the United States Government or any agency thereof.
\end{abstract}

\section{MASTER}

$$
i / 2
$$


The cask sandard Review Plan (CSRP) has been prepared as guidance to be used in the review of Cask Safety tnalysis Repons (CSARs) for storage packages. The principal purpose of the CSRP is to assure the quality and untifomity of storage cask reviews and to present a welldefined base irom which to evaluate proposed changes in the scope and requirements of reviews. The CSRP also sets forth solutions and approaches determined to be acceptable in the pasi by the VRC staff in dealing with a speciñc satety issue or safety-related design area. These solutions and approaches are presented in this torm so that reviewers can take consistent and well-understood positions as the same safety issues arise in future cases. An applicant submitting a CSAR does not have to follow the solutions or approaches presented in the CSRP. However. applicants should recognize that the NRC staff has spent substantial time and effor in reviewing and developing therr positions ior the issues. A correspording amoun of time and effort will probnbly be required to review and accepe new or different solutions and approaches. 
TABLE OF CONTENTS

$\underline{\text { Title }}$

1.0 INTRODUCTION

1.1 PURPOSE

1.2 SCOPE

1.3 DEFINITIONS

1.4 APPROACH

1.5 CASK STANDARD REVIEW PLAN SECTIONS

1.6 CASK STANDARD REVIEW PLAN SUBSECTIONS

1.6.1 General

1.6.2 Areas of Review

1.6.3 Acceptance Criteria

1.6.4 Review Procedures

1.6.5 Findings

1.6.6 References

Page №.

1.7 CASK STANDARD REVIEW PLAN REVISIONS

1.8 REFERENCES

2.0 PRINCIPAL DESIGN CRITERIA

2.1 AREA OF REVIEW

2.1.1 Spent Fuel to be Stored

2.1.2 Quality Standards

2.1.3 Protection Against Environmental Conditions and Natural Phenomena

2.1.4 Protection Against Fire and Explosions 2-2

2.1.5 Confinement Barriers and Systems 2-2

2.1.6 Instrumentation and Control Systems 2-2

2.1.7 Criteria for Nuclear Criticality Safery 2-2

2.1.8 Criteria for Radiological Protection 2-3

2.1.9 Criteria for Decommissioning 2-3

2.2 ACCEPTANCE CRITERIA

2.2.1 Spent Fuel to be Stored

2.2.2 Quality Standards

2.2.3 Protection Against Environmental Conditions and Natural Phenomena

2.2.3.1 Tomado and Wind Loading

2.2.3.2 Flood

2.2.3.3 Earthquakes

2.2.3.4 Thermal Loadings

2.2.4 Protecrion Against Fire and Expiosion

2.2.5 Confinement Barriers and Systems

2.2.5.1 Fuel Cladding

2.2.5.2 Mechanical Seals

2.2.6 Instrumentation and Control Systems $2-8$

2.2.7 Criteria for Nuclear Criticality Safety 2.8

2.2.8 Criteria for Radiological Protection 2-8

2.2.9 Criteria for Decorisnissioning 2-9

2.3 REVIEW PROCEDURES

2.3.1 Spent Fuel to be Stored

2.3.2 Quality Standards

2.3.3 Protection Against Environmental Conditions and Natural Phenomena 
2.3.4 Protection Against Fires and Explosions $2-10$

2.3.5 Confinement Barriers and Systems 2-10
2.3.5.1 Fuel Cladding

2.3.5.2 Mechanical Seals

2.3.6 Insrumentation and Control Systems 2-11

3.0 STRUCTURALEVALUATION 3-1

3.1 AREA OFREVIEW $3-1$

3.1 .1 Loads 3.1

3.1 .2 Materials 3-1

3.1.2.1 Material Properties 3-1

3.1.2.2 Fracture Resistance 3-2

3.1.2.3 Fasteners for Dry Spent Fuel Casks 3.2

3.1.2.4 Fabrication and Processing of Cask Components 3-2

3.1.3 Allowable Stresses $3-2$

3.1.4 Structural Design $3-3$

3.2 ACCEPTANCE CRITERIA

3.2.1 Loads 3-3

3.2.1.1 Nomal Operaing Conditions $3-3$

3.2.1.2 Extermal Environmental Conditions

3.2.1.3 Postulated Accidents 3-3

3.2.2 Materials 3.4

3.2.2.1 Material Properties 3-4

3.2.2.2 Fracture Resistance 3.4

3.2.2.3 Fasteners for Spent Fuel Casks 3-5

3.2.2.4 Fabrication and Processing of Cask Components

3.2.3 Allowable Stresses 3.5

3.2.4 Stuctural Design 3.5

3.2.4.1 Discussion 3-6

3.2.4.2 Sirucrural Design Criteria 3-6

3.2.4.2.1 Primary Containment Vessel 3-6

3.2.4.2.2 Baskets 3-6

3.2.4.3 Weights and Center of Gravity 3-6

3.2.4.4 Lifting Devices 3-6

3.2.4.5 Nomal Conditions of Storage 3-7

3.2.4.6 Hypocherical Accident Condivion $3-7$

3.2.5 Fuel Rod Integrity 3-7

3.2.5.1 Nomal Conditions of Storage $\quad 3.7$

3.2.5.2 Hypothetical Accident Conditions 3.8

3.3 REVIEW PROCEDURES 3.8

3.3.1 Loads 3.8

3.3.1.1 Nomal Operaung Conditions 3.8

3.3.1.1.1 Pressure Calcularions $3-8$

3.3.1.1.2 Decay Heat 3-10

3.3.1.1.3 Residual Stresses 3-10

3.3.1.2 Extreme Environmental Conditions
and Natuial Phenomena

3.3.1.3 Postulated Accidents 3.10 
3.3.2 Materials 3-10

3.3.2.1 Materials Properties $\quad 3+10$

3.3.2.2 Corrosion Resistance 3-11

3.3.2.3 Fracture Resistance 3-11

3.3.2.3.1 Austenitic Steels 3-11

3.3.2.3.2 Ferricic Steels 3-12

3.3.2.4 Fasteners for Spent Fucl Casks 3-13

3.3.2.5 Fabrication and Processing of Cask Components 3-13

3.3.2.5.1 Special Processes 3.13

3.3.2.5.2 Forming Processes 3-13

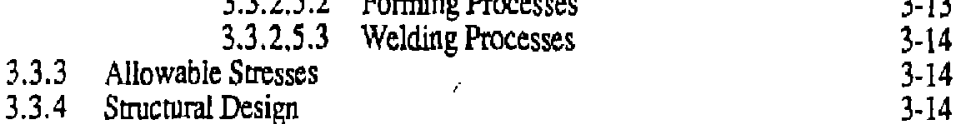

$\begin{array}{lll}\text { 3.3.4 Structural Design } & 3-14 \\ \text { 3.3.4.1 Description of Cask Components } & 3-14\end{array}$

3.3.4.2 Structural Design Criteria 3-15

3.3.4.3 Weights and Centers of Gravity 3-15

3.3.4.4 Lifting Devices 3-15

3.3.4.5 Nomal Conditions of Storage 3-15

3.3.4.5.1 Heat 3.16

3.3.4.5.2 Cold 3-16

3.3.4.6 Hypothetical Accident Conditions 3-16

3.3.4.6.1 Drop and Tipover Accidents 3-17

3.3.5 Fuel Rod Integricy $\quad 3-20$

3.3.6 Appendix 3-21

3.4 FINDINGS 3.21

3.5 REFERENCES 3-21

4.0 THERMAL EVALUATION 4-1

4.1 AREA OF REVIEW 4-1

4.2 ACCEPTANCE CRITERIA 4-1

4.2.1 Thermai Design Features 4-1

4.2.2 Thermal Loads 4.1

4.2.3 Thermal Properties of Materials 4-2

4.2.4 Thermal Specificarions on Cask Components $\quad 4.2$

4.2.5 Themal Evaluation of Nomal Conditions $4-3$

4.2.6 Hypothetical Accident Thermal Conditions 4.3

4.2.7 Appendix 4-3

4.3 REVIEW PROCEDURES $4-4$

4.3.1 Thermal Design Features $\quad 4-4$

4.3.2 Thermal Loads 4-4

4.3.3 Thermal Properties of Materials 4-4

4.3.4 Themmal Specifications on Cask Components 4.4

4.3.5 Thermal Evaluation of Nomal Conditions 4.5

4.3.5.1 Thermal Model 4.5

4.3.5.2 Test Model 4-5

4.3.5.3 Maximum and Minimum Temperatures $4-5$

4.3.5.4 Maximum Intemal Pressures 4-6

4.3.5.5 Maximum Thermal Stresses $4-6$

4.3.5.6 Evaluation of Cask Performance $\quad 4-6$

4.3.5.7 Documentation 4-6

4.3.6 Hypotherical Accident Thermal Evaluation 4.7

4.3.6.1 Thermal Model $4-7$

4.3.6.2 Test Model 4.7 
4.3.6.3 Cask Conditions and Environment 4-7

4.3.6.4 Cask Temperaures $\quad 4.7$

4.3.6.5 Maximum Intemal Pressures $\quad 4-8$

4.3.6.6 Maximum Thermal Stresses $\quad 4.8$

4.3.6.7 Evaluation of Package Performance 4-8

4.3.6.8 Documentation $4-9$

4.3.7 Appendix

$4-9$

4.3.8 Confirmatory Thermal Analyses $\quad 4-9$

4.3.8.1 Scoping Calculations $\quad 4-9$

4.4 FINDINGS

4.3.8.2 Thermal Computer Codes 4-10

$4-12$

5.0 SHIELDING EVALUATION $5 \cdot 1$

5.1 AREA OF REVIEW $5-1$

5.1.1 Source Specification 5-1

5.1.2 Model Specification 5-1

5.1.3 Shielding Evaluation 5.1

5.2 ACCEPTANCE CRTERIA $5-1$

5.3 REVIEW PROCEDURES $5-2$

5.3.1 Source Specification $5-2$

5.3.1.1 Gamma Source $\quad 5-2$

5.3.1.2 Neutron Source $5-3$

5.3.2 Model Specification 5-3

5.3.2.1 Radial and Axial Shielding Configuration 5-3

5.3.2.2 Shield Regional Densities $5-3$

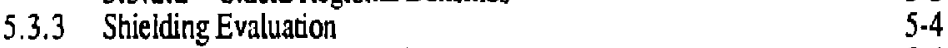

5.3.3.1 Methods of Analysis $\quad 5.4$

5.3.3.2 Computer Codes for Shielding Evaluation 5-5

5.4 FINDINGS 5-6

5.5 REFERENCES

6.0 CRJTICALITY EVALUATION 6-1

6.1 AREA OF REVIEW 6-1

6.1.1 Spent Fuel to be Stored 6-1

6.1.2 Model Specification 6-1

6.1.3 Cricicality Calculation 6-2

6.1.4 Critical Benchmark Experiments $\quad 6-2$

6.2 ACCEPTANCE CRITERIA $6-2$

6.2.1 Spent Fuel to be Stored $6-2$

6.2.2 Model Specificarion 6-2

6.2.2.1 Description of Calculational Model $6-2$

6.2.2.2 Spent Fuel Cask Regional Densicies 6-3

6.2.3 Criticality Calculation 6-3

6.2.3.1 Calculational or Experimental Method $\quad 6-3$

6.2.3.2 Fuel Loading Optimization 6-4

6.2.3.3 Criticality Results 6-4

6.2.4 Critical Benchmark Experiments 6-5

6.3 REVIEW PROCEDURES 6.5

6.3.1 Spent Fuel to be Stored 6.5

6.3.2 Model Specification 6.5

6.3.2.1 Description of Calculational Models 6-6

6.3.2.2 Spent Fuel Cask Regional Densities $\quad$ 6-6 
6.3.3 Criticality Calculation

6.3.3.1 Calculational or Experimental Method

6.3.3.2 Fuel Loading Optimization

6.3.3.3 Criticality Resulus

6.3.4 Critical Benchmark Experiments

6.3.4.1 Benchmark Experiments and Applicability 6-8

6.3.4.2 Details of Benchmark Calculations 6.9

6.3.4.3 Results of Benchmark Calculations 6.9

6.3.5 Confirmatory Calculations

6.10

6.4 FINDINGS

$6 \cdot 10$

6.5 REFERENCES

$6-10$

7.0 CONFINEMENT EVALUATION 7.1

7.1 AREA OF REVIEW 7-1

7.2 ACCEPTANCE CRITERIA

7.3 REVIEW PROCEDURES $7-2$

7.3.1 Confinement Boundary $7-2$

7.3.1.1 Primary Containment Vessel $\quad 7-2$

7.3.1.2 Primary Containment Penetrations $7-3$

7.3.1.3 Seals and Welds

7.3.1.4 Closure 7.3

7.3.2 Confinement of Radioaccive Material 7-3

$\begin{array}{ll}7.3 .2 .1 & \text { Seal Effectiveness } \\ 7.3 .2 .2 & 7-3\end{array}$

$7.3 .2,2$ Fuel Cladding 7.4

7.3.3 Confinmatory Analysis $\quad 7.4$

7.3 .4 Apperdix $\quad 7.4$

7.4 FINDINGS $7-5$

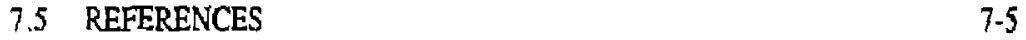

8.0 OPERATING PROCEDURES 8.1

8.1 AREA OFREVEW $8-1$

8.2 ACCEPTANCE CRITERIA 8-1

8.3 REVIEW PROCEDURES 8-1

8.3.1 Generd Description 8-1

8.3.2 Procedures for Loading and Sealing the Cask 8-2

8.3.3 Cask Draining and Drying Procedure 8-2

8.4 FINDINGS $8-2$

8.5 REFERENCES $8-3$

9.0 ACCEPTANCE TESTS AND MAINTENANCE PROGRAM $9-1$

9.1 GENERAL 9-1

9.2 AREASOFREVEW $9-2$

9.2.1 Acceptance Tests 9.2

9.2.2 Maintenance Program 9-2

9.3 ACCEPTANCE CRTIERIA 9-2

9.3.1 Acceptance Tests 9.2

9.3.1.1 General 9.2

9.3.1.2 Confinement 9.3

9.3.1.3 Gamma Shield 9.3

9.3.1.4 Neutron Shield 9.3

9.3.1.5 Subcriticality Assurance

9.3.1.6 Thermat . $9-3$

9.3.2 Mainrenance Program 9-4

9.3.2.1 Tesing $9-4$ 
9.4 REVIEW PROCEDURES

9.4.1 Acceptance Tests

9.4.1.1 Visual Inspection

9-5

9.4.1.2 Structural and Pressure Tests

$9-5$

9.4.1.3 Leak Test

9.4.1.4 Component Tests

9.4.1.4.1 Valves and Rupture Discs 9-5

9.4.1.4.2 Gaskets

$9-5$

9.4.1.4.3 Miscellaneous $9-6$

9.4.1.5 Tests for Shielding Integrity 9-6

9.4.1.6 Thermal Acceplance Tests 9-6

9.4.1.6.1 Discussion of Test Setup 9-6

9.4.1.6.2 Test Procedure 9-7

9.4.1.6.3 Acceptance Criteria

9.4.2 Maintenance Progran

9.4.2.1 Leak Tests

9.7

9.4.2.2 Subsystem Maintenance $\quad 9-7$

9.4.2.3 Valves and Ruprure Discs

9.4.2.4 Shielding 9.8

9.4.2.5 Thermal 9.8

9.5 FINDINGS

9.4.2.6 Miscellaneous 9.8

9.6 REFERENCES 9.9

10.0 RADIATION PROIECTION 10-1

10.1 AREA OF REVIEW $10-1$

$\begin{array}{ll}10.2 & \text { ACCEPTANCE CRITERIA } \\ 10.3 & \text { REVIEW PROCEDURES }\end{array}$

10.3 REVIEW PROCEDURES
10.3.1 Ensuring that Occupational Radiation Exposures

are ALARA

10.3.1.1 Policy Considerations

$10-2$

10.3.1.2 Design Considerations

$10-2$

10.3.1.3 Operational Considerations

$10-2$

$10-3$

10.3.2 Radiation Protection Design Features

$10-3$

10.3.2.1 Access Control of Radiation Areas

$10-3$

10.3.2.2 Radiacion Shields and Geometry

$10-3$

10.3.2.3 Process Instrumentation and Controls

10-3

10.3.2.4 Control of Airbome Containments or Gaseous Radiation Sources

$10-4$

10.3.3 Estimated Onsite Collective Dose Assessment

$10-4$

10.3.3.1 Single Cask Dose Rates

10.3.3.1.1 Doses From Direct Radiation

10.3.3.1.2 Doses From Gaseous Activity Release

$10-4$

$10-4$

10.4 FINDINGS

$10-5$

$10-6$

10.5 REFERENCES

$10-6$

11.0 ACCIDENT ANALYSIS $11-1$

11.1 AREA OF REVIEW

$11-1$

11.2 ACCEPTANCE CRITERIA

$11-1$

11.2.1 Radiological Consequences

11.1

11.2.2 Safely Analysis Report Requirements

11.2

11.2.2.1 Off-normal Occurrences

$11-2$

11.2.2.2 Accidents

11.2 
11.3.1.1 Identification of Component or System Malfunction 11-2

11.3.1.2 Postulated Cause of the Event 11-2

11.3.1.3 Detecrion of the Event

$11-3$

11.3.1.4 Analysis of Effects and Consequences $\quad$ 11.3

11.3.2 Accidents

11.3.1.5 Comective Actions

$11-3$

11.3.2.1 Cask Drop

11-3

11.3.2.2 Cask Tipover

11-4

11.4 FINDINGS

\section{GS}

11.5 REFERENCES

$11-5$

11.6

11-7

12.0 DECOMMISSIONING

12.1 AREA OF REVIEW

12.2 ACCEPTANCE CRITERIA

12.2.1 General

$12-1$

12.2.2 Assurance of Public Safery

12-1

12.3 REVIEW PROCEDURES

12.3.1 Provisions to Faciliate Decontamination

12.3.1.2 Decontamination

12.3.2 Decommissioning of Cask Components

12.5 REFERENCES

13.0 OPERATTNG CONTROLS AND LIMITS

13.1 AREA OF REVIEW

13.1.1 Functional and Operating Limits 13-1

13.1.2 Limiting Conditions

13-1

13.1.3 Surveillance Requirements

13-1

13.1.4 Design Features

13-2

13.2 ACCEPTANCE CRITERIA

13-2

13.3 REVIEW PROCEDURES

13-2

13.3.1 Proposed Operating Controls and Limits

13-2

13.3.2 Funcional and Operating Limits

13-3

13.3.2.1 Integrity of Stored Fuel

13.3.2.2 Protection of Employees Against

Occupational Exposures

13.3.2.3 Guarding Against the Release of Radioactive Materials to the Environment

13.3.3 Limiting Conditions for Operation 


\section{ABBREVIATIONS}

\begin{tabular}{ll} 
CSRP & Cask Standard Review Plan \\
DSC & Dry Metallic Spent Fuel Storage Cask \\
CSAR & Cask Safety Analysis Report \\
NRC & (U.S.) Nuclear Regulatory Commission \\
SER & Safety Evaluation Report \\
ASME & American Society of Mechanical Engineers \\
ANSI & American National Standards Institute \\
ALARA & As low as reasonably achievable. \\
& \\
ISFSI & Independent spent fuel storage installation \\
& \\
\hline TSAR & Topical Safety Analysis Repor
\end{tabular}




\subsection{INTRODUCTION}

The Cask Standard Review Plan (CSRP) is designed to facilitate safety teview of cask safety analysis reports (CSARs) for dry metallic spent fuel storage casks (DSCs). The CSRP is developed in concer with and stippont of a site independent dry spent fuel storage cask certification rulemaking that was initiated in Fiscal Year 1987 by the U.S. Nuclear Regulatory Commission (NRC) in response to congressional direction giver in Sections 133 and 218 (c) or the Nuclear Waste Policy Act of 1982. It is anticipated that this rulemaking will result in two new subpans to 10 CFR Part 72 (Ref. 1.1) designated Subpars K and L. Under a storage cask certification rule, a general license would be issued under Subpart K of Part 72 to holders of commercial power reactor licenses to receive, handle, transfer and store spent fuel at their sites in casks which have feceived cerification under Subpar L of Part 72. As users of certified storage casks, reactor licenses would be subject to those restrictions set forth in the certificates of the casks used in addicion to the conditions and technical specifications of their Part 50 reactor operating licenses.

\subsection{PURPOSE}

The Dry Spent Fuel Storage Cask Standard Review Plan (CSRP) is prepared for the guidance of staff reviewers in performing safety reviews of applics:ions to fabricate and use dry metallic spent fuel storage casks (DSCs). The principle purpose of CSRP is to assure the quality and uniormity of staff reviews, and to present a well-defined base from which to evaluate proposed changes in the scope and requirements of reviews. It is also a purpose of the CSRP to make information about regulatory matters widely available and to improve communication and understanding of the staff review process by interested members of the public, the nuclear induscry, and paricularly, potential applicants.

\subsection{SCOPE}

The safety review is primarily based on the information provided by an applicant in a CSAR. Draft Subpart K of 10 CFR Pan 72 will require that each application for the site independent certificaion of dy metallic casks for the storage of spent fuel on a licensed operating power reactor site shall include a CSAR. The CSAR must be sufticienty detailed to permit the staff to determine whether the cask can be fabricared, handled, and can store spent fuel at the reactor site without undue risk to the health and safely of the public and without further license review. Prior to submission of the CSAR, an applicant must have desigied and analyzed the cask in sufficient detail to conclude that it can be fabricated and used safely. The CSAR is the principle document in 
which the applicant provides the information needed to understand the basis upon which this conclusion has been reached.

Subpar $\mathrm{K}$ specifies, in general terms, the information to be supplied in the CSAR. Specific information requested by the staff for an cvaluation of a certification application is identified in associated Regulatory Guides.

The CSRP is written to cover enveloping site conditions for potentially acceptable cask designs. Each section is written to provide the procedure and arceptable criteria for the areas of review pertinent to that section. However, for any given appication, the staff reviewers may select and emphasize particular aspects of each CSRP section as is appropriate for the application.

\subsection{DEFINITIONS}

"As low as reasonably achievable" (ALARA) means as low as reasonably achievable taking into account the state of technology and the economies of improvements in relation to (1) benefits to the public health and safety; (2) other societal and socioeconomic considerations; and (3) the utilization of atomic energy in the public interest.

"Cask" in the context of this SRP is a metallic containment for commercial nuclear spent fuel having provisions for shielding against gamuna and neutron radiation and maintaining the contents in a subcritical condition.

"Commission" means the Nuclear Regulatory Commission or its duly authorized representatives.

"Confinement systems" means those systems that act as barriers between areas containing radioactive substances and the environment.

"Controlled area" means the area immediately surrounding an ISFSI for which the licensee exercises authority over its use and within which ISFSI operations are performed.

"Decay heat" means the heat generated by the process of radioactive decay of the fission products in the spent fuel.

"Design bases" means that information that identifies the specific functions to be performed by a structure, system or component of a storaze cask and the specific values or ranges of values chosen for controlling parameters as reference bounds for design. These values may be rescraints derived from generally accepted "state-of-the-art" practices for achieving functional goals or 
requirements derived from analysis (based on calculation or experiments) of the effects of a postulated event under which a structure, system or component must meet its functional goals. The vaiues for controlling parameters for extemal events include:

(1) Estimates of severe natural events to be used for deriving design bases that will be based on consideration of physical data or analysis of the upper limits of the physical processes involved.

(2) Estimates of severe exlemal man-induced events to be used for deriving design bases that will be based on analysis of human activity in the design and the risks associated with the event.

"Design capacity" means the quantity in meric tons of spent fuel, fissile material enrichment. its maximum bumup in MWD/MTU and the total heat generation in watts that the storage cask is designed to accommodate.

"Independent Spent Fue! Storage Installation" (ISFSI) means a complex designed and constructed for the storage of spent fuel and other radioactive materials associated with spent fuel storage.

"Neutron poisons" are materials incorporated in the cask components to absorb neutrons.

"Radioactive materiol" is any material, or combination of materials, that spontaneously emits ionizing radiation and has a specific activity in excess of 0.002 microcurie per gram of marerial.

"Site" means the real property on which the ISFSI is located.

"Spent fuel" means irradiated nuclear fuel that has undergone at least five years' decay since being used as a source of energy in a power reactor.

"Structures, systems and components important to safety" means those features of the storage cask whose function is:

(1) To mainain the condirions required to store spent fuel safely;

(2) To prevent damage to the fuel during handling and storage; or

(3) To provide reasonable assurance that spent fuel can be stored and retrieved without undue risk to the health and safety of the public. 


\subsection{APPROACH}

The overall safety of a DSC is the responsibility of the applicant. The applicant is responsible for meeting the regulations in the design, development, use, and maintenance of the DSC. The CSAR must be sufficiently detailed to permit the reviewer to determine both that the DSC has been designed and analyzed in sufficient detail, and to conciude that it can be built and operated without undue risk to the health and safety of the public. The CSAR is the principal document in which the applicant provides the information needed for the reviewer to verify the basis upon which this conclusion has been reached. The reviewer is to verify that the applicant has properly documented in the CSAR the adequacy of the DSC with respect to regulations. The reviewer should not perform design analysis or modify the design for the applicant. The reviewer should perform only confirmatory analyses as provided in this guide to verify the adequacy of the design. The review should emphasize those components of the DSC that are most important to safety.

The regulations are intended to assure that the public and operating personnel will be protected in the event that a DSC is involved in an accident or exposure to a severe environmental condition. The regulations state that a DSC must meet certain confinement, radiation contol and subcrivicality assurance requirements when it is subjected to specified normal operating conditions, hypotherical accidents and extreme erivironment $\lrcorner$ conditions.

The regulations do not define the allowable structural or thermal damage a D:C may sustain, but instead use radiological criteria; i.e., radioactivity release (leakage) and radiation levels external to the DSC as a measure of the acceptability of the design. Therefore, the DSC response must be such that it can (1) meet containment requirements (any radioactive material release must be restricted within stated limirs); (2) keep external radiation levels within stated limits; and (3) ensure that a criticality event cannot occur.

DSCs are designed to meet the normal, accidental and extreme environmental conditions by using established codes and standards.

10 CFR 72.122 (a) requires that "structures, systems and components iriportant to safety shall be designed, fabricated and tested to quality standards commensurate with the imporance of safeety or the function to be performed."

At a minimum. codes and standards provide quality assurance criteria, acceptance criteria. and margins of safery. In general, margins of safety are included in established codes and standards such as the ASME code (Ref. (.2) and the A.XSI Standards and Regulatory Guides. 
These margins of safety ensure that the design will compensate for the uncertainties inherent in the design basis loading conditions.

In performing a CSAR review, a reviewer should have an open mind toward evaluating new technology and methods. However, in evaluating new materials, technologies and methods, a reviewer must consider the intent of the regulations not to expose the public to undue risk. For example, if a DSC structural design uses ASME or other authoritative code material, the design limits usually have sufficient margins embedded in them to protect the public from undue risk for impact conditions exceeding hypothetical accident conditions. If a new material not specified in an authoritative code is used for structural design, the embedded margin is likely unknowil, and may be insufficient. If unknown, the margin would have to be determined and, perhaps, a risk assessment would have to be performed. The risk assessment would have to include not only the material properties for all anticipated environmental conditions but must also cover all possible conditions to assess the total risk.

\subsection{CASK STANDARD REVIEW PLAN SECTIONS}

This review is primarily based upon information provided by an applicant in the CSAR. The CSAR is to be prepared in accordance with draft Regulatory Guide CE-306-4: "Standard Format and Content for a Topical Safety Analysis Report for a Dry Spent Fuel Storage Cask." The sections of this CSR? parallel the standard format in CE-306-4.

\subsection{CASK STANDARD KEVIEW PLAN SUBSECTIONS}

The individual CSRP sections address in detail the objectives and methods of the review, the areas that are reviewed, the acceptance criteria for the review, how the review is accomplished, and the rypes of conclusions that are sought. One of the objectives of the CSRP is to identify the disciplines required to perform the review and to define the sometimes complex interfaces between them. Each CSRP identifies the primary discipline required to teview that section. In some areas the primary discipline may require support. Each CSRP section also identifies the other disciptines that are required to perform their supplemental reviews.

\subsubsection{General}

This subsection discusses the overall objectives. approach and methods of the review. The information required to complete the review is identified. Acceptable methods of analysis and computer codes for pertorming analyses are identified and discussed. Acceptable testing methods 
are also discussed. The guidance provided assists the reviewer to estimate the depth and complexity required to accomplish specific reviews.

Each review procedure is organized into six subsections as follows:

\section{1,6.2 Areas of Review}

This subsection describes the scope of review in parallel with draft guide CE-306-4. This subsection contains a description of the systems, components, analyses, data, or other information that is reviewed as part of the particular CSAR section in question.

\subsubsection{Acceptance Criteria}

This subsection contains the purpose of the review and the technical basis for determining the acceptability of the design or the programs within the scope of the area of review of the section. The technical bases consist of specific criteria such as NRC Regulatory Guides, sections of Part 72, and Branch Technical Positions.

The technical bases for some sections of the CSRP are provided in Branch Technical Positions or other documents which may be referenced in the CSRP. These documents typically set forth the sointions and approaches determined to be acceptable by the staff in dealing with a specific safety problem or design area which is important to safety. These solutions and approaches are codified in this form so that staff reviewers can take uniform and well-understood positions as the same safety problems arise in future cases.

Some Branch Technical Positions and referenced documents may be converted into Regulatory Guides if it appears that this step would aid the review process. Like Regulatory Guides, the Branch Technical Positions and referenced documents represent solutions and approaches that are acceptable to the staff, but they are not required as the only possible solutions and approaches. However, applicants should recognize that, as in the case of Regulatory Guides, substantial time and effort on the part of the staff has gone into the development of the Branci Technical Positions that a corresponding amount of time and effor will probably be required to review and accept new or different solutions and approaches. Thus, applicants proposing other solutions and approaches to safety problems or design areas which are important to safety than those described in the Branch Technical Positions and referenced documents must expect longer review times and more extensive questioning in these areas. The staff is willing to consider 
proposals for other solutions and approaches on a generic basis, apart from a specific license applicanion, to avoid the impact of the additional review time on individual cases.

\subsubsection{Review Procedures}

This subsection will discuss how the review is accomplished. The section is generally a step-by-step procedure that the reviewer goes through to provide reasonable verification that the applicable safery criteria have been met.

\subsubsection{Findings}

This subsection will present typical conclusions for the particular review area. For each section. a conclusion is included in the staff's Safety Evaluation Report (SER) in which the staff publishes the results of their review. The SER also contains a description of the review including such subjects as which aspects of the review were selected or emphasized; which matters were modified by the applicant, require additional infomation, will be resolved in the future, or remain unresolved; where the facilities design of the applicant's report deviate from the criteria stated in the CSRP; and the bases for any deviations from the CSRP or exemptions from the regulations.

\subsubsection{References}

This subsection will list the references used in the review process. Division 3 and other division regulatory guides, as applicable, will be referenced throughout this repor.

\subsection{CASK STANDARD REVIEW PLAN REVISIONS}

The CSRP not only documents current methods of review but also provides the base for orderly modifications of the review process in the future. The CSRP will be revised and updated as the need arises to clarify the content to correc! errors, or to incorporate modifications approved by the NRC.

The revision number and publication date are priated at the lower comer of each page of each CSRP seccion. Since individual sections have been, and will continue to be revised as needed, the revision numbers and dates will not be the same for all sections. The Table of Contents indicates the revision numbers of the currently effective sections. Comments and suggestions for improvement will be considered and should be sent to the Director, Office of Nuclear Material 
Safely and Safeguards, U.S. Nuclear Regulatory Commission Washington, DC 20555. Notices of errors or omissions should also be sent to the same address.

\subsection{REFERENCES}

1. Office of Federal Register, Title 10, Code of Federal Regulations, Part 72, Office of the Federal Register, Washington, DC, August 1988.

2. American Society of Mechanical Engineers, ASME Boiler and Pressure Vessel Code, 1986 Edition, the American Socicty of Mechanical Engineers, United Engineering Center, $345 \mathrm{E}$. 47th Street, New York, New York 10017.

3. U.S. Nuclear Regulatory Commission, Regulatory Guide CE-306-4: Standard Format and Content for a Topical Safery Analysis Report for a Dry Spent Fuel Storage Cask, U.S. Nuclear Regulatory Commission, Office of Standards Development, Washington, DC 


\subsection{PRINCIPAL DESIGN CRITERIA}

\subsection{AREA OF REVIEW}

Subpart F of 10 CFR Part 72 (Ref. 2.1) sets forth general design criteria for the design, fabrication, constiuction, testing and performance of structures, systems and components important to safety in an independent spent fuel storage installation (ISFSI). Mary of these criteria are applicable to the DSC and should be established by the applicant in the CSAR. The principal design criteria review covers the following specific areas:

\subsubsection{Spent Fuel to be Stored}

A detailed description of the physical, thermal and tadiological characteristics of the spent fuels that the DSC is designed to store is a fundamental rezuirement for establishing and assessing the validity of the principal design criteria associated with thermal, shielding, confinement and criscality evaluarions.

\subsubsection{Quality Standards}

Paragraph 72.122 (a) specifically requires that quality standards be used for suructural systems and components important to safety. A quality standard provides numerical criteria cr accepiable methods or both for the design, fabrication, testing, and performance of these structures, systems and components important to safety. Application of these standards provides confidence in the capability of the structures, systems or components to perform their required safety functions.

\subsubsection{Protection Against Environmental Conditions and Natural Phenomena}

Section 72.122 (b) of 10 CFR Part 72 requires the licensee to provide protection against environmental conditions and natural phenomena - the review assesses the adequacy of the loadings assumed to result from exposure to these environmental conditions and natural phenomena. The specific environmencal conditions and natural phenomena to be considered are:
A. Tomado and wind loading
B. Flood
C. Earthquake
D. Thermal Loading 
1. Ambient temperature limits

2. Snow and ice loadings

3. Solar insulation

\section{L.4 Protection Against Fire and Explosions}

Section 72.122 (c) of 10 CFR Part 72 requires the applicant to provide protection against fires and explosions. Fires can increase the heat flux into the DSC as well as cause degradation of materials used for components and structures important to safety. The overpressure due to explosion is additive to the loads that exist under both normal and accident conditions.

\subsubsection{Confinement Barriers and Systems}

This area of review addresses the degree of confinement provided by the DSC to ensure that there will be no uncontrolled release of radioaccivity to the environment. The first barrier is the fuel rod cladding which 10 CFR Part 72.122 (h) specifically requires to be protected against degrajation and gross rupture. A secondary barrier is the containment vessel itself and the hermetic seals at all mechanically fastened closures that not only prevent the release of radioactive gases and particulates but also serve to retain an internal inert cover gas if such cover gas is specified in the design.

\subsubsection{Instrumentation and Control Systems}

10 CFR Part 72.122 (i) requires that the applicant provide instrument and control systems that monitor systems important to saiety over anticipated ranges for normal and off-normal operations. This area of review covers the manner in which the applicant addresses this issue.

\subsubsection{Criteria for Nuclear Criticality Safety}

10 CFR Par 72.124 requires that spent fuel handling, tansfer and storage systems be designed to be maintained subcritical. The review under this section addresses only the specified maximum effective multiplication factor ( $k$-eff) for the prevention of criticality. All other issues involving nuclear criticality safety are addressed in Chapter 6. 


\subsubsection{Criteria for Radiological Protection}

10 CFR Part 72.126 requires the applicant to provide adequate (a) protection systems for radiation exposure control, (b) radiological alarm systems, (c) systems for monitoring effluents and direct radiation, and (d) effluent and control systems in a radiological protection program. However, under the generic rule of subpart $L$, only item (a) is relevant. The others relate more directly to the entire ISFSI. Consequently, review under this section only addresses the design criteria for the primary systems of the DSC that provide protection against radiation exposure.

\subsubsection{Criteria for Decommissioning}

10 CFR Part 72.130 requires the applicant to design the ISFSI for decommissioning. Under the generic rute the requirement for decommissioning is limited to the DSC. The review under this section examines the applicant's decommissioning provisions with emphasis upon decontamination of the DSC components following removal of the radioactive spent fuel. All other issues conceming decommissioning are addressed in Chapter 12.

\subsection{ACCEPTANCE CRITERIA}

\subsubsection{Spent Fuel to be Stored}

A description of the spent fuel to be stored must include, but is not limited to, the following characteristics:
A. Type (BWR, PWR)
B. Number of fuel assemblies
C. Enrichment
D. Specific power
E. Burnup
F. Decay time
G. Heat generation rate
H. Cladding description
I. Dimensions
J. Weight
K. Internal fuel rod pressure at $300^{\circ} \mathrm{K}$ 


\subsubsection{Quality Standards}

The design, fabrication, testing and perfomance of structures, systems and components important to safety will conform to quality standards if widely accepted and authoritative codes and standards are cited as the basis for all these activities. Some examples of quality standards implied by the regulation are:

A. The American Society of Mechanical Engineers Boiler and Pressure Vessel Code (ASME)

B. The American Society for Testing and Materials (ASTM)

C. The American Iron and Steel Insirute (AISI)

D. American National Standards Institute (ANSI)

E. United States Military Specifications (Mil-Specs)

F. Foreign Codes and Standards of highly industrialized countries (U.K., France. DFR of Germany, Japan, etc.)

G. Provisions of IAEA Codes where applicable

\subsubsection{Protection Against Environmental Conditions and Natural Phenomena}

10 CFR Pur 72.122 (b) (2) provides acceptance criteria for sinuctures, systems and components associated with the entre spent fuel storage installations (ISFSI). $10 \mathrm{CFR}$ Part 72.122 (b) (2) (i) requires that appropriate consideration be given to the "most severe of the natural phenomena reported for the site and surrounding areas ....." For the purpose of generic rulemaking for the DSC under Subpart $L$ of Part 72, it is intended that acceptance criteria for the storage cask be site-independent. This implies that the design criteria for the DSC velope credible extremes of environmental conditions and natural phenomena that may be expt...nced throughout the entire United States. This also obviates the further requirement under 72.122 (b) (2) (i) that appropriate margins be applied to take into account any limitations of the data accumulated for site-specific environmental conditions and natural phenomena. However, this does not relieve the applicant from addressing appropriate combinations of the effect of normal and accident conditions and the effects of natural phenomena.

According to 72.122 (b) (2) (ii) the entre ISFSI need not be protected from tornado missiles but should be designed to prevent massive collapse of building structures or the dropping of heavy objects on the stored spent fuel as a result of building failures. Since the DSC's will generally be positioned in arrays unprotected by building scructures, it is appropriate that they be invulnerable to 
the effects of tornado generated or other high speed missiles. The following acceptance criteria are established for the environmental conditions and natural phenomena outlined in Paragraph 2.1.3.

\subsubsection{Tornado and Wind Loading}

The acceptance criteria established for tornado and wind loading are those contained in USNRC Regulatory Guide 1.76 (Ref. 2.2), "Design Basis Tornado for Nuclear Power Plants," which provides enveloping design basis tomado characteristics for the contiguous United States. Of the three regionalized design basis tomados specified in Table 1 of the Regulatory Guide 1.76, the maximum wind speed and pressure drop occur in Region I for which the following characteristics are cited:

$\begin{array}{lcr}\text { Maximum wind speed } & 360 \text { miles } / \text { hour } & (161 \text { meters } / \mathrm{sec}) \\ \text { Maximum rotational speed } & 290 \mathrm{miles} / \mathrm{hour} & (130 \mathrm{~meter} / \mathrm{sec}) \\ \text { Maximum ranslational speed } & 70 \text { miles/hour } & (31.3 \mathrm{~meters} / \mathrm{sec}) \\ \begin{array}{l}\text { Minimum translational speed } \\ \text { Radius of maximum }\end{array} & 5 \text { miles } / \text { hour } & (2.24 \mathrm{~meters} / \mathrm{sec}) \\ \text { rotacional speed } & & \\ \text { Pressure drop across tomado } & 150 \mathrm{feet} & (45.7 \mathrm{~meters}) \\ \text { Rate of pressure drop } & 3 \mathrm{psi} & (20,684 \mathrm{p} 2) \\ & 2.0 \mathrm{psi} / \mathrm{sec} & (13790 \mathrm{pa} / \mathrm{sec})\end{array}$

The recommended design criteria for tomado generated missiles is contained in NUREG0800, SRP 3.5.1.4 (Ref. 2.3). "Missiles generated by natural phenomena," in which three types of missiles are defined. The first type of missile is a high kinetic energy object that deforms on impact and is representative of an $1800 \mathrm{~kg}$ (3968 lb) automobile. The second type of missile is a rigid object to test penetration resistance of the DSC. It weighs $125 \mathrm{~kg}(276 \mathrm{lb})$ and is representative of an armor piercing artillery shell. The third type of missile is a small rigid object that is able to pass through any openings in procective barriers. It is characterized by a solid steel sphere one inch $(2.54 \mathrm{~cm})$ in diameter. All these missiles are assumed to impact the cask at $35 \%$ of the maximum horizontal wind speed of the tornado which, based upon a maximum speed of 368 miles/hour, is 126 miles/hour at a location that is most damaging to the DSC,

\subsubsection{Flood}

The SAR must describe the ability of the DSC to resist the sffects of floods, tsunami and seiches which are characterized by the impact of massive torrents of water and deep submergence. 
Since a credible bound for submergence has nowhere been specified for the entire United States, an acceptable approach is to determine the submergence limit for the DCS that would not cause stresses to exceed the allowable limits. Similarly, since no credible bound for torrent velocity exists for the entire United States, it should be assumed that its magnitude is sufficient to topple the DSC and an analysis provided to show that the safety function of the cask is not compromised by the tipover.

\subsubsection{Earthquakes}

The SAR must describe the ability of the DSC to resist the effects of earthquakes. 10 CFR Part 72.102 (a) (2) requires that for sites that have not been evaluated under the criteria of Appendix A of 10 CFR Part 100, that are east of the Rocky Mountain front, and that are not in areas of known seismicity, a standardized ISFSI design earthquake described by an appropriate response spectrum anchored at $0.25 \mathrm{~g}$ may be used. This requirement applies to massive water basin and air cooled canyon types of ISESI. For other designs employing canisters, casks or silos, 10 CFR Part 72.102 (b) requires a site specific investigation to establish site suitability. However, under generic rulemaking, the DSC must be able to resist a maximum credible earhquake within the entire United States without compromising its ability to perform its required safety function. Ground acceleration much higher than $0.25 \mathrm{~g}$ have been recorded and it must be assumed that a DSC may experience an earthquake strong enough to cause it to topple. Consequently, the SAR must demonstrate the ability of the DSC to resist the effects of a tipover without exceeding performance limits defined by the regulation.

\subsubsection{Thermal Loadings}

The thermal environment of a DSC has a direct effect upon jts ability to dissipare decay heat and maintain the fuel at a temperature below which gross rupture of the fuel cladiding cannol occur over the design life of the ISFSI.

\section{A. Ambient tempernnure minge}

Boundary site characteristics relating to the ambient temperature range shall be:

Maximum $\quad 130^{\circ} \mathrm{F} \quad\left(55^{\circ} \mathrm{C}\right)$

Minimum $\quad .40^{\circ} \mathrm{F} \quad\left(-40^{\circ} \mathrm{C}\right)$ 


\section{B. Snow and Ice Loading}

In contrast with ISFSI conventional storage structures, the dead loading of ice and snow is of little concern for a DSC. On the other hand, periodic precipitation of snow and $p$ issible formation of ice can cause thermal gradients in the containment structure and the generation of fluctuating stress conditions. The long term effect of these stress cycles should be addressed to assure that the materials of components and structures important to safety are not degraded to a point where structural integrity is compromised.

\section{Solar Insolation}

The maximum beat flux due to solar insolation normal to a sufface at sea level is about 443 BTU/ft2/hr (Ref. 2.4). Bounding site characteristics should assume this level of heat fiux 365 day/yr. However, the flux may be redneed by considering the diumal variations of solar altitude and the acrual geometry of the DSC.

\subsubsection{Protection P.gainst Fire and Explosion}

The acceptance criterion defined by $10 \mathrm{CFR}$ Part 72.122 (c) 1equires that structures, systems and components important to safety be designed and located so that they continue to pefform their 5. ervy functions effectively under credibie fire and explosion conditions.

\subsubsection{Confinement Barriers and Systems}

\subsubsection{Fuel Cladding}

It has now been accepted that a diffusion controlled cavity growth mechanism is the primary damage mechanism applicable to the conditions of storage of spent fuel rods that could cause degradation and gross rupture of the cladding. Under the influence of stress and temperarure, this damage mechanism progresses by the nucleation and growth of cavities along grain boundaries. This damage mechanism is of concern since it can progress without external evidence of damage. may not cause pin holes or through cracks to relieve internal pressure, and manifests itself by a sudden non-ductile type of fracture.

The only parameters that the DSC designer may control to prevent cladding degradation or gross rupture in an iner environment are the maximum initial temperature of the fuel rods and their temperature decay characteristics over the design life of the ISFSI. Both are governed by the quantity, specific power and age of the fuel assemblies and by the hear dissipation propenies of the 
DSC. For the conditions of intemal rod pressure and temperature decay characteristics established by the applicant in the CSAR, the level of damage to the cladding should not exceed the equivalent of a $15 \%$ reduction in cladding cross section.

\subsubsection{Mechanical Seals}

The design criterion for the mechanical seals will be acceptable if it is demonstrated that the anticipared maximum leakage rates through the seals are small enough to preclude both loss of inert cover gas over at least a twe!ty year storage period or release of radioactive materials in excess of the limits defined by the confinement criteria specified in Chapter 7.

\subsubsection{Instrumentation and Control Systems}

The design criteria for the instrumentation and control systems must identify the systems important to safety that need to be monitored and the limits that detise the acceptable range for normal operation.

\subsubsection{Criteria for Nuclear Criticality Safety}

Criticality safery is assured if, for all credible configurations and environments, the maximum effective multiplication factor, $k$-eff, does not exceed 0.95 .

\subsubsection{Criteria for Radiological Protection}

The principal radiation exposure protection design features of the DSC are the inherent shielding capability of the cask and the integrity of the seals at the closure joints. These subjects are treated in more detail in Chapter 5 dealing with shielding and Chapter 7 dealing with confinement. From the point of view of radiological protection criteria, 10 CFR Parts 72.67 and 72.68 mandate the limits of exposure both to the public outside the controlled area and the operating personnel within it. Under the generic rule, the CSAR for the DSC need not consider the issue of the controlled area boundary directly since this is a site-specific matter. However, the DSC applicant needs to appreciate the regulatory limits for radiation exposure imposed upon the ISFSI designer and must be aware that the radiation levels from the DSC, especially in multiple arrays, need to fall within these regulatory limits. The essential element in reviewing the design criteria is that the applicant clearly state the dose rate limits that governs the design. The methods by which the limits are assured are the subjects of Chapters 5. 7, 10, and 11 . 


\subsubsection{Criteria for Decommissioning}

Acceptable design criteria for decommissioning must include, but are not limited to, the specification of the maximum quantity of residual activity present in the cask that will qualify it for disposal or reuse in accordance with applicable regulations.

\subsection{REVIEW PROCEDURES}

\subsubsection{Spent Fuel to be Stored}

Review the secrion of the CSAR that deals with the description of the spent fuel to be stored and assure that it includes, at least, all the information outlined in paragraph 2.2.1 of the acceptance criteria.

\subsubsection{Quality Standards}

Assure that the applicant has identified all structures, systems and components important to safety and review the codes and standards used for design, fabrication, testing and performance to assure that they are truly quality standards as defined in paragraph 2.2 .2 of the acceptance criteria.

\subsubsection{Protection Against Environmental Conditions and Natural Phenomena}

A. Review the CSAR to assure that all the environmental conditions listed in paragraph 2.1.3 are addressed.

B. Check to ascertain that appropriate design criteris are documented for each environmental condition and naural phenomena and that applicable references are cited.

\subsubsection{Tornado and Wind Loading}

A. Determine that the design parameters applicable to the design tornado and tomado generated missiles recommended in paragraph 2.2.3.1 are specified.

B. Review the methodology for convering the tomado wind and missile loadings to forces on the DSC and ascerain that they are adequately described by appropriate free body diagrams. 


\subsubsection{Flood}

Review the analysis for the effect of deep submergence on the DSC and check that the resulting stresses do not exceed the allowable limits applicable for this condition.

\subsubsection{Earthquake}

Review the analysis for the effect of DSC tipover in accordance with guidance outlined in the structural review section of this SRP.

\subsubsection{Thermal Loadings}

A. Check the ambient temperature range assumed by the applicant for subsequent thermal analysis.

B. Examine the assumptions provided by the applicant in establishing temperature range, cooling rates and frequency of snow and ice precipitation.

C. Verify the basis upon which the heat flux due to solar insolation is established.

\subsubsection{Protection Against Fires and Explosions}

Review the assumptions made by the applicant with regard to the intensity and duration of a fire and explosion in the vicinity of the DSC. Under the generic rule there is no provision for limiting the amount of combustible or explosive material in the vicinity of the DSC installation. Consequently, a bounding condition should be assumed that meets the regulatory reference to credibility. If the applicant chooses an upper limit for fire corresponding to the conditions specified for transport cusks under accident conditions in 10 CFR Purt 71.73 (c) (3), (Ref. 2.5) this would be considered acceptable.

\subsubsection{Confinement Barriers and Systems}

\subsubsection{Fuel Cladding}

Verify that the internal rod pressure and temperature decay characieristics of the fiuel are provided in the CSAR. The confimatory analysis to assure that the level of damage toes not exceed the requirement of a $15 \%$ reduction in cladding cross section is dealt with in Chapter 3 . 


\subsubsection{Mechanical Seals}

Verify that all seals that prevent the leakage or radioactive materials or inert cover gas are identified and that leakage rate limits for these seals under normal conditions are specified.

\subsubsection{Instrumentation and Control Systems}

\subsection{REFERENCES}

1. Office of the Federal Register, Title 10. Code of Federal Regulations, Part 72, Office of the Federal Register, Washington, DC, January 1984.

2. U.S. Nuclear Regulatory Commission, Regulatory Guide 1.76: Design Basis Tomado for Nuclear Power Plants, U.S. Nuclear Regulatory Commission, Office of Standards Development, Washington, DC, April 1974.

3. Standard Review Plan, Missiles Generated by Natural Phenomena, NRC NUREG-0800, Rev. 2, Office of Nuclear Reactor Regulation, July 1981.

4. F.S., Johnson, Solar Constant, Journal of Meteorology, VII, Dec. 1954, pp. 431-439.

5. Office of the Federal Register, Title 10. Code of Federal Regulations, Part 71, Office of the Federal Register, Washington, DC, January 1984. 


\subsection{STRUCTURAL EVALUATION}

\subsection{AREA OF REVIEW}

The objectives of this review are to confirm that the structural design of the DSC uses acceptable analytical and/or test methods and complies with the intent of 10 CFR Part 72 (Ref. 3.1). This chapter gives guidance for review of the structural design of the DSC submitted in a CSAR for NRC certification under generic rulemaking. The structural evaluation covers the following specific areas:

\subsubsection{Loads}

The structural loads applied to the DSC are reviewed. The structural loads can include impact, temperature gradients, puncture, pressure and cyclic loading. Fabrication processes can also affect the load on the package. In many cases, various loading combinations of severat loading conditions have to be reviewed. The loading combinations must be considered for normal conditions. loads due to environmental conditions and natural phenomena and loads due to postulated accidents.

\subsubsection{Materials}

The regulatory emphasis on quality standards referred to in paragraph 2.1.2 applies to materials selection. Information relative to materials of construction should be furnished in sufficient detail to provide a basis for evaluation of the DSC. The regulatory requirement, by implication, compels the applican to provide materials property data that is thorough and of high quality. The following areas that relate to materials for consoructing a DSC are reviewed:

\subsubsection{Material Properties}

Review the material specifications used for the DSC components. Assess adequacy on the basis of the material mechanical, thermal, and physical properties. their corrosion resistance and fabricability. Review information submitted by the applicant for any special process used in the manufacture of the DSC components. If impact limiters are specified, review the mechanical properiies used in the analyses. 


\subsubsection{Fracture Resistance}

Review the fracture resistance of materials used for the primary containment structure of the DSC to assure that the containment will not fracture under operating and postulated accident conditions.

\subsubsection{Fasteners for Dry Spent Fuel Casks}

Review the materials selected for the srud bolts, washers and nuts or other fasteners used to secure the closures to ensure that they will provide their function under normal and accident conditions. Check mechanical properties to ensure that all requirements are met. Review lubricants or surface treatments to assure that studs will be resistant to stress corrosion cracking under the environmental conditions during service. Review the adequacy of the destructive and non-destructive testing procedures used to ensure initial integrity.

\subsubsection{Fabrication and Processing of Cask Components}

A. Review the influence of fabrication and processing upon the structural adequacy of materials used for components important to safety. This review is particularly relevant to containments constructed of ferritic steels and ductile cast irons, and baskets consuruted of borated austenitic stainless steels, ferritic stainless steels and aluminum alloys.

B. Review the effect of special processes of the fracture toughness and stress corrosion characteristics of the material.

C. Review methods of nondescrucave examination. Nondestructive examination methods differing from those described in authoritative codes are reviewed. Attenion is directed toward calibration methods, instrumentation. methods of application, sensitivity, reliability and standards used.

\subsubsection{Allowable Stresses}

The margin of safety concept used to establish allowable stresses is the fundamental principle for DSC design. Review the allowable stresses specified in the CSAR for siructural design to assure that they reflect margins of safety consistent with the imponance to safety of the component and the uncertainty associated with the mechanical properties of the materials. 


\subsubsection{Structural Design}

The significant structural design features of the package are identified and reviewed for their adequacy to provide their intended safery functions. The structural review requires an in-depth assessment of the structural mechanics aspects of the DSC design. The reviewer must evaluate structural models and their assumptions and must be familiar with structural dynamic behavior under impact loading and the methods available for calculating response to impact. The structurat review should assess the adequacy of the structural design of each component for all loading conditions. The review evaluation of the structural results should be provided to other disciplines which include themal, subcriticality, shielding, containment, operations and acceptance testing. The deformation determined by the structural analyses from the CSAR are used in other areas to evaluate heat transfer, reduction in the subcriticality margin, containment or shielding capabilities and establishing temperature limits on certain operations.

\subsection{ACCEPTANCE CRITERIA}

\subsubsection{Loads}

\subsubsection{Normal Operating Conditions}

Loads under normal operating conditions shall include, at least, those due to internal pressure, residual stress, and those imposed by thermal gradients and fluctuations over the design life of the DSC. The applicant is required to specify the loading conditions in the CSAR based upon planned handling and lifing operations for the DSC and those implied by 10 CFR Part 72.

\subsubsection{External Environmental Conditions and Natural Phenomena}

The design basis loads due to environmental and naturnd phenomena shall be those described in Chapter 2.

\subsubsection{Postulated Accidents}

The loads due to postulated accidents arise as a result of impact due to handling accidents or yas cloud explosions. For the case of a cask drop, the load is proponional to the height from which a cask falls upon the concrete pad. The applicant must specify the maximun drop height :Issumed in the structural analysis. Not only is this height necessary for computing the magnitude of the loads. but it also becomes at of the limiations and operating conditions. 


\subsubsection{Materials}

\subsubsection{Material Properties}

A. Acceptable material specifications are those listed in the ASME Boiler and Pressure Vessel Code, Section III, Appendix I, and are presented in detail in Section II, Parts A, B, and C. (Ref. 3.2)

B. The acceptability of materials not specified in the ASME Code is considered on an individual basis. Materials that conform to other authoritative codes and standards may be acceptable. Where no code or standard exists for a material, suitability is evaluated on the basis of data submitted in accordance with the requirements of ASME Code Section III, Appendix IV-1400. These data must include not only information on mechanical properties but also a description of any physical or mechanical changes of the material that might be caused by fabrication and processing.

C. All material properties required for the analysis of components imporant to safety must be described, and all mechanical properties used in the structural evaluation must be listed If impact limiters are used, a compression stress-strain curve for the material or a force-deformation relationship for the limiter, as appropriate, should be included for the range of temperatures astablished by the environmental design criteria. For materials that are subjected to dynamic loadings or elevated temperatures, the appropriate mechanical properties under these conditions should be specified to the extent needed for the structural evaluation. The source of all material properties information should be clearly and specifically referenced as to publication and page number.

D. Where material properies are determined by testing, test procedure, conditions, and measurements should be described in sufficient detail to conclude that the results are valid. For materials used in components important to safery, a sufficient number of test specimens should be used to characterize the material properies statistically. The design basis material property should reflect an exceedence of 0.95 at a 0.9 confidence level.

\subsubsection{Fracture Resistance}

Fracture resistance of structures and components important to satety may be determined by the appiication of linear elastic fracture mechanics. Resistance to fracure initiation must be 
demonstrated at yield strength levels of stress with the cricical flaw size at least twice the maximum allowable flaw size specified. Design basis fracture critical stress intensities must be established in accordance with the provisions of 3.2.2.1 (D) above.

\subsubsection{Fasteners for Spent Fuel Casks}

A. Fasteners used for closures and lifting lugs are considered components important to safety. The ASME Code, Section III, defines acceptance criteria for closure bolts, studs, and fasteners applicable to DSCs. Studs and bolts used for lifting lugs are required to meer similar acceptance criteria.

B. The material for studs, bolts, nuts and other types of fasteners should be selected from those that are listed in the material specifications of the ASME Code. In addition, the material for the fasteners important to safety should conform to the requirements of sub-article NB-2580 of Section III of the ASME Code.

C. Surface treatments, plating, or thread lubricants used must be shown to be compatible with the fastener materials and stable at operating temperatures.

\subsubsection{Fabrication and Processing of Cask Components}

The applicant must demonstrate that the fabrication and processing methods used to fashion materials into components does not have an adverse effect upon the design basis allowable stresses.

\subsubsection{Allowable Stresses}

For materials listed in Sectiun III, Appendix I of the ASME Code the allowable stresses shall be the stress intensity limits associated with the materials. For materials not listed in the ASME Code. the allowable stress intersities shall be determined in accordance with the methods discussed in Aricle III-2000 of ASME Code Subsection NA. If the material is one nor yer adopted by the ASTM. the methods of Subsection NA will not be applicable. In that case, allowable stresses may be established by materials testing subject to the acceptance criteria described in 3.2.3.I (D).

\subsubsection{Structural Design}

The description of the structural design features and criteria must include the following: 


\subsubsection{Discussion}

The DSC must be described in sufficient detail to identify it accurately and provide a sufficient basis for its strucural evaluations. The description must include enough drawings in adequate detail to fully describe those components to be evaluated.

\subsubsection{Structural Design Criteria}

The structural design analysis section of the CSAR must provide the load combination assumed for the analysis. These will consist of various combinations of the loads discussed in Chapter 2, "Principal Design Criteria."

\subsection{Primary Containnant Vessel}

For spent fuel casks, Regulatory Guide (R.G.) 7.6 (Ref. 3.3) adopts portions of the ASME Code, Section II, Subsection NB, to form acceptable structural design criteria for spent fuel cask containment vessels. Design criteria for Level A service limits and Level D service limits in R.G. 7.6 are associated with nomal and accident conditions, respectively, for application to spent fuel casks. R.G. 7.6 also requires that linear elastic analysis be applied for designing spent fuel contairment vessels. Figure 4-2 describes an acceptable method for identifying and combining loads, with the acceptance criteria specified in R.G. 7.6 for spent fuel casks.

\subsection{Baskets}

Baskets that are fabricated by welding shall conform to the requirements of the ASME Code. Section III, Subsection NG.

\subsubsection{Weights and Center of Gravity}

The total weight of the DSC and contents must be listed. The weights of major subassemblies should be tabulated such that the sum of the parts equals the total weight of the DSC. A sketch or drawing should clearly show the reference points for locating the ask center of gravity.

\subsubsection{Lifting Devices}

Lifting devices must meet the requirements of ANSI N14.6 (Ref. 3.4) normal load requirements are as follows: the load beaning members shall be capable of lifting three times the 
combined weight of the DSC without generating a combined shear stress or maximum tensile stress at any point in excess of the maximum yield strength. They shall also be capable of lifting five times that weight without exceeding the ultimate strength of the materials. In addition, if the package to be lifted constitutes a critical load, then either a dual load path system must be designed, or the design stress must be twice as large as stated above. A critical load is any lifted load whose uncontrolled movement or telease could adversely affect any safety-related system when such system is required for unit safety, or which could result in potential off-site exposures. All the above acceptance criteria are valid as long as the material of the lifting devices is sufficiently duccile to accommodate higher stresses at stress concentrations. If the duccility or toughness of the lifting device materials is questionable, the applicant should be notified that a material change will probably be required. In no case should acceptance be based upon fracure mechanics analyses.

\subsubsection{Normal Conditions of Storage}

Undet nomal conditions of storage the DSC is subjected primarily to intemal pressure, decay heat load, the extremes of environmental temperature variations and the effects of atmospheric precipitation and contaminants. The ability of the DSC to perform its function with regard to confinement of radioacrive materials and effectiveness of shielding must not be decreased as a result of the normal loads and degrading effects of the storage environment.

\subsubsection{Hypothetical Accident Condition}

The hypotherical accident conditions associated with a DSC are accidental drop during handling, tipover due to extreme environmental conditions and natural phenomena. and impact or penetration of tornado generated missiles. Since an accident may occur anytime during the design storage life of the DSC, any change in material properties during this period should be considered when evaluating the effects of the accident. The ability of the DSC to perform its safety functions should not have been reduced as a resulc of such accidents.

\subsubsection{Fuel Rod Integrity}

\subsubsection{Normal Conditions of Storage}

Under normal conditions of storage, fuel rod integrity is assured over the design life of the ISFSI if the combination of cladding temperanre and internal pressure limit the creep damage of the cladding to the equivalent of a $15 \%$ reduction in cladding cross secrion. 


\subsubsection{Hypothetical Accident Conditions}

For any extreme environmental condition, natural occurrence or handling accident that tesults in a cask drop or tipover, the basket and fuel assemblies will be subjected to a large dynamic load. While there is no regulatory requirement to maintain fuel integrity under accident condicions, the maximum decelerations that may be sustained by a nurnber of different types of fuel assemblies are described in Ref. 3.5.

\subsection{REVIEW PROCEDURES}

\subsubsection{Loads}

\subsubsection{Normal Operating Conditions}

Verify that the loads defined for normal operating conditions include, at least, those due to internal pressure. residual stress and those imposed by thermal gradients and fluctuations over the design life of the ISFSI.

\subsection{Pressure Calculations}

Verify that the intemal pressure represents the maximum that could occur from the release of all pressurized gases that might escape from the cask contents even under normal conditions of storage. The reviewer is to assess whether all phenomena that could affect the internal pressure have been properly considered in the pressure calculanions.

The pressure in the cavity of a DSC can vary from the initial value when the DSC is filled, sealed shut, and leak checked. The pressure depends primarily on the contents and the temperanure of the contents. The pressure increases as the DSC heats up from the decay heat sources. The environment can also affect the cavity pressure.

For all practical purposes, the pressure in a storage cask containing only solids and gases is the gas pressure. The gas pressure is assumed to follow the perfect gas law and varies with bulk gas temperature and the initial fill pressure by

$$
P=\frac{P_{i} T}{T_{i}}
$$


where $\mathrm{P}_{\mathrm{j}}=$ initial pressure, $\mathrm{T}_{\mathrm{i}}=$ initial bulk temperature, and $\mathrm{T}=$ bulk temperature at conditions for which the pressure is being calculated such as equilibrium storage conditions or accident conditions. The bulk temperature can be conservatively assumed to be the maximum temperature of the gas.

Casks which contain an inert cover gas may have residual liquid such as water that did not drain from the cask or was not completely removed by the dry down procedure. In the case where the residual liquid does not totally vaporize, the total cavity pressure is the sum of the gaseous coolant pressure and the vapor pressure of the liquid at their appropriate bulk temperatures. In the case where the residual liquid totally vaporizes, the total pressure in the cavity is the sum of the gaseous coolant pressure and the vaporized liquid pressure at the appropriate bulk temperature for the mixed gases. The reviewer can calculate the vaporized liquid pressure by using the perfect gas law and the mass of the liquid from

$$
F_{v}=\frac{m R T}{V}
$$

where $m=$ the mass of the liquid, $R=$ the gas constant of the vaporized liquid, $T=$ the bulk temperature. and $V=$ the free cavity volume available for the vaporized liquid.

Pressure increases can also be caused by gas releases from the radioactive materifi connents. As an example, spent fuel rods can rupture and vent high pressure fission products and other gases into the cavity. In all cases the pressures created by these sotirces have to be added to pressures from the other sources previously discussed.

The pressure caused by spent fuel venting can be calculated from

$$
P_{s}=P_{R}\left(\frac{X V_{R}}{V_{s}+X V_{R}}\right)\left(\frac{T}{T_{R}}\right)=\frac{X N_{R}}{\left(V+X V_{R}\right)} R T
$$

where $\mathrm{X}=$ number of rods failed, $\mathrm{V}=$ free volume in the cavity, $\mathrm{T}=$ bulk temperature of gases in the cavity. $P R=$ rod pressure before venting, $V R=$ gas volume in the rod, $T R=$ gas temperature in the rod, $R=$ the universal gas constant, and $\mathrm{NR}=$ moles oi gases in the rod. Typically the number of gas moles in a spent fuel (BWR/PWR) rod is less than $2.5 \times 10^{-4}$. 


\subsection{Decay Heat}

The decay heat of the spent fuel must be considered as part of the thermal load. The maximum amount of the decay heat must be considered in combination with the thermal environment conditions described in 2.2.3.4.

\subsection{Residual Stresses}

Verify that residual stresses that might arise from fabrication processes such as weldini, lead pouring, force fits, bolt preload and shrink fits are included as loading cenditions in addition to those that are externally applied.

\subsubsection{Extreme Environmental Conditions and Natural Phenomena}

Verify that the loads arising from extreme environmental conditions and natural phenomena are correctly derived and that they are described in terms of magnitude, distribution, direction and point of application.

\subsubsection{Postulated Accidents}

Verify that the drop height and orientations of the DSC are described and that sufficient cases are examined to assure that the worst case is tevealed by the analysis. Verify that the energy absorbing characteristics of the DSC and impact urget are conservatively derived. Re-examine the effect upon internal pressure that might result from a postulated accident and evaluate the cask response accordingly.

\subsubsection{Materials}

\subsubsection{Materials Properties}

A. Verify that the material specifications for the DSC components conform to the acceprable specificarions listed in the ASME Code, Section III, Appendix i, ,rid Section II, Parts $A, B$ and $C$.

B. Identify any materials not listed in the ASME Code, or any deviations in a listed authoritative specification, and evaluate the effect of the deviacion or nonconformance. A study of the suitability of the material and comparison with precedents set in earlier cases enable the reviewer to determine the acceptability of the proposed exception. In 
those instances where the reviewer has taken excepuion to the use of a specific material, or questions certain aspects of a specification, the applicant should be notified which material is not acceptable and the reason for disapproval. Verify that for materials not specified in any authoritative code, the applicant has provided sufficient information to support the structural analyses that demonstrate safety of the DSC under the design loading conditions. The key to the acceptability of materials not described iy any authoritative code is the submission of a specification for the material in ASTM format with the CSAR.

C. Verify that all material properties required for the aralyses of components important to safety are described in an appropriate format. Verify ihat for materials subjected to dynamic loads or elevated temperatures, the appropriate mechanical and physical properties are specified. Review the thermal analysis to ascertain whether the component temperatures result in phase changes or thermal degadation over the design life of the DSC that might affect the material properties assumed in the various analyses. Verify that the sources of all material properties are referenced.

\subsubsection{Corrosion Resistance}

Verify that the following information is provided:

A. A list of construction materials for DSC components that are exposed to corrosive or other aggessive environments.

B. A description of material compatibility with the containment or radiolytic products to which the materials may be exposed.

C. An assessment of the degree to which the material or suructural properties of the material are affected by exposure to the corrodants. This may be reflected by reductions in design stress intensity, fatigue limits or fracture toughness.

\subsubsection{Fracture Resistance}

\subsection{Austenitic Steels}

Austenitic steels do not exhibit a cransition from ductile to brittle fracture behavior with a decrease in temperature. They normaily retain their ductility and toughness at extremely low temperatures. However, austenitic stainless steels are subject to stress corrosion cracking and 
intergranular conosion and must be protected from contaminants and environments that promote cracking and corrosion. Test data and service experience indicate that sensitized stainless steel is significantly more susceptible to stess corrosion cracking. Sensitization is caused by intergranular precipitation of chromium carbide in austenitic stainless steels that are exposed to temperatures in the appropriate range $427^{\circ} \mathrm{C}\left(800^{\circ} \mathrm{F}\right)$ to $870^{\circ} \mathrm{C}\left(1599^{\circ} \mathrm{F}\right)$. Precipitation increases with increasing carbon content and exposure time. Because excessive cold working in austenitic stainless steels can render this material more susceptible to stress corrosion cracking, the cracking must be controlled by placing an upper limit on yield strength. Review the following iterms:

A. Plans to avoid sensitization during welding. Reference to Regujatory Guide 1.44, "Control of the Use of Sensitized Stainless Stee!" is acceptable. (Ref. 3.6)

B. Plans for isol:tion of austenitic stainless steels from halogens or halogen-bearing compounds (e.g., die lubrication, marking compounds. and masking tape) and othes environments that may promote stress carrosion cracking.

C. For cold worked stainless steels, the upper limit on yield strength, as indicared by tests and experience, does not exceed 90,000 PSI.

\subsection{Ferritic Steels}

Ferritic steels exhibit a transition with temperature from ductile to brittle behavior. Recognizing that flaws may be present, it is essential to evaluate fracture resistance. One method is to ascertain whether the material has a nil ductility transition temperature (NDTT) far enough below the lowest service temperature to satisfy the requirements described in References 3.7 and 3.8. It should be noted that the criteria in these references were developed specifically for shipping containers. An alternate method is fracture resistance by analysis which implies the use of linear elastic (LEFM) or elastic/plastic fracture mechanics to assess the likelihood of catastrophic brittle fracture given the presence of a flaw. Stress levels, fracture critical stress intensity, flaw size and flaw' geomerty are essential parameters for evaluating fracture resistance by this method. LEFM methodology to quatify a component for resistance to brittle fracture has its inherent uncertainties. Verify that the margin of safety against fracture conservatively reflects the uncernaincies in the data. Furhermore, since allowable stresses under accident conditions could exceed the elastic limit and, in fact, could result in a small amount of plastic deformation, insist that flaws do not exceed sizes that would cause catistrophic crack propagation even at yield strength levels of stress. A pplicable techniques of non-destructive examination (NDE) must be capable of reliably detecting flaws appreciably smaller than the maximum allowable flaw size. 


\subsubsection{Fasteners for Spent Fuel Casks}

A. Verify that specified materials for all DSC fasteners important to safety are listed in the material specifications of the ASME Code.

B. Verify that the special requirements relating to bolting materials for nuclear applications are specified in the CSAR. Specifically, verify that provisions of the joint ASME/ASTM specification SA-614 are included.

C. Review the CSAR for informstion relating to the application of surface treatments, plating, or thread lubricaris. Verify that if such are applied, they are compatible with fastener materials and remain stable at operating temperatures.

\subsubsection{Fabrication and Processing of Cask Components}

Verify that the CSAR considers the effect of fabrication procedures upon the mechanical, physical or structural properties of the materials. Some fabrication processes that may affect these properies are identified below:

\subsection{Special Processes}

Review information on special processes used for manufacture of DSC components.

A. Identify each process.

B. Determine whether there are any code restrictions on use.

C. Establish the adequacy of the process in providing components with suitable mechanical and physical requirements on the use of special processes. The suitabitity of a process is assessed on the basis of service experience with similar parts fabricated

D. Establish the effects of such processes on the stress-corrosion characteristics of the

E. Identify whether special requirements for non-destructive examination are needed if a special process is used.

\subsection{Forming Processes}

The fracture toughness properties of materials can be reduced during fabrication by forming or bending. The magnitude of the reduction is usually determined by test and should be considered 
when establishing fracture toughness limits. While Reference 3.9 contains guidance relating to recommended fabrication criteria for shipping containers, much of it is valid for DSCs.

\subsection{Welding Processes}

The mechanical and structural properties of a material are significantly affected at the heat affected zone adjacent to a weld. In addition, the welding process may introduce stresses, cracks and other imperfections that compromise the base material properties. Ascertain that the CSAR considers the effect of the welds upon the assumed design stress intensity, fatigue limits or fracture toughness limits. While Reference 3.10 contains guidance relating to welding criteria applicable to shipping containers, much of it is valid for DSCs.

\subsubsection{Allowable Stresses}

Verify that the allowable stresses used for design are listed for every material used in a component subject to analysis. Verify that the allowable stresses are provided for the complete range of temperature to which the component will be exposed over its design life.

Verify the validity of the allowable stresses by examining their source. Check to see if the allowable stresses are consistent with the methods used for fabrication or special processes.

For materials not jdentified by any authoritative code, verify that the allowabie stresses have been derived with sufficient conservatism. Design basis allowables shouid be derived in a manner described by ML-Handbook 5 (Ref. 3.11).

\subsubsection{Structural Design}

\subsubsection{Description of Cask Components}

Verify that the DSC has been described in sufficient detail to identify it accurately and provide a sufficient basis for its struccural evaluation. Verify that the description includes enough drawings in adequate detail to fully describe the component to be evaluated. These include, at least, the primary containment vessel. closure lids and fasteners, basket, fuel rods, neutron absorber system. lifting devices and impact limiters. Verify that the locacion of these items on drawings is clearly indicated. 


\subsubsection{Structural Design Criteria}

Verify that the load combinations and factors that serve as design criteria are described. For each criteria identified, verify that the maximum allowable stresses for ductile failure are stated. Review how other structural failure modes such as brittle fracture, fatigue, buckling etc. are considered. When different design criteria are used in various parts of the DSC or for different conditions, the appropriate values for each case should have been indicated. Verify that the criteria used in the impact evaluation has been discussed. Verify that all codes and standards that are used to determine material properties, design limits, or methods of combining loads and stresses have been identified. In cases of deviation from standard codes, or if certain components are not covered by such codes, detailed description of the design criteria used as substitutes should have been provided.

\subsubsection{Weights and Centers of Gravity}

Verify that the total weight of the DSC and contents is listed. The weights of major individual subassemblies should be tabulated such that the sum of the pans equals the total of the DSC. Verify that the center of gravity of the DSC and any other centers of gravity have been located. Calculations do not need to be included, but a sketch or drawing that clearly shows the individual subassembly referred to and the reference point for locating its center of gravity should be included.

\subsubsection{Lifting Devices}

Verify that all devices and attachments that can be used to lift the DSC or its lids have been identified. Review all analysis to show that these devices comply with the requirements of Secrion 3,2.4.4 of this guide. Drawings or sketches should be included that show the location and construction of these items. Verify that the effects of the forces imposed by lifting on vital DSC components, the interfaces between the lifting device and other DSC surfaces, have been determined.

\subsubsection{Normal Conditions of Storage}

Verify that the DSC, when subjected to normal conditions of storage is evaluated as described in the following paragraphs. The DSC should be assessed against each condition separately and a determination made that the performance requirements implied by the regulations have been satisfied. 


\subsection{Heat}

A. Verify that the thermal evaluation is reponed in Section 4.6 of the CSAR and is being reviewed for adequacy.

B. Verify that all temperatures, have been summarized to permit the review of thermal expansion and thermal stress effects on the DSC. These temperaures should reflect the principal design criteria of Chapter 2.

C. Review the calculations of the circumferential and axial deformations and stresses that may result from differential thermal expansion. Both steady-state and transient conditions should have been considered. These calculations must be sufficiently comprehensive to demonstrate structural integrity under normal storage conditions.

D. Review the calculated stressed due to the combined effects of thermal gradients, pressure, and mechanical loads (including fabrication stresses from lead pour and lead cooldown). Review the sketches that show the configuration and dimensions of the members or systems being analyzed. These sketches should consider whether repeated cycles of thermal loadings, together with other loadings, will cause fatigue failure or extensive accumulations of deformation.

E. Review the stress combinations, and the resulting stress comparisons with the design criteria. All the performance requirements specified in the acceptance criteria must be shown to have been sarisfied.

\subsection{Cold}

Review the package for the effects of a steady-state ambient temperature of $-40^{\circ} \mathrm{F}\left(-40^{\circ} \mathrm{C}\right)$, Review both material properties and possible freezing of liquids and leag shrinkage under this condition. Review, for components important to safety of the DSC, the resulting temperatures and their effect on operation of the DSC. Brittle fracture may have to be considered.

\subsubsection{Hypothetical Accident Conditions}

Verify that the DSC, when subjected to hypotherical accident conditions is evaluated as described in the following paragraphs. 


\subsection{Drop and Tipover Accidents}

Verify that the performance and structural integrity of the DSC has been evaluated for the drop orientation that causes the most severe damage. An orientation that results in the most damage to one system or component may not be the most damaging for other systems and components. For this reason, it is usually necessary to consider several drop orientations. The minimum requirement is that orientations for which the center of gravity is directly over the point of impact must be considered.

The assessment of the cask may be by analysis, prototype testing, model testing, or comparison with a similar cask.

\section{A. Analysis}

Review the drop and structural calculations. The calculations should be presented in sufficient detail to allow the results to be verified. Adequate naration and use of sketches and free body force diagrams should be included. For equations used in the analysis, either the soure should be referenced or the derivation should be included.

The analysis should show how all the kinetic energy will be dissipated and which local deformation and dynamic forces occur during impact. The response of the DSC in terms of stress and strain to components and structural members should be shown. The structural stability of individual members, as applicable, should be investigated as well as stress due to impact combined with those stresses caused by temperature gradients, differential thermal expansions, pressure, and other loads.

Two analytical methods have been used for impact evaluations: quasi-static and dynamic finite element. Each method can be used to predict the response of a cask to an impact load under certain conditions. The dynamic analysis method is more accurate for predicting cask response under impact loading since this loading produces dynamic response of the cask.

The quasi-static method is based on D'Alembert's principle for substituting equivalent static forces for inertial forces created by impact. This method assumes constant, homogeneous deceleration and cannot capture dynamic cask response. It is not recommended for analyzing oblique impact cases. In applying this method. a deceleration force is calculated by assuming that all of the kinetic energy of the falling cask is absorbed by deformation of cask and target materials and that the deceleration is constant. The 
acceptability of this method is predicated on several factors. First the target or limiter, if $\mathrm{it}$ is used, must be relatively soft compared to the cask body so that the load rate is slow enough to reduce the probability of dynamic amplification. Second, since even for a soft limiter there may exist a stiff initial modulus, a dynamic amplification factor should be applied to the results. Third, since there are many uncertainties in this method, there should be a large margin of safety in the final stresses if this method is used.

In order to obtain detailed stress recovery or accurately model nonlinear behavior, such as plastic deformation or buckling, a dynamic finite element analysis should be performed. In this method, each component can be modeled separately, and srresses in each element can be calculated directly during the analysis. The model may range from simple to complex with a corresponding range of accuracy in the results. While they can be expensive and time consuming, dynamic finite element analysis methods can provide the most accurate and detailed estimates of cask response to impact loads. The dynamic finite element method hould be used for reviewing cask components that have predicted stresses close to illowables, complex geometry, or complex loading conditions.

A more detailed discussion of the impact analysis methods described above relating to transportation casks can be found in Ref. 3.12.

\section{B. Protorme Testing}

Review the test method, procedures, and target that were used. Review the cask orientation at time of impact. If the cask tested is not identical in all respects to the cask described in the application, the differences should be explained to show that these differences would not affect the test results. Review all analyses performed to establish the cask configuration and orientation for the testing.

Review in detail materials used as subsritutes for the radioactive contents during the tests. Verify that this substitution would not affect the test results. The effects of intemal decay heat and pressure buildup must be considered if these effects had arisen with the actual loading.

Review the damage caused by the impact and the results of any quantitative measurements that were made. Both interior and exterior damage shall be included. Review photographs of the damaged cask. Review analyses performed to demonstrate that adequate margins of safety have been included in structural design. 


\section{Model Testing}

Review the model description and the detailed drawings that show its dimensions and materials of construction. Review the dimensional tolerances to which the model was fabricated, and the comparison of these to the tolerances that are used for the prototype. Review all analyses performed which relate the scale model to the prototype for the regulatory test conditions.

For the acrual model tests, review all the information required for item $B$ above.

Review the correlation method used and the amount of damage done to the model with damage to a prototype. Model testing should be performed primarily to benchmark computer codes used to analyze the prototype. Review the discussion which demonstrates that the prototype would be adequate to meet all the performance requirements of 10 CFR Part 72.

\section{Comparison with Similar Casks}

Review the comparison with similar casks. The comparison must demonstrate that the proposed cask is, in all respects, better than or equal to the cask previousiy approved and that the proposed cask can meet all the regulatory performance requirements. The following information showld be included for your review:

(1) The dimensions, materials, and configurations of both casks

(2) The overall weight of both casks, and

(3) The weight and form of the contents of both casks.

The comparison should demonstrate:

(1) That the caskr will have a similar response to the specified tests,

(2) That the forces acting on all vital safety systems and components of the proposed DSC are less than the tested cask or that all vital safety systems and components of the proposed cask have sufficient structeral integrity, and

(3) That the proposed DSC will meet all the regu'atory performance requirements.

\section{E. End Drop}

Review the cask for the effects of the end drop test. 


\section{F. Side Drop}

Review the cask for the effects of the side drop test.

\section{G. Comer Drop}

Review the cask for the effects of the comer drop test.

\section{H. Summary of Results}

Review the discussion of the condition of the cask after each drop orientation. The extent to which the cask would be damaged in each orientation should have been summarized for your review.

\subsection{Tornado Generated Missiles}

Review the effects of the impact of tomado generated missiles. Verify that both local damage near the point of impact and the overall effect on the cask have been evaluated. The point of impact could be at any locarion on the exterior surface of the cask. Review how the point of impact was selected. It is particularly important that all valves and fittings necessary for containment be considered.

One approach to the puncture problem is to use the method described by P.P. Bijlaard in Ref. 3.13. This technique may be used as an approximate method for radial loads which may be idealized as uniformly distributed over a rectangular region.

Another approach is to use the Hagg-Sankey formulation presented in Ref. 3.14. This method involves a set of semi-empirical eçuations for the analysis of missile/target interactions based upon small scale test results of turbine fragment impact on steel cylinders and flat paneis.

A third approach is to run dynamic finite element analyses of various loading conditions. This is the method that can offer the greatest degree of accuracy, especially if local deformation of a region of complex geometry is needed.

\subsubsection{Fuel Rod Integrity}

Review the arguments put forward in the CSAR to ensure the integrity of the fuel rod cladding under normal conditions of storage for the life of the ISFSI. Guidance in this regard is provided by Ref. 315. 


\subsubsection{Appendix}

Review supporting information such as justification of assumptions or analytical procedures, test results, photographs, computer program descriptions and input/output, reference lists, and applicable pages from referenced documents.

\subsection{FINDINGS}

In the Safety Eva'uation Repor (SER), briefly discuss the process that was carried out (list confirmatory analyses, other pertinent information), and discuss conclusions for each structural component reviewed. If the reviewer does not agree with the design or the structural analysis method described in the CSAR for a particular component, but nonetheless agrees with the conclusion that the component meets the regulations based on confirmatory analyses, clearly state this in the Evaluarion Findings. Maintain for each CSAR a separate file or document which contains detailed engineering discussions on all confimatory analyses.

\subsection{REFERENCES}

1. Office of the Federal Register, Title 10. Code of Federal Regulations, Part 72, Office of the Federal Register, Washington, DC, 1980.

2. American Society of Mechanical Engineers, ASME Boiler and Pressure Vessel Code, 1983 Edition, American Society of Mechanical Engineers, United Engineering Center, 345 East 47th Street, New York, New York 10017.

3. U.S. Nuclear Regulatory Commission, Regulatory Guide 7.6: Design Criteria for the Structural Analysis of Shipning Cask_Containment Vessels, U.S. Nuclear Regulatory Commission, Washington, DC, January 1980, Rev. 1.

4. American National Standards Institute, American National Standard for Special Lifting Devices for Shipping Containers Weighing $10,000 \mathrm{lbs}$ or More for Nuclear Materials, ANSI N 14.6

5. R.C. Chun, M.C. Witte, and M.W. Schwartz. Dvamic Impact Effects on Spen Fuel Assemblies, Lawrence Livermore National Laboratory, Livermore. CA, UCID-21246. October 1987. 
6. U.S. Nuclear Regulatory Commission, Requlatory Guide 1.44: Control of the Use of Sensitized Stainless Steel, U.S. Nuclear Regulatory Commission, Washington, DC.

7. W.R. Holman, and R.T. Langland, Recommendations for Protecting Against Eailure by Brittle Fracture in Ferritic Steel Shipping Containers Un to Four. Inches Thick, Lawrence Livermore National Laboratory, Livermore, CA, NUREG/CR-1815, UCRL-53013, June 1981.

8. M.W. Schwarz, Recommendations for Protecting Apainst Brittle Fractures in Ferritic Steel Shipping Containers Greater Than Four Inches Thick, Lawrence Livermore National Laboratory, Livermore, CA, NUREG/CR-3826, UCRL-53538, April 1984.

9. L.E. Fischer, and W. Lai, Fabrication for Shippine Containers, Lawrence Livermore National Laboratory, Livermore. CA, UCRL-53544, NUREG/CR-3854, March 1985.

10. R.E. Monroe, H.H. Woo, and R.G. Sears, Recommended Welding Criteria for Use in the Fabrication of Shipping Containers for Radioactive Materials, Lawrence Livermore Nacional Laboratory, Livermore, CA, UCRL-53044, NUREG/CR-3019, March 1984.

11. ML-Handbook 5, Guidelines for the Presentations of Data - Chapter 10, Batelle Memorial Instiure Columbus, Laboratories, October 1970.

12. T.A. Nelson, and R.C. Chun, Methods for Impace Analysis of Shipping Containers, Lawrence Livermore National Laboratory, Livermore, CA, NUREG/CR-3966, October 1987.

13. P.P. Bijlaard, Stresses from Radial Loads in Cylindrical Pressure Vessels, Welding Research Journal Supplement, December 1954.

14. M.W. Schwarz, and M.C. Witte, Spent Fuel Cladding Integrity During Dry Storage, Lawrence Livermore National Laboratory, UCD-21181, Seplember 1987. 


\subsection{THERMAL EVALUATION}

This section deals with the thermal design and evaluation of a DSC submitted in a CSAR for NRC cerification. Fig. 4-1 shows the types of information required fre $\mathrm{t}$ other sections of the CSAR to perform the thernal review. Information is required on the DSC configuration, component materials and thermal environment. If the DSC undergoes any deformation under accident conditions, that affect the configuration of the component assumed in the thermal analysis, such information should be supplied by the structural analysis. The thermal results from the CSAR are used in those areas to evaluate thermal stresses, temperature effects on material properties, and reductions in confinement or shielding capabilities caused by material phase changes or degradation. Thermal results are also used in performing leak testing and establishing temperature limits. The thermal review evaluation should be provided to other disciplines that review structures, materiais, shielding, confinement, operations and acceptance testing.

\subsection{AREA OF REVIEW}

The following areas of review are reviewed for compliance with the regulations. The significant thermal design criteria and operating characteristics of the DSC are identified and reviewed for adequacy to provide their intended safety functions.
A. Thermal Design Features
B. Thermal Loads
C. Thermal Properties of Materials

\subsection{ACCEPTANCE CRITERIA}

\subsubsection{Thermal Design Features}

All the thermal design functions and operating characteristics of the cask must be described. As for other analyses, the cask components must be clearly described in the rext and accompanying drawings. In particular, the structural and mechanical means for the transfer of heat must be identified and described. These incilude such features as cooling fins, clearances and gaps between heat conduction regions, and the nature and thermal characteristics of the iner cover gas.

\subsubsection{Thermal Loads}

Thermal loads assumed in the andyses must include the heat flux due to radioactive decay of the cask contents, extreme environment conditions including solar insolation and fire as a 
hypothetical accident conditions. The effects of themal loading must reflect the wo.st credible combination of these loads. Intermediate temperature c'onditions should also be evaluated by the applicant if they can cause a more severe structural response than the extreme conditions given in Chapter 2.0.

\subsubsection{Thermal Properties of Materials}

Specific criteria for judging the acceptability of the thermal properties of materials used in the package design are as follows:

A. Criteria for acceptable specifications for structural materials are given in Chapter 3.0. For non-structural materials such as thermal coatings, lead shielding, and neutron shielding, information or references should be included to permit an evaluation of the material properies, makeup, processes, and intended use.

B. All material properties required for thermal analyses of components and parts important to safety must be described. All material properties used in the thermal analyses should be listed for their range of application. These properties include at least, the heat capacity, corrodants, and thermal conductivity. The source of all material properties information should be clearly and specifically referenced as to the publication and page number. Where material properties are determined by testing, the test procedure, conditions, and measurements should be described in sufficient detail to conclude that the results are valid

\subsubsection{Thermal Specifications on Cask Components}

The applicant must include thermal specifications for all safety-related components and parts. In many cases the marerial specifications required in Chapter 3.0 may be referenced and supplemented with information on the fabrication and assembly processes, particularly for structural materials. However, for closure systems and valves which include parts such as seais and gaskets, the material specification may have to be supported by appropriate qualificaticn testing. All specifications should include information on the component description, safety function, materials of conscruction, significant fabrication processes, temperature and pressure ranges of operation, the time period of use before replacement or maintenance is required, and all limitations that could affect the component's safety function. Supponing qualification tests for valves should be performed in accordance with the appropriate articles of the ASME Code, Section III, and for burst discs in accordance with the ASME Code, Section VIJI. The component 
specification should include operation for both normal and hypothetical accident conditions. All resting and analysis must include the effects of normal operation for the maximum time without replacement or maintenance of parts for the component, followed by analysis for the hypothetical accident condition. Any deterioration of the component's safety function stould be idenritied. Evidence should be provided that the qualification test has been successfully performed.

\subsubsection{Thermal Evaluation of Normal Conditions}

The applicant must include thermal evaluations of the DSC for normal condicions. The evaluations must include thermal models, heat transfer analysis, and temperature distributions for each safety-related component. All modeling and analysis assumptions, including those used in computer codes, must be stated and justified. When the DSC design includes various operating modes or configurations such as different content loadings, each mode and operation must be evaluated to determine the adequacy of the design for all conditions. The results of the thermal evaluation trust demonstrate that the thermal component specifications are adequate for the component to provide its safety funcion under nomal conditions. The thermal evaluation must consider any deteriorating effects or damage caused by time dependent damage mechanisms operating over the design life of the ISFSI.

\subsubsection{Hypothetical Accident Thermal Conditions}

The applicant must include thermal evaluations of the package for hypothetical accident conditions as specified in Section 3.2.1.3 of this SRP. The evaluations must include thermal models, heat tansfer analysis, and minimum/maximum temperature distributions for each safetyrelated component. All modeling and analysis assumptions, including various operating modes or configurations such as different content loadings must be evaluated to determine the adequacy of the design. The results of the thermal evaluation must demonstrate that the thermal component specifications are adequate for the component to provide its safety function under hypothetical usident conditions. The thermal evaluation must consider any deteriorating effects or damage caused by time dependent damage mechanisms operating over the design life of the ISFSI.

\subsubsection{Appendix}

All supplemental information to the thermal evaluation should be included as an appendix. This information should include material and component specifications, qualification tests, and computer codes used in the thermal evaluations. 


\subsection{REVIEW PROCEDURES}

The reviewer will ensure tha: the information discussed below is provided in appropriate detail.

\subsubsection{Thermal Design Features}

Verify that all thermal design features have been properly identified and discussed to determine their relationship to the thermal safety function and the overall evaluation. The thermal design features may include items such as cooling fins, thermal barriers that may be activated under accident conditions, contact and clearance regions, and special materials for controlling heat conduction. Verify that all of the acceptance criteria in 4.2 .1 have been considered or are irrelevant to the DSC.

\subsubsection{Thermal Loads}

Verify that the acceptance criteria of $\mathbf{4 . 3 . 2}$ have been considered and documented.

\subsubsection{Thermal Properties of Materials}

Compare the material specifications for the packaging components with acceptable specifications listed in the ASME Code, Section III, Appendix I, and Section II, Parts A, B, and $C$. Verify that any materials not listed in the code, or any deviations in a listed specification, are clearly identified, and the bases for deviation or nonconformance evaluated. Determine the acceptability of the proposed exception through a study of the suitability of the material and comparison with precedents set in earlier cases. In many cases ASTM specifications with additional controls as required to upgrade them to Code level can be used. In those instances where the reviewer takes exception to the use of a specific material or questions certain aspects of a specification, advise the applicant which material is not acceptable, and the reason for disapproval,

\subsubsection{Thermal Specifications on Cask Components}

Verify that thermal specifications are included for all safety-related components, particularly for valves and closures. Verify that each specification is complete and contains the information required in acceptance criteria per 4.2.4. Review in detail the qualification tests and analyses which qualify a component for jts use against the thermal specifications to verify that the temperature requirements in the thermal specification have been met. In those cases where the 
reviewer determines that a thermal specification or a qualification test and analysis are not acceptable or questions centain aspects of them, advise the applicant of the determinations and the reasons for any rejection.

\subsubsection{Thermal Evaluation of Normal Conditions}

Verify that the following information is included in the thermal evaluation for nomal storage conditions. In those instances where the fabrication processes can affect the thermal evaluation, similar types of information should be included.

\subsubsection{Thermal Model}

Verify that the thermal model and evaluation are described in detail and are related to the DSC design. The evaluation should include gaskets, valves, internal supports, contents, neutron absorbers, thermal barriers, and impact limiters. Critical gaps or clearances should be included. Modeling assumptions should be identified and justified. The model can be 1-, 2-, or 3dimensional and can be done piecewise as components as long as the modeling is justified and the thermal boundary conditions are comparible at each component interface. All heat sources and sinks should be identified. When contents vary or their heat absorption capability cannot be ensured, they should not be in:luded in the model as a heat sink bue included only as a heat source.

\subsubsection{Test Model}

Verify that any test performed to support the thermal model is clearly described and related to the model. The specific objectives of the test and how they support the thermal model should be stated. The procedures used to correlate the test data to the thermal environment specified in Section 2.2.3.4 should be described. Verify that heat flux, heat transfer area, and temperature data are provided for all components being modeled and tested, particuiarly at the boundaries.

\subsubsection{Maximum and Minimum Temperatures}

Verfy that maximum and minimum temperature distributions for each component are listed for normal storage conditions for the various boundary conditions. The minimum temperature distriburion should consider the minimum heat load. 


\subsubsection{Maximum Internal Pressures}

Verify that thermal data needed to determine the maximum intemal pressures are provided for normal storage conditions. The details should include temperatures, quantities of fluids and their physical states, and the associated fluid volumes. Where chemical reactions, dissociations, or phase changes occur, the following should be discussed: 1) the reaction or phase change mechanism, 2) the reactants and products involved, 3) estimates of the extent and the rate of reaction or phase change, and 4) the consequences of the reaction or phase change. The additional pressure that wouid result from fuel rod failure should be considered.

\subsubsection{Maximum Thermal Stresses}

For DSC designs that involve fabrication processes (such as lead pouring or shrink fitting assembly of parts) where the suructural response can be significantly affected, verify that the appropriate initial conditions are determined to be at the point where the parts involved in the process are free of any significant stresses. In these cases, verify that the applicant performs a thermal evaluation to determine the thermal smesses as discussed in Chapter 3.0 of this SRP.

\subsubsection{Evaluation of Cask Performance}

Evaluate DSC performance, including system and subsystem operation for nomal storage conditions. Compare the temperature calculated in the thermal analysis or measured in the themal rest with the allowable temperature and pressure limits for DSC components. Assess fatigue and aging effects on the components. Determine if each component properly provides a specified safery function for nomal and accident conditions in accordance with regulations.

\subsubsection{Documentation}

Information to be used in ocher evaluations should be summarized and supported by comments. Verify that the comments state where the information is to be used and the specific conditions that apply. For example, temperature gradient information may be provided for thermal stress evaluation for nomal conditions. Closure seal temperature information should be provided for continement evaluations. 


\subsubsection{Hypothetical Accident Thermal Evaluation}

Verify that the following information is included in the thermal evaluations for hypothetical accident conditions. In those instances where the fabrication processes can affect the themal evaluation, similar types of informarion should be included.

\subsubsection{Thermal Model}

Verify that the thermai model and evaluation are described in detail and relate to the DSC design. The evaluation should include gaskets, valves, intemal supports, contents, neutron absorbers, thermal barriers, and impact limiters. Critical gaps or clearances should be included. Modeling assumptions should be identified and justified. The model can be 1-, 2-, or 3 . dimensional and can be done piecewise as components as long as the modeling is justified and the thermal boundary conditions are compatibie at each component interface. All heat sources and sinks should be identified. Wher contents vary or their heat absorption capability cannot be ensured, they should not be included in the model as a heat sink but included only as a heat source.

\subsubsection{Test Model}

Verify that any test performed to support the thermal model is clearly described and related to the model. The specific objectives of the test and how they support the thermal model should be stated. The procedures used to correlate the test data to the thermal environment specified in Section 2.2.3.4 for hypothetical accident conditions should be described. Heat flux, heat transfer area, and temperature data should be provided for all components being modeled and tested. particularly at the boundaries.

\subsubsection{Cask Conditions and Environment}

For the hypothetical accident condicions, verify that the thermal model and analysis include the effects of any damage resulting from the cask drop and tipover events. Also any aging or fatiguing effects on the components and parts caused by normal storage conditions must be included.

\subsubsection{Cask Temperatures}

Verify that the transient temperature distributions for each component are listed for the hypothetical accident concuivisis as determined by test and analysis. The temperatures listed should 
be at locations on the componenss such that the reviewer can assess the ability of the component to provide its safety function or can use the information in other evaluation areas, such as structural, in determining thermal stress levels. Verify that temperatures of items such as contents, internal support structure, valves, closure seals, and shielding are listed. The temperature distributions for all components should represent maximum values. In addition, the steady state temperature distriburions following the hypothetical fire should be included in the CSAR, particularly when a thernal barrier that restricts heat ransfer is accivated.

\subsubsection{Maximum Internal Pressures}

Verify thas the themal data needed to determine the internal pressures are provided for the hypothetical accident conditions. The details should include temperatures, quantities of fluids and their physical states, and the associated fluid volumes. Where chemical reacions, dissociations, or phase changes occur, the following should be discussed: 1) the reaction or phase change rechanism, 2) the reactants and products involved, 3) estimates of the extent and the rate of reaction or phase change, and 4) the consequences of the reaction or phase change. The addicional pressure that would result from fuel rod failure must be considered.

\subsubsection{Maximum Thermal Stresses}

For DSC designs that involve fabrication processes such as lead pouring or shrink fitting zssembly of parts, where the structural response can be significantly effected. verify that the appropnate initial conditions are determined to be at the point where the pars involved in the process are free of any significant stresses. In these cases, the applicant is to perform a thermal evaluation to determine the thermal stresses as discussed Chapter 3.0 of this SRP.

\subsubsection{Evaluation of Package Performance}

Verify that the DSC performance is evaluated and includes system and subsystem operation for hypothetical accident conditions. Compare the temperature calculated in the thermal analysis and measured in the thernal test with the allowable temperature and pressure limits for the DSC components. Fatigue and aging effects on the components should also be assessed. Determine if each component properly provides a specified safety function for normal and accident condirions in accordance with regulations. 


\subsubsection{Documentation}

Verify that information to be used in other evaluations is summarized and supported by comments. The comments should state where the information is to be used and the specific conditions that apply. For example, remperature gradient information may be provided for thermal stress evaiuation for hypothetical accident condisions. Closure seal temperature information should be provided for confinement evaluations.

\subsubsection{Appendix}

Review all supplemental information in the CSAR which supports the thermal evaluation for the DSC and contents. This appendix could include information such as justification of assumptions. analyrical procedures, test resuits, computer program descriptions, and computer input/output.

\subsubsection{Confirmatory Thermal Analyses}

\subsubsection{Scoping Calculations}

When sufficient information is available in the CSAR, scoping calculacions are performed during the initial review to provide an overview of the thermal design and to identify the critical areas for concentrating the review efforts. One-dimensional steady-state heat balances are performed at major boundaries such as component interfaces to determine the primary heat flow paths, the primary modes of heat transfer, and the sensitivity of the heat flow to any changes in the controlling heat transfer parameters.

Several references discuss heat transfer by conduction, convection, and radiation. (Ref. 4.2 4.10). They also give engineering formulas which can be used for scoping calculations. For these scoping calculations, most DSC components and assemblies or portions of them can be approximately represented by plane walled rectangles, annular walled cylinders, or solid cylinders.

By using simple representations and appropriate engineering formulas for each mode of heat transfer, the reviewer can make a heat balance between defined boundaries as shown in Fig. 4-2. The temperatures $T_{1}$ and $T_{2}$ at the boundaries are values taken from the CSAR, which are used to estimase the total heat flow that could occur. Realizing that the scoping calculation is an approximation, the calculated heat flow is compared with the appropriate decay heat values documented in the CSAR. 
Next, the maximum permissible temperature gradient across the boundaries is determined from a structural evaluation of maximum allowable stresses due to thermal gradients or is calculated by using the maximum permissible qualification temperature for the component for $T_{1}$. The reviewer can calculate the maximum allowable heat flow by comparing the maximum permissible temperature gradient to the decay heat value. The difference between the maximum permissible heat flow and the decay heat is the thermal margin. Components that have large positive thermal margins may not require additional evaluation. Components with small or negutive margins will require detailed verification analyses.

\subsubsection{Thermal Computer Codes}

Many codes are available for performing the various calculations to verify the themal evaluation. It is important to select a thermal code that has been well benchmarked and that interfaces with a structural code in order to perform thermal stress analysis. The capabilities of public available themal codes vary significantly. Reference 4.11 evaluates the themal codes using tesc procedures. The five codes described in the following paragraphs include two codes recently developed and benchmarked at LINL.

HEATING-5 is a large, general-purpose conduction computer code originally developed at Oak Ridge National Laboratory. It can handle steady state and transient heat transfer in one, two, or three dimensions, and with all types of boundary conditions. It has been used for many applications in heat transfer. HEATING-5 is a Finite Difference Method (FDM) code. HEATING-5 cannot compute naturally driven convection, and it allows radiation only suaight across a gap with an assumed shape factor of 1 . It does allow radiation and convection gaps in the interior of a model as well as on a boundary. It is not built to handle grids other than triangles, but it is very easy to set up and use.

NACHOS also is a large, general-purpose code with rigorous conduction and convection capabilicies. The code was developed by and is in primary use at Sandia National Laborarory. NACHOS is a Finite Element Method (FEM) code, so supplying the structural design team with convenient thermal data may be easier when using this type of code. Handling an irregular grid using the FEM is also easier. It can handle more of the important physics than any other code in this report. However. it has two drawbacks: it is only two-dimensional. and it allows radiation boundary conditions only on the exterior of the model.

TEMPEST is a large, general-purpose conduction/convection code developed at Pacific Northwest Laboratory. The advantage of TEMPEST is that it solves computed convection, like 
NACHOS, but is also three-dimensional. Unlike NACHOS it cannot do phase changes with or without convection. Its conduction and radiation capabilities are similar to HEATING-5; thus it too has only a gap radiation model. Like HEA'TING-5, it is easy to set up and use, and the documentation and verification are excellent. It comes with a user's manual as well as a verification manual. Approximately twelve sample problems containing sample input and output are provided.

CINDA-3G is a large, general-purpose conduction code developed by Chrysler. CNDA-3G can do everything HEATING-5 can do, and its convection and radiation capabilities are more general. The user's manual covers a mulitude of capabilities including user written subroutines, but it is more difficult to learn than HEATING-5. CINDA-3G can handle any number of radiation connections (generalized gray body enclosure radiation), which makes it superior to the analogous capabilities of HEATING-5, NACHOS, and TEMPEST.

TRUMP is a large, general-purpose FDM conduction code originally developed at the Lawrence Livermore National Laboratory. It can handle irregular geometries. TRUMP seems more versatile that CINDA-3G because it has a more general treatment of convection (except not compured convection) and radiation. Like CINDA-3G, TRUMP can handle any number of radiation connections. It is a vincage code (1966), and so the verification state of TRUMP can be considered excellent. Because of its very general geometry capabiliry, more input specification is required. It is harder to set up than HEATING-5 or TEMPEST.

TOPAZ is a two-dimensional or trree-dimensional FEM computer code for heat conduction analysis (Ref. 4.12). The user's manual presents sample problems with analytical solutions. TOPAZ has been implemented on the CRAY, VAX, and IBM PC compurers. TOPAZ can be used to solve for the steady state or transient temperature field on two-dimensional planar or axisymmetric geometries. Material properties may be temperature- or time-dependent and either isotropic or orthotropic. A variety of temperanse- and time-dependent boundary conditions can be specified including temperanure, flux, convection, and radiation. By implementing the userdefined subroutine feature, users can model chemical reaction kinetics and allow for any type of functional representation of boundary conditions and internal heat generation. TOPAZ can solve problems of diffuse band tadiation in an enclosure coupled with conduction in the material sumounding the enclosure. Additional fentures include thermal contact resistance across an interface, bulk fluids, phase change, and energy balances. Mainframe versions of TOPAZ interface with the structural codes DYNA, NIKE, and GEMINI and the pre- and post-processor codes MAZE and ORJON. 


\subsection{FINDINGS}

The reviewer verifies that sufficient and adequate information has been provided to saisfy the general requirements of the review plan for the DSC, and that the evaluation supports the following conclusion, to be included in the cask safety evaluation repon:

"This section of the applicant's CSAR has been reviewed to determine that the thermal design features have been designed in a manner that will assure compliance with the performance requirements of 10 CFR Part 72."

"Basis for acceptance in the review has been conformance with established guidelines and criteria. The evaluation of the thermal design provides reasonable assurance that, from the standpoint of general requirements for the DSC, it will be possible to store radioactive material safely for at least 20 years."

"The staff concludes that the protective features provided in the design of the DSC conform to applicable Regulations, Regulatory Guides, and industry standards, and are acceptable."

\subsection{REFERENCES}

1. Office of the Federal Register, Title 10, Code of Federal Regulations, Part 72, Office of the Federal Register, Washington, DC, January 1984.

2. F. Kreith, Principles of Heag Transfer, Second Edition, International Textbook Company, Scranton, PA, July 1968.

3. E. R. G. Eckert and R. M. Drake, Jr., Analysis of Heat and Mass Transfer, McGraw-Hill Book Company, New York, NY, 1972.

4. W. H. McAdams, Heat Transmission, Third Edition, McGraw-Hill Book Company, Inc., New York, NY, 1954.

5. E. M. Sparrow and R. D. Cess, Radiarion Heat Transfer, Revised Edition, Brooks/Cole Publishing Company, Belmont, CA, 1977.

6. R. Siegel and J. R. Howell, Thermal_Radiation Heac Transfer, McGraw-Hill Book Company, 1972.

7. H. C. Hottel and A. F. Sarofim, Radiative Transfer, McGraw-Hill Book Company, 1967. 
8. General Electric Company, Heat Transfer Data Book, General Electric Company, Corporate Research and Development, Schenectady, NY, 1977.

9. J. H. Van Sant, Conduction Heat Transfer Solutions, Lawrence Livermore National Laboratory, Livermore, CA, UCRL-52863, Rev. 1, August 1983.

10. R. O. Wooten and H. M. Epstein, Heat Transfer from a Parallel Rod Fuel Element in a Shipping Container, Nuclear Science and Engineering, 1964.

11. M. J. Budden, Comparison and Evaluation of Several Computer Programs for Use in Design of Spent Fuel Shipping Casks, PNL-5213, UC-71, Prepared for the U.S. Department of Energy by Pacific Northwest Laboratory, Richland, WA, July 1984.

12. A. B. Shapiro, IOPAZ - A Finite Element Heat Conduction Code for Analyzing 2-D Solids, Lawrence Livermore National Laboratory, Livemore, CA, UCID-20045, March 1984.

13. U.S. Nuclear Regulatory Commission, Draft Regulatory Guide (CE 306-4): Standard Format and Content for a Topical Safety Analysis Repon for a Dry Spent Fuel Storage Cask, U.S. Nuclear Regulatory Commission, Washington, DC, Revision 0, August 1984. 


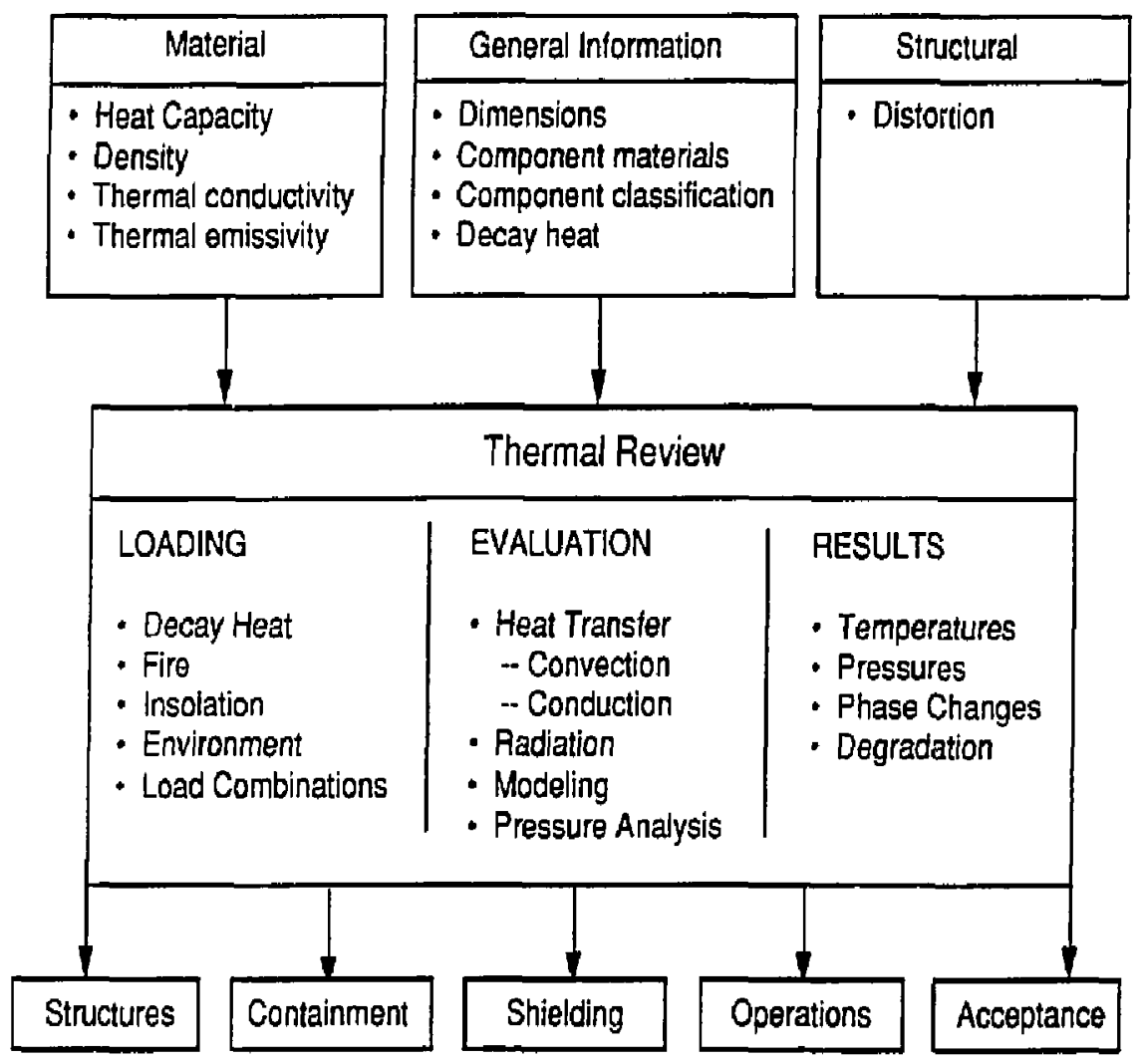

Figure 4-1 Inpur and output information for the thermal review process. 


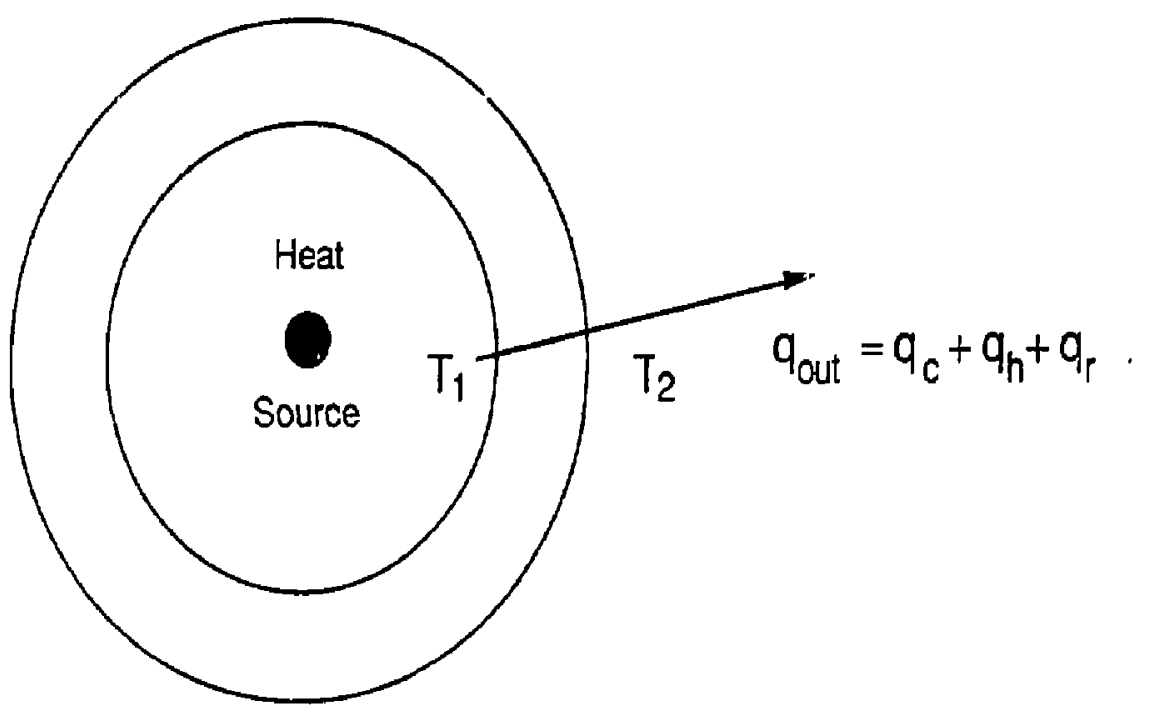

Figure 4-2 Heat balance across component boundaries. 


\subsection{SHIELDING EVALUATION}

\subsection{AREA OF REVIEW}

This section of the review deals with the shielding design analyses for normal and accident conditions of storage. The type of information required from other sections of the CSAR to perform the shielding review are shown in Fig. 5-1. Specific areas to be reviewed are described in the following paragraphs.

\subsubsection{Source Specification}

A description of the contents and the gamma and neutron source terms used in the analyses are reviewed.

\subsubsection{Model Specification}

The model used in the shielding evaluation is reviewed. This includes an assessment of the degree to which the model reflects the geometry, dimensions and material properties of the DSC duing normal and accident conditions of storage.

\subsubsection{Shielding Evaluation}

The method used to determine the gamma and neutron does rates at selected points outside the cask for normal and accident conditions of storage is reviewed. This includes consideration of the following:
A. The assumed spatial source discribution
B. The computer programs used
C. Validity of the basic input parameters
D. Flux to dose rate conversion factors as a function of energy

\subsection{ACCEPTANCE CRITERIA}

Section 72.67 (a) of 10 CFR Part 72 (Ref. 5.1) tequires that during normal operations and anticipated occurrences the annual dose equivalent to any real individual located beyond the controlled area of the ISFSI shall not exceed $25 \mathrm{mrem}$ to the whole body, 75 mrem to the thyroid and 25 mrem to any other organ as a result of exposure to direct radiation trom ISFSI operations and any other radiation from uranium fuel cycle operation within the region. 
Part 72.68 (b) requires that "any individual located on or beyond the nearest boundary of the controlled area shall not receive a dose greater than $5 \mathrm{rem}$ to the whole bady or any other organ from any design basis accident."

Since the CSAR is generic in nature, no specific requirements can be established that relate the degree of attenuation of gamma and neusron radiation to the boundary of a controlled area.

Consequently, with regard to safety of the public beyond the controlled area, acceptance criteria for shielding evaluation needs to be primarily concerned with the accuracy and precision of the estimate of the effectiveness of the shielding under normal and accident conditions. Dose limits for operating personnel that may be in contact with the cask are dealt with in Chapter 10 , "Radiation Protection."

\subsection{REVIEW PROCEDURES}

The shielding review requires in-depth knowledge of shielding analysis for both gamma and neutron radjation. The reviewer must be able to evaluate shielding models and their assusptions. Penerrations, streaming paths, voids, etc., could affect shielding and have to be recognized, understood and evaluated. The reviewer should have a general knowledge of materials, their shielding properties, and how these properties depend on the radiations at every level.

\subsubsection{Source Specification}

Verify that the contents and the gamma and neutron source strengths used in the shielding analysis are adequately described for normal and accident conditions.

\subsubsection{Gaiama Source}

Verify that the quantity of radioactive material included as contents is stated, and the gumma decay source strength (photons/sec and/or MeV/sec) are tabulated as a function of both the source photon energy and the photon energy group structure used in the shielding calculations. Verify that the method used to determine the gamma source strength, spectra and spatial disuribution, including the computer codes employed, are adequately detailed. Ensure that the gamma source strength and distributions for the active fuel and structural support regions (e.g. the head and foor pieces) are detailed separately. Verify that all figures and tabies are sufficiently detailed to stand alone. 


\subsubsection{Neutron Source}

Verify that the quantity of radioactive material included as contents is stated, and the neuron source strength (neutrons/sec) is tabulated as a function of both the source neuron energy and the neutron energy group structure used in the shielding calculations. Verify that the method used to determine the neutron source strenghh, spectral and spatial distribution, including the computer codes employed, are adequately detailed. Verify that the subcricical mulaiplication and axial source dist:bution are tabulated and adequately described. Verify that all figures and tables are derrited to stand alone.

\subsubsection{Model Specification}

Verify that the model used in the shiclding evaluation is adequately described for normal and accident conditions of storage.

\subsubsection{Radial and Axial Shielding Configuration}

Verify that drawings to scale are provided, showing dimensions of the radial and axial shielding materials under normal conditions of storage. Verify that a clear distinction has been made between the active fuel and structural support regions (e.g. head and foot pieces). Verify that dose point locations for the various calculations on and off the external surface of the cask are shown relative to the source regions in the drawings supplied. Verify that voids or irregularities not taken into account in the model are discussed in detail and their effect on the resultant dose rate calculacions are shown to be conservative. Ensure that sufficient detail is provided in the drawings and discussion to cover all configurations evaluated by the shielding calculations.

\subsubsection{Shield Regional Densities}

Verify that material densities $(\mathrm{g} / \mathrm{cm} 3$ ) and atomic number densities (atoms/barm- $\mathrm{cm}$ ) for constituent nuclides of all materials used in the calculational models are provided in sufficient detail to allow compuational verification. Differences, if any, in material and atomic number densities between normal conditions of storage and accident conditions must be clearly stared. For uncommon materials, the source of the data must be referenced, and validation must be provided as described in Section 3.2.2. 


\subsubsection{Shielding Evaluation}

Verify that a general description of the basic method used to determine the gamma and neutron dose rates at the selected points on and off the extemal surface of the DSC under nomal conditions of storage is provided. This must include a description of the spatial source distribution and any computer codes used, including their referenced documentation. The basic input parameters should be discussed in detail. Verify that the basis for selecting the various compurer codes employed, including any pertinent assumptions and parameters, is provided. Flux-to-dose conversion factors must be tabulated as a function of the group structure energy used in the shielding calculations and must be based upon ANSI/ANS6.1.1-1977 (Ref. 5.2). Neutron dose rates must include the primary neutrons and subcritical multiplication; gamma dose rates must inciude the primary gamma rays and any seccrndary gamma rays derived from a coupled neurrongamma problem. Verify that all figures and tables are sufficiently detailed to stand alone, and any data used are supported by appropriate references.

\subsubsection{Methods of Analysis}

The ultimate requirement of any shielding design is the attenuation of the neutrons and/or photons emitted by the source to a level implied by regulatory requirements. Care must be taken to ensure that adequate consideration is given to shield penetrations and/or streaming paths which may result in local increases in the radiation field. Accident effects must be closely examined to ensure that all scenarios involving a loss or local reduction in cask shielding are evaluated for their radiation dose consequences.

As a first step in the shielding evaluation, the reviewer may elect to estimate the overall adequacy of the DSC shielding using basic and simplistic geometry specific formulas. Formulas and their use for such source and shield geometries as a point source and slab shield, line source and slab shield, cylindrical volume source with slab shield at side and end, and a spherical volume source with slab shield are discussed in detail in References 5.3 and 5.4. Formulas to estimate the effects of siield irregularities such as penetrations, streaming paths, voids, etc., are also presented and discussed. Also included are general discussions of neurron and photon attenuation and the concept and application of neutron removal cross sections and photon buildup.

For a thorough shielding evaluation of a DSC, more sophisticater! computational techniques will ultimately be required. The following section highlights some computer codes presently available for such a purpose. 


\subsubsection{Computer Codes for Shielding Evaluation}

A number of computer cedes are available to perfori.t the various calculations necessaiy to complete the shielding evaluation. For generation of the source terms, ORIGEN is generally the code of choice. For the shielding analysis, there are the large compurer codes MORSE, ANISN, and DOT and a personal computer code version of QAD-CGGP. ORIGEN and MORSE are available as part of the SCALE system.

SCALE is a comprehensive computational system that was designed for evaluating nuclear fuel facilities and transport package designs (Ref. 5.5). It was developed for the NRC staff by the Oak Ridge National Laborarory to serve as a standard analysis tool. Criticality, shielding, and/or heat transfer calculations may be performed by the automated analycical sequences within SCALE. The use may run the computer codes within each analytical sequence in either a stand-alone job or coupled sequence.

ORIGEN is a versatile point-depletion code that caiculates the radioactive growth and decay for large numbers of isotopes with arbitrary coupling (Ref. 5.6). The matrix exponential method is used in the solution of coupled, linear, first-order differential equations with constant coefficients. With ORIGEN it is possible to calculace composition and activity of fuel, fission products, and structural materials in light-water reactors (LWR), liquid metal fast breeder reactors (LMFBR), molten salt breeder reactors (MSBR), and high-temperature gas reactors (HTGR). For given decay times, gamma source distributions and neutron emission rates can be calculased.

MORSE is a multigroup monte carto radiation transport code with specialized onedimensional and turee-dimensional geomeries (Ref. 5.7). Time dependence for both shielding and criticality is provided Anisotropic scattering is treated for each group-to-group transfer utilizing a generalized Gaussian quadrature technique. For shielding purposes, both neutron, photon, and coupled neutron-photon problems may be solved.

ANSIN solves the one-dimensional energy-dependent Boltzmann transport equation with high-order anisotropic scattering in slab, cylindrical, and spherical geomerries, for neutons and photons (Ref. 5.8). The method of discrete ordinates is used to solve for the angular dependence of the neuron or phoron flux with anisotropic scattering treated as a Legendre expansion of the scattering cross section. For shielding purposes, both neutron, photon, and coupled neutronphoton problems may be soived.

DQT solves the two-dimensional energy-dependent Boltzmann transport equation with highorder anisotropic scattering in plane, cylindricul, and spherical geometries. for neutrons and 
photons (Ref. 5.9). In terms of method and utility, DOT is essentially a two-dimensional version of ANISN.

QAD-CGGP is a combinatorial version of QAD-P5A, a point kemel code system for neutron and photon shielding calculations using the geometric progression fitting function for the photon buildup factor (Ref. 5.10). A modified Albert-Welton kemel or kernels obtained from the moments method solution of the Boltzmann transport equation are used for neutron penetration problems.

\subsubsection{Appendix}

Ensure that all supponive information or documentation is provided. This would include, but not be limited to, information such as justification of assumptions or analytical procedures; cask test results, photographs, computer program descriptions and input/output; and applicable pages from referenced documents.

\subsection{FINDINGS}

The reviewer verifies that sufficient and adequate information has been provided to sapisfy the general requirements of the review plan for the DSC, and that the evaluation supports the following conclusion, to be included in the SER:

"This section of the applicant's CSAR has been reviewed to determine that the DSC shielding has been designed in a manner that will assure compliance with the performance requirements of 10 CFR Part 72.67 (a) under normal conditions of storage and 10 CFR Part 72.68 (b) under accident conditions of storage. The scope of the review covers the shielding design features of the DSC, the source and model specifications, the shielding evaluation, and any supportive information or documentation."

"The CSAR reported maximum surface dose rates are , and mrem/hour at the top, side, and bottom, respectively under nomial conditions. Under the worst case accident conditions, the CSAR reported maximum surface dose rates are , and mrem/hou at the top, side. and bottom, respectively. Staff calculations confirm these results."

"Confirmatory analyses of the dose consequences to any individual continuously present at the site boundary due to direct radiation from a single DSC under nomal and accident conditions ure in substantial agreement with those doses reported in the CSAR and are estimated to be less than mremiyear and mrem/year to the whole body, respectively. Vormal 
consequences are less than the 25 mrem limit established in 10 CFR Par 72.67 (a). Accident consequences are less than the $5 \mathrm{rem}$ limit established in 10 CFR Part 72.68 (b)."

"Basis for acceptance in the review has been conformance with established guidelines and criteria. The evaluation of the DSC shielding provides reasonable assurance that, under normal and accident conditions of storage, it will be possible to store radioactive material in the DSC safely."

"The staff concludes that the protective features provided in the design of the DSC conform 10 applicable Regulations, Regulatory Guides, and industry standards, and are acceptable."

\subsection{REFERENCES}

1. Office of the Federal Register, Title 10. Code of Federal Regulations, Part 72, Office of the Federal Register, Washington, DC, January 1984.

2. American Nuclear Society, Neutron_and Gamma-Rav Flux-to-Dose Rate Factors, American Nuclear Society, La Grange Park, IL, ANSU/ANS-6.1.1-1977, (1977).

3. T. Rockwell III, Ed., Reactor Shielding Design Manual (D. Van Nostrand Co., Inc., New York, 1956).

4. E. P. Blizard and L. S. Abbott, Eds., Reactor Handbook: Volume III, Pan B. Shielding (John Wiely and sons, New York, 1962).

5. Oak Ridge National Laboratory, Nuclear Engineering Applications Department, SCALE: A Modular Code System for Perfoning Standardized Computer Analvses for Licensing Evaluations, Vol. 1-3, Oak Ridge National Laboratory, Oak Ridge, TN, NUREG/CR-0200, ORNL/NUREG/CSD-2/R, January 1982.

6. M. J. Bell, ORIGEN - The ORNL Isotope Generation and Depletion Code, Oak Ridge National Laboratory, Oak Ridge, TN, ORNL-4628, May 1973.

7. E. A. Straker, et al., MORSE Code - A Multigroup Neutron and Gamma-Rav Monte Ciurlo Transport Code, Oak Ridge National Laboratory, Oak Ridge, TN. ORNL-4585, September 1970. 
8. W. W. Engle, Ir., A Users Manual for ANISN - A One Dimensional Discrete Ordinates Transport Code with Anistropic Scattering, Oak Ridge Nationgl Laboratory, Oak Ridge, TN, k-1693, March 1967.

9. W. A. Rhodes and F. R. Mynatt, DOT-III Two Dimensional Discrete Ordinates Transport Code, Oak Ridge National Laboratory, Oak Ridge, TN, ORNL-TM-4280, September 1973.

10. D. K. Trubey, OAD-CGGP: A Combinatorial Version of QAD-P5A, A Point Kernel Code System for Neutron and Gamma-Ray Shielding Calculations Using the GP Buildup Factor, Radiation Shielding Information Center, Oak Ridge National Laboratory, Oak Ridge, TN, CCC-493, April 1986.

11. U.S. Nuclear Regulatory Commission, Chapter 12: Radiation Protection, in Standard Review Plan for the Review of Safery Analysis Repons for Nuclear Power Plants, U.S. Department of Commerce, Washington, DC, NTISUB/B201-0012, NUREG-75/087, (1975), Rev-1. 


\section{Table 5.1}

Summary of Maximum Dose Rate (mrem/hr) Normal Conditions of Storage

\begin{tabular}{lccc}
\hline & \multicolumn{3}{c}{ Cask Surface } \\
\hline & Side & Top & Bottom \\
\hline Gamma & & & \\
Neuron & & \\
Total & & & \\
\hline
\end{tabular}




\subsection{CRITICALITY EVALUATION}

This chapter of the neview confinns that the nuclear sub-criticality design of a DSC submitted in a CSAR for USNRC certification uses acceptable analytical and/or test methods and complies with requirements of $10 \mathrm{CFR}$ Part 72.73 (Ref. 6.1). The maximum allowable k-eff for nuclear criticality safety has already been defined in par. 2.2.7 of this CSRP. This chapter deals mainly with the requirement to assure that margins of safety for the nuclear criticality parameters are commensurate with the uncenainties in the storage conditions and in the data and methods used in the calculations to determine the maximum $k$-eff. This involves issues concerning the models used to represent the DSC for criticality, the material properties in the models and the convergence criteria for computational tools. Also addressed are issues concerning the benchmarking of computational tools, the calculation of a bias and some operitional concerns. Figure 6.1 shows the types of information required from other sections of the CSAR 10 perform the criticality review. General information is required on dimensions, component materials, fissile contents and neutron absorber materials. If the DSC undergoes any deformation under accident conditions or if thermal conditions alter the configuration of the criticality model then information for both the strucnures on such deformation and from thermal are required.

\subsection{AREA OF REVIEW}

\subsubsection{Spent Fuel to be Stored}

The description of the spent fuel to be stored is reviewed for adequacy in providing sufficient information for generating the criticality evaluation mociel.

\subsubsection{Model Specification}

It is difficult to construct an exact representation of a DSC for criticality evaluation. When such models are prepared as input to a compositional tool. simplified idealizations are cften made. The conservation inherent in these models provides the margin against a criticality event and should be carefully reviewed.

Properties used to represent the materials in the models must be reviewed. These properties include the nuclear cross-sections for each material in the model and the number densities in each of the models. The conservatism applied for number densiries in modeling the fuel is reviewed. 


\subsubsection{Criticality Calculation}

Since the consequences of a criticality accident in terms of dose rate outside the cask are severe, the criticality calculations presented in the cask should be carefully reviewed. Of particular concem is the manner in which the applicant has arrived at the worst case of fuel loading conditions, temperature, moderation and tolerance buildup. More specific items to be reviewed include the calculational or experimental method, fuel loading optimizarion, and criticality results. $k$-eff results from the computational tools should be reviewed for adequate convergence. For casks containing neutron poisons the methods used to ensure the presence of these poisons over the design life of the ISFSI should be reviewed. Since loading, unloading and deterioration of rnaterials over a long period of time may affect the reactivity of the spent fuel the overall operations or a DSC should be reviewed for their effect upon criticality.

\subsubsection{Critical Benchmark Experiments}

Computational tools used in criticality calculations must be benchmarked against critical experiments. The critical benchmark experiment provides justification for the validity or the calculational method and neutron cross-section values used in the analysis by presenting results of calculations for selected critical benchmark experiments. The critical benchmark experiments for yalidating the computational tools are reviewed for relevance to the DSC design.

\subsection{ACCEPTANCE CRITERIA}

\subsubsection{Spent Fuel to be Stored}

The CSAR must completely describe the spent fuel to be stored. Much of this information may already be contained in Section 2.2.1. However, a discussion of the information reiating to how it is to be used in the criticality evaluation should be presented.

\subsubsection{Model Specification}

\subsubsection{Description of Calculational Model}

Since it is difficult to consmuct an exact physical model of a fuel assembly in a basket in a Cin ' , conservadism should be applied to any model used to evaluate criticality. If the complexity of some components such as steel pins that separates fuel or grid plates to separate bundles is sach that they cannot be modelled accurately, they should be ignored or replaced by water. Where tolerances may result in dimensional uncerainties for components important to criticality safety 
such as neutron poisons, for example, the model should always assume the thinnest value allowed by the manufacturing tolerance.

Preparing a discrete fuel rod-water-channel-basket assembly for every fuel rod may exceed the memory or capability of the evaluational tuol. In this case, a homogenization process is used. However, use of the homogenization technique may not result in k-eff values that are conservative relative to $\mathrm{k}$-eff values for discretely modelled fuel assemblies. Therefore, if the CSAR should base its criticality evaluation upon a homogenized model, a comparison calculation for a single celf should be presented between a homogenized fuel cell and a discreetly modelled fuel cell. This model should include the neutron poison basket modelled discretely. If the mean value or k-eff for the homogenized calculation is lower than the mean value or k-eff for the discrete calculation by more than the one sigma of the discrete calculation, then the bias should be no less than the difference of the means berween the homogenized and discrete calculations.

\subsubsection{Spent Fuel Cask Regional Densities}

Modeling of the spent fuel should assume maximum initial enrichment, and neither credit for burnup nor the presence of neutron poisons formed during irradiation. Conservatism relating to burmup recognizes that fuel rods do not burn evenly from top to bottom in a reactor nor do they burn evenly across a fuel bundle. Neutron poisons formed during imadiation have different half life values and demonstrating that $k$-eff results are still valid after a twenty year storage period is difficult. However, rough calculations show that the bum-up rate of boron-10, used as a poison in the cask, is relatively small over 20 years due to the low neutron flux levels.

The CSAR should provide a calculation for the worst case showing the $k$-eff of the DSC modelled with uniradiated fuel.

\subsubsection{Criticality Calculation}

\subsubsection{Calculational or Experimental Method}

The computational method acceptable for the calculation of $k$-eff are the "monte carlo" codes such as COG (Ref, 6.2), KENO IV (Ref. 6.3) and KENO Va (Ref. 6.4) on the SCALE SYSTEM (Ref. 6.5). Although "monte carlo" codes are not the only computational cools found in applications, they are preferred since they permit modelling of very complex geometry with relative ease, the $k$-eff values obtained are accurate, they are available and their computation expense is moderate. 


\subsubsection{Fue! Loading Optimization}

The CSAR should identify all the design conditions that are important and then address these conditions for normal and accident conditions.

The CSAR should consider deviarions from nominal design configurations. For example, the evaluation of $k$-eff should not be limited to a model in which all the fuel bundles are neatly centered in each basket comparment with the centerline of the basket coincident with the centerline of the cask. This model may not produce the highest $k$-eff. Furthermore, in some casks that have steel containments and lead shielding, the $k$-eff will increase when the basket containing neutron poisons is off-center and pushed over as close to the lead as it can get as also would be the fuel bundle in the basket comparment. In extreme cases, increases as much as 0.04 have been calculated.

\subsubsection{Criticality Results}

The results of the calculations for k-eff of the DSC should be modified by the application of an appropriate bias depending upon the k-eff results of calculations that moiel critical experiments. Only negative biases should be applied. If, for example, a computational tool gives a result for a critical experiment that is always greater than unity then the calculated k-eff is not corrected downard. Only corrections that increase $k$-eff are made.

The upper limit for $k$-eff should represent the 2-sigma variation appled to the compured value of the DSC $\mathrm{k}$-eff with bias applied. The value of 2-sigma is widely used in the nuclear industry. It appears in many Special Nuclear Materials licenses granted to licenses handling nuclenr fuel.

$K$-eff results from the computational tools should display adequate convergence. For monte carlo calculations, as the number of neutron histories increases, the mean value for $k$-eff should be seen to be slowly approaching some fixed value. In addition, the standard deviation associated with each mean value should slowly decrease as the number of neutron histories increase.

Monte carlo codes often present a $k$-eff histogram for the mean value for each set of neutron histories calculated. This histogram for the mean value should show a nearly nomnal statistical distribution. If the histogram is highly skewed, the calculation of more neutron histories for the problem is indicated.

For other computational tools, a convergence unit is often set. The selection of a proper convergence limit and the achievement of this limit should be described. 


\subsubsection{Critical Benchmark Experiments}

When KENO is used to calculate $k$-effective for a critical experiment (benchmarking), each fuel rod in the fuel assemblies should be modeled discretely in three dimensions. Homogenized fuel-clad-water cross-sections should not be used. This $i^{\prime}$ !ecause the homogenization calculations are really done in two dimensions, and the leakage of neutrons from the ends of the fuel assembly are not considered. This two-dimensional technique could result in a calculation of $k$ effective for the critical experiment that is ton high, meaning that the corresponding bias for the computational tool is too low. For example, $k$-eff for a homogenized model of a critical experiment might be 0.99; k-eff for a discrete model of a critical experiment migh: be 0.98 . The bias for the computational tool should be $2 \%$ rather than $1 \%$.

It is unlikely that a critical experiment will be found that precisely matches the fissile material configuration and neuton poisoning configuration in a model for a DSC. More than one critical experiment should be calculated. If a DSC includes low enriched water moderatel fuel rods held in a basket containing neutron poisons, and the fuel and basket are inside of a cask, then one set of critical experiments should be calculated for just the low enriched fuel rods in water at two different fuel rod pitches. Another set of critical experiments should be calculated for low enriched fuel rods in water with fixed poisons first placed very close to the fuel rod assembly and then farther away from the fuel rod assembly. From the results of such calculations, an appropriace bias for the computational tool may be determined.

\subsection{REVIEW PROCEDURES}

\subsubsection{Spent Fuel to be Stored}

Verify that a statement of the DSC fuel loading is given. This is a legalistic statement of the fissile material loading. This statement should also appear in the cask certificate.

\subsubsection{Model Specification}

Verify that the geometric model used in the calculation is given. 


\subsubsection{Description of Calculational Models}

Dimensioned sketches to scale may be used. Verify that all materials used in all regions of the models are presented. Differences between the actual DSC configuration and the models should be idenified, and the models should be shown to be conservative. Verify that differences between the models for normal conditions of storage and for accident conditions are clearly identiried.

Some of the models are prepared as input to a computer code. Tables listing the inputs to the codes for each of the models may be presented here.

\subsubsection{Spent Fuel Cask Regiona! Densities}

Verify that the material densities ( $\mathrm{gm} / \mathrm{cm}^{3}$ ) and the atomic number densities (atoms/barm-cm) for the consrituent nuclides of all materials used in all the calculational models for the normal conditions and accident conditions are given. Fissionable isotopes should be considered at their most nuclear reactive credible concentration. The atomic number densities for al! of the isotopes should be checked to show that they are consistent with the masses and the volline occupied for the material specified for each of the regions. Any special constants used such as the molecular weights for $235 \mathrm{U}, 238 \mathrm{U}, 238 \mathrm{Pu}$, oxygen, density of $\mathrm{UO}_{2}$ and water, number density for oxygen etc., should be given in this section.

\subsubsection{Criticality Calculation}

\subsubsection{Calculational or Experimental Method}

Verify that a "monte carlo" code such as COG, KENO IV or, preferably, KENO V is used to evaluate $k$-eff. If an application contains fuel models that use cross-section sets that are collapsed from larger cross-section sets (more energy groups), verify that an explanation is provided to show how the collapsing is accomplished. This should involve consideration of resonance absorption, selfshielding scattering effects, etc. In any event, the validity of the method reponted in the CSAR will be chicked by confurming calculations.

\subsubsection{Fuel Loading Optimization}

Verify that all the design configuracions for nomal and accident conditions are addressed. Verify that all deviations from nominal design configurations are considered with respect to tolerance build-up. 


\subsubsection{Criticality Results}

Verify that the results of reactivity calculations establishing the most reactive configuration for both normal and accident conditions are displayed in tabular and graphical form. Verify that agreements justifying the validity and conservatism of the analyses are included.

The bias established with the benchmark calculations should be aken into account. The method used to apply this bias is as follows:

Assume that the $\mathrm{k}$-eff result from the cask calculation gives a value of 0.8423 with a 1 sigma value of 0.0042 . Assume, further, that the results of a critical experiment indicate a 0.023 bias to be applied to the mean value with a 0.003 bias for the 1 sigma value. The mean value for the cask with the bias applied then becomes

$$
0.8423 \times 1.023=08617
$$

The 1 sigma value for the cask with the bias applied comes

$$
0.003 \times 0.8423+0.0042=0.0067
$$

Note that since the bias indicated by the crivical experiment relate to a k-eff close to unity, it is reculuced to the extent that the mean $k$-eff for the cask is less than urity.

The upper limit for the cask is now set at the mean (with bias) plus 2 sigma with bias applied (see 6.2.3.3) or

$$
\text { Max k-eff }=0.8617+2 \times 0.0067=0.8751
$$

Note that the upper limit without bias is

$$
\text { No bias } k \text {-eff }=0.8423+2 \times 0.0042=0.8507
$$




\subsubsection{Critical Benchmark Experiments}

\subsubsection{Benchmark Experiments and Applicability}

Verify that the CSAR provides a general description of the selected benchmark experiments. Verify that the experiments analyzed used the same calculational tool (calculational method and cross-section) used to calculate the $\mathrm{k}$-eff values for DSC.

An example of the use of more than one critical experiment for benchmarking a computarional tool is given below:

Reference gives a cross-section set name 27GROUPNDF4 on the SCALE system for use with the KENO criticality codes. The 27GROUPNDF4 set is collapsed from a 218 group ENDF/B-IV may be seen in Ref. 6.6. It is the benchmarking of the 27GROUPNDF4 set with the KENO criticality code that is of concern here.

In this example, five critical experiments are selected. These experiments are to be used for benchmarking a compucational tool for storing fuel bundles in a poison basket in a cask. Table 6.2 gives some information on these experiments.

The first two experiments, TRX1 and TRX2, were run at the Bettis facility in the mid1950's. These experiments used uranium metal fuel clad with aluminum and enriched to $1.3 \mathrm{w} / \mathrm{o}$ 235U. The fuel rods were 48 inches long. The difference between the two TRX experiments involved fuel rod pitch: TRX1 has a triangular pitch of 0.711 inches and TRX2 has a triangular pitch of 0.856 inches.

Experiments 3, 4 and 5 in Table 6.2 PNL 2438-2, PNL 2438-20 and PNL 2438-32, involve $\mathrm{UO}_{2}$ fuel rods clad with aluminum and enriched to 2.35 w/o $235 \mathrm{U}$. The fuel rods are 36 inches long. These experiments were made at Pacific Northwest Laboratories in the mid-1970's. These experiments were run with a square pitch of 0.8 inches for the fuel rods and used a plate containing neutron poisons. The difference between the PNL experiments which involve the composition of this plate, the thickness of this plate. and the spacing of this plate to the edge of the fuel rod array is discussed below.

The PNL experiments use three fuel rod arrays. From a plan view, each aray has 20 rods in the $x$-direction and 17 rods in the $y$-direction. These rods are in a square lattice at a pitch of 0.8 inches. Two neutron poison plates are then placed near the center array; one poison plate is between the center atray and the aray just below it. The two outer fuel rod arays are separated from the center array and the aray just below it. The two outer fuel sod arrays are separated from 
the center array and the poison plates at a great distance initially; these two outer arrays are then moved slowly toward the center array in a symmerrical fashion until criticality is achieved.

In PNL 2438-20, the neutron poison plates are constructed from 0.281 inches thick Boral. The plates are placed 0.254 inches away from the edge of the fuel rods in the center array. In PNL 2428-32, the neutron poison plates are constructed from 0.117-inch-tic 304L stainless steel containing 1.05 w/o boron (borated stainless steel), and are placed 1.59 inches away from the edge of the fuel rods in the central array.

In PNL 2438-2, only the central array is used. It contains 20 rods in the $x$-direction and 18 rods in the $y$-direction.

\subsubsection{Delails of Benchmark Calculations}

Some results of these experiments may be seen in Table 6.2. An example of the PNL2438-2 results prepared as input to KENO-V.a is shown in Table 6.3 .

\subsubsection{Results of Benchmark Calculations}

Table 6.2 shows the results of these experiments in terms of the mean values and the 1 standard deviation values for both $k$-effective and the bias.

A comparison of TRX1 and TRX2 shows that the rod pitch decreases from 0.856 inches to 0.711 inches, the bias on the mean value k-effective increases from $1.7 \%$ to $2.3 \%$. A comparison of PNL 2438-2 and TRX 1 and 2 shows the bias for the 0.8-inch-square pitch to be about the same as the bias for the 0.711-inch triangular pitch. A comparison of PNL 2438-20 and PNL 2438-32 shows that as the poison plate is moved farther away from the fuel bundle, the bias increases. perhaps approaching the value for only fuel rods in water.

From these results, a bias of $2.3 \%$ would be appiied to the mean value of $k$-effective, and a bias of $0.3 \%$ would be applied to the 1 standard deviation value of $k$-effective for the 27 GROUPNDF4 cross-section set. This bias would be applied for fuel rod pitch/diameter ratios at 1.8 for fuel rods with outside diameters berween 0.38 inches and 0.44 inches. This bias would be applied when neutron poison sheets were present near the fuel rods in a cask. 


\subsubsection{Confirmatory Calculations}

Since criticality evaluation is very complex and the computational tools may not be completely understood by the applicant, confirmatory calculations should be performed to assure that the worst case has been addressed in the CSAR and that the reponed k-eff is comect.

A model for the confirmatory calculations shou't be made independently from the models presented in the CSAR. If the reported $k$-eff for the worst case is substantially lower than the acceptance limit of 0.95 , then a simple model known to produce very conservative k-eff values may be used for confimatory calculations.

At least one confirmatory calculation should be made for the worst case in which the components in the DSC are modelled at temperanires determined from the thermal evaluation. The $k$-eff results from this model should be lower than for those results obtained for models at room temperanure. If this is not the case, more calculations are required to find the peak $k$-eff for all the possible thermal conditions.

\subsection{FINDINGS}

The reviewer should determine that sufficient information has been provided to satisfy the requirements of this review guide section. The results of this determination should be expressed in a paragraph. The results often contain the legalistic statement of the permitted loading conditions for the DSC.

The confirmatory calculation should also be discussed. This discussion should include tie model used for the confirmatory calculation, the computational tools used, ithe results of the confirmatory calculation, and the comparison of these results with those presented in the SARP. The bias applied to the resulis of the confirmatory calculation, if any, should be presented and discussed.

\subsection{REFERENCES}

1. Office of the Federal Register. Title 10. Code of Federal Regulations, Part 72, Office of the Federal Register. Washington, $\mathrm{DC}_{\text {. January } 1984 .}$

2. T. P. Wilcox, Jr and E. M. Lent, COG: A Particle Transport Code Designed to Solve the Boltzmann Equation for Deep Penetration (Shielding) Problems, Lawrence Livermore Narional Laborałory, Livermore, CA. 
3. L. M. Petrie and N. F. Cross, KENO-IV Improved Mone Carlo Criticality Pragram, Oak Ridge National Laboratory, Oak Ridge, TN, ORNL-4938; November 1975.

4. L. M. Petrie and N. F. Landers, KENO-V. a An Improved Monte Carlo Criticaliry Program with Super Grouping, Oak Ridge National Laboratory, Oak Ridge, TN, NUREG/CR-0200, Volume 2, Section F11, ORNL/NUREG/CSD 2N1/R2; December 1984.

5 J. A. Bucholz et al., SCALE. A modular Code System For Perfoming Standardized Compurer Analysis for Licensing Evaluation, Oak Ridge National Laboratory, Oak Ridge, TN, NUREG/CR-0200, ORNL/NUREG/CSD/2, Volume 1, Oak Ridge National Laboratory, July 1980.

6. E. M. Bohn et al, Benchmark Testing of ENDE/B-IV, Brookhaven National Laboratory, Brookhaven, NY, BNL-NCS 21118 (ENDF-230) Vols. I \& II, March 1976.

7. J. Hardy, Jr., D. Kein, and J. J. Volpe: A Study of Phusics Paramerers in Several WaterModerated Lantices of Slightly Enriched and Nanual Uranium, WAPD-M-931; March 1970.

8. J. Hardy, Jr., D. Klein, and J. J. Volpe; Nucl Sci. Eng, 40, 101 (1970),

7. J. J. Volpe, J. Hardy, Jr., and D. Klein, Nucl. Sci, Eng., 40, 116 (1970).

10. J. Hardy, Jr., D. Klein, and R. Dannels; Nucl. Sci. Eng, 26, 462 (1966).

11. J. R. Brown et al., Kinerics and Buckling Measuremens in Larrices of Slightly Enriched U or U02Rods in H2O. WAPD-176, January 1958.

12. R. Sher and S. Fiarman, Studies of Thermal Reactor Benchmark Data Inceroretation: Experimental Comections, EPRI NP-209; October 1976.

13. S. R. Bierman, E. D. Clayton, B. M. Durst, Critical Separation Besween Sub-Critica: Clusters of 2.35 w/o U235 Enriched Un2 Rods in Water with Fixed Neurron Poisons, PNL2438; October 1977. 


\section{TABLE 6.1}

Volume is Variable

Extrapolation Distance

$\mathrm{U}(3.0) 02-\mathrm{H} 20$ Cylindrically Shaped

Homogeneous Mixtures Length Varies

Data From: Carter, R.D. et al., "Criticality Handbook"

ARH-600, Vol. II, Figures III.B.10(3.0)

Diameter $=13.91$ " ID

K-Infinite and migration area vs. concentration data from and full water extrapolation

Distance Data from DP-1014 (Clumped, 0.4 in. od)

\begin{tabular}{|c|c|c|c|c|c|c|}
\hline $\begin{array}{l}\text { U Density } \\
\text { (H/Fissile) }\end{array}$ & K-Infinite & $\begin{array}{c}\text { Migration } \\
\text { Area, SQCM }\end{array}$ & $\begin{array}{l}\text { Bare } \\
\text { Exra: } \\
\text { polating } \\
\text { Distance, CM }\end{array}$ & $\begin{array}{c}1.0^{n} \mathrm{H} 2 \mathrm{O} \\
\text { Exora- } \\
\text { polating } \\
\text { Distance, CM }\end{array}$ & $\begin{array}{l}\text { Full H20 } \\
\text { Extra- } \\
\text { polating } \\
\text { Distancr }-\mathrm{m}\end{array}$ & $\begin{array}{l}2,0^{n} \mathrm{H} 20 \\
\text { Extra- } \\
\text { polating } \\
\text { Distance, CM }\end{array}$ \\
\hline $\begin{array}{r}1011.30 \\
919.14 \\
827.45 \\
735.57 \\
043.73 \\
551.74 \\
505.94 \\
459.91 \\
414.06 \\
368.07 \\
322.14 \\
276.22 \\
230.31 \\
184.36 \\
138.43 \\
92.50\end{array}$ & $\begin{array}{l}1.091541 \\
1.129870 \\
1.169376 \\
1.207628 \\
1.249253 \\
1.291533 \\
1.312548 \\
1.333635 \\
1.353958 \\
1.373364 \\
1.390861 \\
1.405075 \\
1.413390 \\
1.411386 \\
1.389508 \\
1.326772\end{array}$ & $\begin{array}{l}32.67 \\
32.29 \\
31.95 \\
31.67 \\
31.40 \\
31.18 \\
31.09 \\
31.03 \\
31.00 \\
31.00 \\
31.07 \\
31.21 \\
31.47 \\
31.93 \\
32.74 \\
34.26\end{array}$ & $\begin{array}{l}2.26 \\
2.22 \\
2.21 \\
2.18 \\
2.17 \\
2.14 \\
2.13 \\
2.12 \\
2.11 \\
2.10 \\
2.10 \\
2.09 \\
2.08 \\
2.08 \\
2.07 \\
2.04\end{array}$ & $\begin{array}{l}4.25 \\
4.24 \\
4.22 \\
4.20 \\
4.20 \\
4.19 \\
4.19 \\
4.18 \\
4.18 \\
4.19 \\
4.19 \\
4.19 \\
4.20 \\
4.22 \\
4.25 \\
4.32\end{array}$ & $\begin{array}{l}6.26 \\
6.23 \\
6.21 \\
6.19 \\
6.19 \\
6.20 \\
6.21 \\
6.22 \\
6.25 \\
6.29 \\
6.34 \\
6.41 \\
6.51 \\
6.65 \\
6.88 \\
7.29\end{array}$ & $\begin{array}{l}5.25 \\
5.24 \\
5.22 \\
5.20 \\
5.20 \\
5.20 \\
5.21 \\
5.20 \\
5.22 \\
5.24 \\
5.25 \\
5.27 \\
5.31 \\
5.36 \\
5.44 \\
5.61\end{array}$ \\
\hline GMS U-235 & $\begin{array}{l}\text { U Density } \\
\text { (HUFissile) }\end{array}$ & $\begin{array}{l}\text { Cylinder } \\
\text { I.D. (in.) }\end{array}$ & Keff (Bare) & Keff (1.0) & Kelf(full) & Keff $(2.0)$ \\
\hline 1970.81 & 1011.30 & 13.912 & .720 & .763 & .800 & .782 \\
\hline 1970.81 & 919.14 & 13.912 & .744 & .789 & .827 & .809 \\
\hline 1970.81 & 827.45 & 13.912 & .768 & .814 & .854 & .835 \\
\hline 1970.81 & 735.57 & 13.912 & .788 & .837 & .878 & .858 \\
\hline 1970.81 & 643.73 & 13.912 & .809 & .860 & .903 & .882 \\
\hline 1970.81 & 551.74 & 13.912 & .825 & .879 & .925 & .903 \\
\hline $1^{17} 70.81$ & 459.91 & 13.912 & .834 & .892 & .942 & .918 \\
\hline 1970.81 & 414.06 & 13.912 & .834 & .895 & .947 & .922 \\
\hline 1970.81 & 368.07 & 13.912 & .830 & .894 & .950 & .923 \\
\hline
\end{tabular}


TABLE 6.1 (Continued)

$\begin{array}{ccccccc}\text { GMS U-235 } & \begin{array}{c}\text { U Density } \\ \text { (HiFissile) }\end{array} & \begin{array}{c}\text { Cylinder } \\ \text { 1.D. (in.) }\end{array} & \text { Kell (Bare) } & \text { Keff (1.0) } & \text { Keft(tull) } & \text { Kelf (2.0) } \\ 1970.81 & 322.14 & 13.912 & .820 & .888 & .948 & .919 \\ 1970.81 & 276.22 & 13.912 & .800 & .874 & .940 & .908 \\ 1970.81 & 230.31 & 13.912 & .768 & .849 & .924 & .887 \\ 1970.81 & 184.36 & 13.912 & .718 & .809 & .895 & .851 \\ 1970.81 & 138.43 & 13.912 & .641 & .744 & .846 & .793 \\ 1970.81 & 92.50 & 13.912 & .523 & .642 & .767 & .700 \\ 2809.32 & 1011.30 & 15.657 & .770 & .806 & .837 & .822 \\ 2809.32 & 919.14 & 15.657 & .796 & .834 & .865 & .850 \\ 2809.32 & 827.45 & 15.657 & .822 & .861 & .894 & .878 \\ 2809.32 & 735.57 & 15.657 & .844 & .885 & .919 & .903 \\ 2809.32 & 643.73 & 15.657 & .867 & .910 & .946 & .929 \\ 2809.32 & 551.74 & 15.657 & .886 & .932 & .970 & .952 \\ 2809.32 & 505.94 & 15.657 & .894 & .941 & .981 & .962 \\ 2809.32 & 459.91 & 15.657 & .899 & .948 & .989 & .969 \\ 2809.32 & 414.06 & 15.657 & .901 & .952 & .996 & .975 \\ 2809.32 & 368.07 & 15.657 & .898 & .953 & 1.000 & .977 \\ 2809.32 & 322.14 & 15.657 & .889 & .948 & .999 & .974 \\ 2809.32 & 276.22 & 15.657 & .872 & .935 & .992 & .964 \\ 2809.32 & 230.31 & 15.657 & .841 & .911 & .976 & .944 \\ 2809.32 & 184.36 & 15.756 & .790 & .871 & .947 & .908 \\ 2809.32 & 138.43 & 15.657 & .711 & .804 & .896 & .848 \\ 2809.32 & 92.50 & 15.657 & .586 & .697 & .812 & .751\end{array}$

Note: Bare $(X=0),. X=1.0$ in. Water and Fill Water $(X=12$ in.) Extrapolation Distance (ED) Values are used in the equation $E D=c l-C 2 / E x p(C 3 * X)$ to calculate $C 1 . C 2$, and $C 3$. Then these calculated constants are used in the same equation to find the extrapolation distance for $X=$ 2.0 inches water reflection. For fissile concentatic ${ }^{2}$ for which exrapolation distances are unavailable in ARH-600, 3.2. CM, 4.5 CM, or 6.7 CM are used for bare, 1 inch water, and full water reflection respectively. 
Titble 6.2

Critical Experiment Results

l.ow Enriched Urunium/UO2 Rods in Wilter

Aluminum Clad Around Rods

\begin{tabular}{|c|c|c|c|c|c|c|c|c|c|c|c|c|c|}
\hline $\begin{array}{l}\text { Experi- } \\
\text { ment } \\
\text { Name }\end{array}$ & $\begin{array}{l}\text { Reler. } \\
\text { Number }\end{array}$ & $\begin{array}{c}\text { Fuel } \\
\text { Enrichment }\end{array}$ & $\begin{array}{c}\text { Fuel } \\
\text { OD. } \\
\text { Inches }\end{array}$ & $\begin{array}{c}\text { Clad OD. } \\
\text { Inches }\end{array}$ & $\begin{array}{c}\text { Fuel } \\
\text { Pod } \\
\text { Length. } \\
\text { Inches }\end{array}$ & $\begin{array}{c}\text { Fuel } \\
\text { Rod } \\
\text { Patch, } \\
\text { Inches }\end{array}$ & $\begin{array}{c}\text { Poison } \\
\text { Plale } \\
\text { Thickness. } \\
\text { Inches }\end{array}$ & $\begin{array}{c}\text { Dist to } \\
\text { Edge of } \\
\text { Fuel, } \\
\text { Inches } \\
\end{array}$ & K-ell & \pm & 1 Sigma & $\begin{array}{l}\text { Bias, } \\
\text { Mean } \\
\text { Valuo }\end{array}$ & $\begin{array}{c}\text { Bias, } \\
1 \text { Sigma } \\
\text { Value }\end{array}$ \\
\hline$F r \times-1$ & $9 \cdot 14$ & $\checkmark$ Metal. 1.3 wro & 0.387 & 0.453 & 48.0 & 0.711 & None & None & 0.9773 & \pm & 0.0030 & 0.023 & 0.0030 \\
\hline $11+\times 2$ & 9.14 & U Metal, 1.3 w/o & 0.387 & 0.453 & 48.0 & 0.856 & None & None & 0.9820 & \pm & 0.0030 & 0.017 & 0.003 נ \\
\hline $\begin{array}{l}\text { PNI } 2438 \\
\text { EXPT } 2\end{array}$ & 15 & UO2. $2.35 . w / o$ & 0.440 & 0.500 & 36.0 & 0.800 & None & 0.254 & 0.9773 & \pm & 0.0035 & 0.023 & 0.0035 \\
\hline $\begin{array}{l}\text { PNI } 2438 \\
\text { EXPT } 20\end{array}$ & 15 & UO2, 2.35 w/s & 0.440 & 0.500 & 36.0 & 0.800 & $\begin{array}{l}\text { Boral, } \\
0.281\end{array}$ & 0.254 & 1.0008 & \pm & 0.0039 & None & 0.0039 \\
\hline $\begin{array}{l}\text { PNL } 2433 \\
\operatorname{EXPT} 32\end{array}$ & 15 & UO2, 2.35 w/o & 0.440 & 0500 & 36.0 & 0.800 & $\begin{array}{c}304 L \text { SS } \\
1.05 \text { w/o } \\
\text { Boron }\end{array}$ & 1.590 & 0.9896 & \pm & 0.0040 & 0.010 & 0.0040 \\
\hline
\end{tabular}


TABLE 6.3

INPUT FOR KENO Va

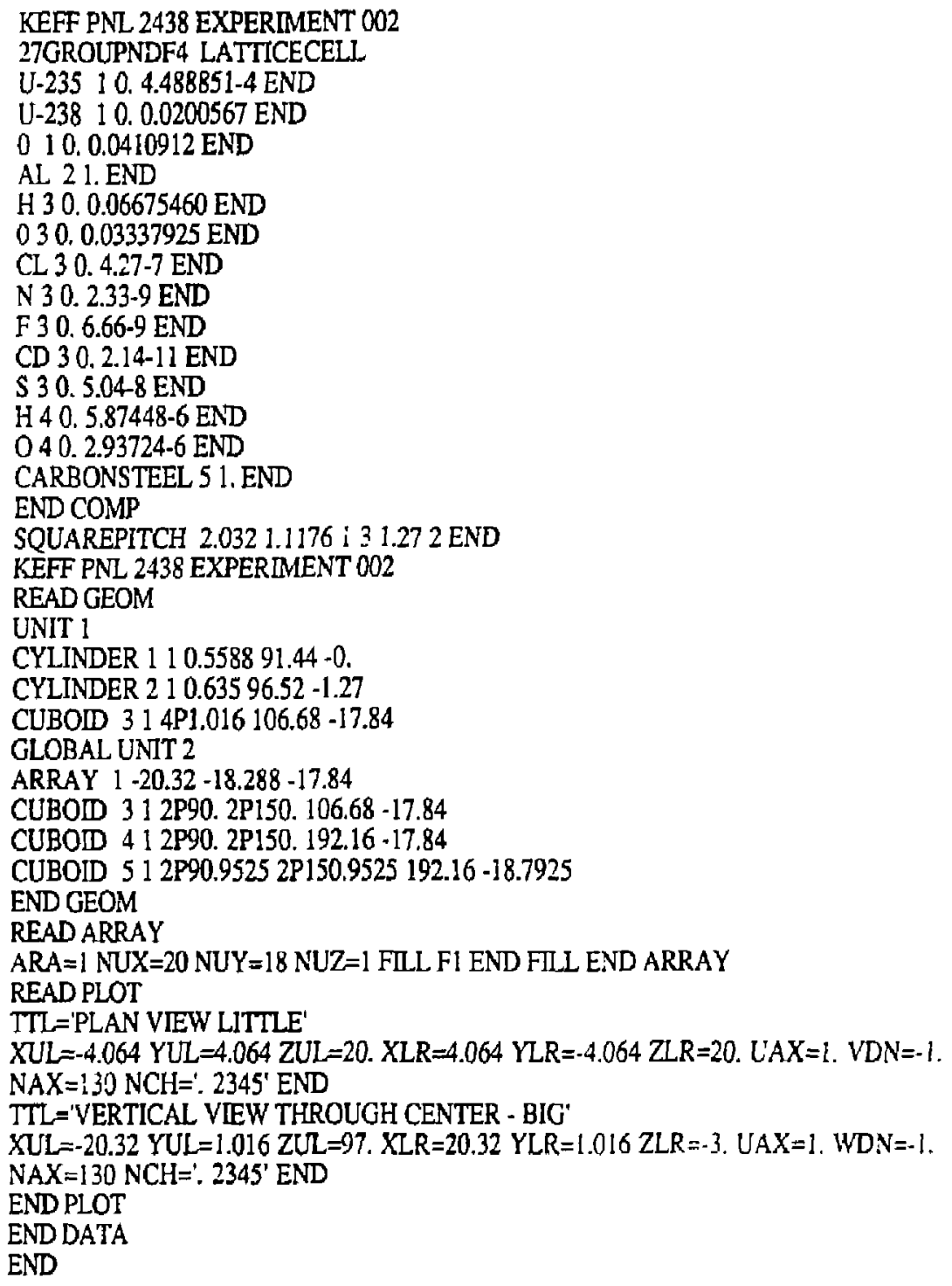




\subsection{CONFINEMENT EVALUATION}

This section of the review provides details of the confinemen: analysis. Compliance with the regulatory requirements must be demonstrated. The discussions presented must detail the DSC confinement during normal conditions of storage, hypothetical accident conditions and natural phenomena events.

Figure 7-1 shows the types of information required from other sections of the CSAR to perform the confinement review. General information is required on the DSC dimensions, component materials, and the radioactive source terms. Information from the structural section should reveal whether any permanent deformation has occured that might compromise confinement systems. The DSC temperatures should be provided from the thermal section.

The confinement evaluation is reviewed to verify that the proper temperatures, pressures, and source terms have been used. The release model is reviewed to verify that all potential leak paths, particularly at flanges and welds, have been identified and properly evaluated.

The results of the confinement review should include information on all potential release paths and release values for normal and natural phenomera events. The confinement results are used 10 set operacional limits and to develop acceptance and maintenance testing criteria.

\subsection{AREA OF REVIEW}

The confinement analysis is reviewed to ensure that the annual doses specified 10 CFR Part 72.67 (a), 72.15 (a) (13) and 72.68 (b) (Ref. 7.1) are not exceeded during nomal operations and under accident conditions. The confinement design features of the DSC and the adequacy of the confinement evaluation are reviewed for compliance with applicable regulatory guides (Refs. 7.2 and 7.3). Included in this review is the adequacy of the description of the confinement boundaries, body, penerations. seals. welds, and closure devices including initial bolt torques.

\subsection{ACCEPTANCE CRITERIA}

Section 72.67 (a) of 10 CFR Pan 72 requires that during normal operations and anticipated occurrences, the annual dose equivalent to any real individual located beyond the conrolled area of the ISFSI shall not exceed $25 \mathrm{mrem}$ to the whole body, $75 \mathrm{mrem}$ to the thyroid and $25 \mathrm{mrem}$ to any other organ as a result of exposure to planned discharges of radioactive material, radon and its daughters excepted, to the general environmen and any other sadiation from uranium cycle operacions within the region. 
Par 72.15 (a) (13) requires, in part, an analysis of the potential dose or dose commitment to an individual outside the controlled area from accidents or natural phenomena events that result in the release of radioactive material to the environment from the ISFSI.

Part 72.68 (b) requires that "any individual located on or beyond the nearest boundary of the controlled area shall not receive a dose greater than 5 rem to the whole body or any organ from any design basis accident."

Since the CSAR is generic in nature, no specific requirements can be established that relate the degree of dilution of radivactive effluents to the boundary of a controlled area. Compliance with the provisions of 10 CFR part 72 noted above is site dependent and also depends upon the number of casks stored in an array. It should be noted that a DSC is a passive storage system for which planned discharges of radioactive materials is not relevant.

Cons. !uently, with regard to the safely of the public beyond the controlled area, acceptance criteria for confinement evaluadion needs to be primarily concemed with the accuracy and precision of the estimated effectiveness of the confinement boundaries under both normal and accident conditions of storage. Dose limits for operating personnel that may be in contact with the DSC are dealt with in Chapter 10, "Radiation Protection."

\subsection{REVIEW PROCEDURES}

\subsubsection{Confinement Boundary}

Verify that the confinement boundary for the DSC is identified. This identification is to include, but is not limited to, the primary containnent vessel, fuet rod cladding, the containment penetrations, seals, welds, and closure devices. All figures and tables describing these components must be sufficiently detailed to stand alone.

\subsubsection{Primary Containment Vessel}

Verify that a summary of design specifications for the primary containment vessel is provided. Drawings, to scale, showing dimensions of the primary containment vessel must be provided. 


\subsubsection{Primary Containment Penetrations}

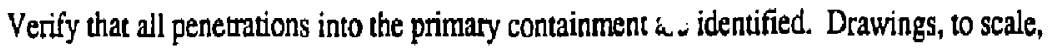
showing dimensions of the containment penetrations must be provided. Verify that a summary of the performance specifications for all components that penetrate the containment boundary are provided in tabular form.

\subsubsection{Seals and Welds}

Verify that all seals and welds that affect the DSC confinement are identified. Drawings, to scale, showing dimensions of these seals and welds must be provided. Verify that a summary of the design specifications for these seals and welds is aiso provided in tabular form.

\subsubsection{Closure}

Verify phat the closure devices used for the containment are identified. Drawings, to scale, showing dimensions of the closure devices must be provided. Verify that initial bolt torque required to maintain a positive seal during normal conditions of storage and accident conditions is presented in tabular form. Methods for evaluating adequacy of bolt torque are described in Chapter 8 of Ref. 7.4

\subsubsection{Confinement of Radioactive Material}

\subsubsection{Seal Effectiveness}

Ver::y that the confinement analysis presented in the CSAR and any confirmatory analysis performed ensure that the efflux of radioactive materials from the DSC confinement boundaries are accurate and weil documented.

Normally, the DSC is loaded with spent fuel in a storage pool. It is then removed from the pool, drained, vacuum dried and back filled with an iner gas. At this point the effectiveness of the seals at the closures are leak checked. Acceptable methods for leak testing are contained in Ref. 7.5. Verify that a specification for maximum leakage rate under this condition is documented. Because of decay heat from the fuel, the pressure in the cask can increase substantially under normal storage conditions. Verify that a leakage rate under the design basis themal condition is documented. Verify furher, that because of seal deterioration with time a leakage rate is reponed for a condition representing at least twenty years of storage life. 


\subsubsection{Fuel Cladding}

While a normal operating temperature limit is established to preclude gross rupture of the fuel cladding over the design life of the ISFSI, conservatism dictates that for public safety an upper bound for the source term assume some degree of cladding failure under both normal and accident conditions. Under these circumstances, the cask pressure can increase beyond that of the nomal condition due to the release of radioactive gases and vapors from the failed fuel rods. The radioactive gases usually considered to be released are tritium (H-3) and krypton (Kr-85) with the release fractions into the cask cavity obtained from Regulatory Guide 1.25 (Reí. 7.3) and NUREG-0069. If any other gases or vapors could form within the confinement barriers, they should be idencified.

\subsubsection{Confirmatory Analysis}

The reviewer should perform independent analyses to confirm the leakage rates and subsequent doses from the DSC for nomal and accident conditions. The maximum pressure may be the same one used for the structural analysis. Leakage rates should be based upon end-of-life condition of the confinement system under nomal conditions. For the accident condition, instantaneous release of 100 percent of the gaseous inventory should be assumed. Additional assumptions for computation of the nomal and accident dose consequences should be: (1) the release fractions of Regulatory Guide 1.25, (2) the population weighted inhalation rate of Regulatory Guide 1.109 (Ref. 7.6), (3) a worst case exposure time of one year and a distance equivalent to the CSAR specified site boundary limit, (4) the inhalation dose and whole body dose factors of Regulatory Guide 1.109, and (\$) F-stability atmospheric diffusion with a wind speed of I meter/sec with plume meander from Regulatory Guide 1.145 (Ref. 7.7).

Particular attention should be paid to the effect of tomado-generated missiles. especially those that impact the lids. A missile impact on top of the cask could cause a failure of metal seais if the stresses in the region approach yjeld.

\section{7.? + Appendix}

Verify that all supportive information or documentation is provided for the confinement evaluation under both normal conditions of storage and hypothetical accident conditions. This would include, but not be limited to, information such as justification of assumptions or analytical procedures, DSC test Jesults and photographs associated with both nomnal conditions of transport 
and hypothetical accident conditions, computer program descriptions and inputivitput, and applicable pages from referenced documents.

\subsection{FINDINGS}

The reviewer verifies that sufficient and adequate information has been provided to satisfy the general requirements of the review plan for the DSC, and that the evaluation supports the following conclusion, to be included in the SER:

"This section of the applicant's Cl AR has been reviewed to determine that the DSC confinement has been designed in a manner that will assure compliance with the performance requirements of $10 \mathrm{CFR}$ Part 72.67 (a) under nomal conditions of storage and $10 \mathrm{CFR}$ Part 72,68 (b) under accident conditions of storage. The scope of the review covers the adequacy of the source description; the adequacy of the confinement boundary description, including design and/or performance specifications for the vessel, penerratiohs, seals, welds, and closure devices; and any supportive information of documentation."

"Confirmatory analyses of the dose consequences to any individual continuously present at the site boundary due to gaseous activity release from a single DSC following nommal and accident events are in substantial agreement with those doses repor ed in the CSAR and are estimated to be less than mrem/year and mrem/year to the whole body, respectively. Normal consequences are less than the 25 mrem limit established in 10 CFR Part 72.67 (a). Accident consequences are less than the 5 rem limit established in 10 CFR Part 72.68 (b)."

"Basis for acceptance in the review has been conformance with established guidelines and criteria. The evaluation of the DSC confinement provides reasonable assuranca that, under nomal and accident conditions of storage, it will be possible to store radioactive material in the DSC safety."

"The staff concludes that the protective features provided in the design of the DSC conform to applicable Regulations, Reguiatory Guides, and industry standards, and are acceptable."

\subsection{REFERENCES}

1. Office of the Federal Register. Title 10, Code of Federal Regulations. Par 72, Office of the Federal Register, Washington, DC, January 1984. 
2. U.S. Nuclear Regulatory Commission, Regulatory Guide CE.306-4: Standard Format and Content for a Topical Saferv analysis Report for a Dry Spent Fuel Storage Cask, U.S. Nuclear Regulatory Commission, Office of Standards Development, Washingion, DC.

3. U.S. Nuclear Regulatory Commission, Regulatory Guide 1.25: Assumprions Used for Evaluating the Potential Radiological Consequences of a Fuel Handling Accident in the Fuel Hendling and Storage Facility for Boiling and Pressurized Water Reaciers, U.S. Nuclear Regulatory Commission, Washington, DC, March 1972.

4. J. E. Shigley, and L. D. Mitchell Mechanical Engineerine Design, McGraw Hill Book Co., Fourth Edition, 1983.

5. American National Standards Institure, American National Standard for Leakage Tests on Packages for Shipment of Radioacive Material, American National Standards Insirute, New York, NY, ANSI N14.5-1985, (1985), Rev-1.

6. U.S. Nuclear Regulatory Commission, Regulatory Guide 1.109: Calculation of Annual Doses to Man from Routine Releases of Reactor Effluents for the Purpose of Evaluating Compliance with 10 CFR Part 50, Appendix 1, U.S. Nuclear Regulatory Commission, Office of Standards Development, Washington, DC, October 1977.

7. U.S. Nuclear Regulatory Commission, Regulatory Guide 1.145: Amospheric Dispersion Models for Potential Accident Consequence Assessments at Nuclear Power Plants, U.S. Nuclear Regulatory Commission, Office of Standards Development, Washington, DC. Novernber 1982. 


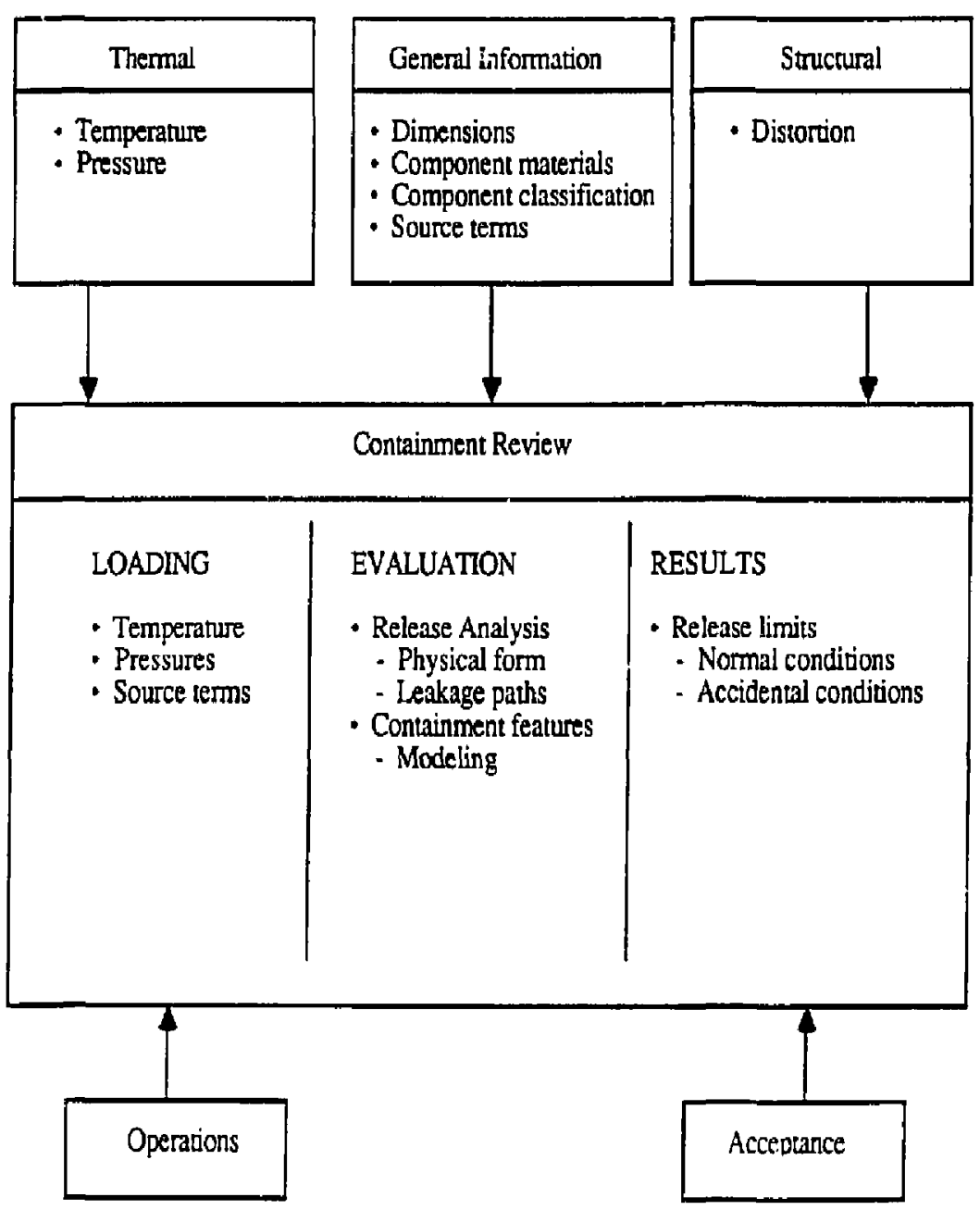

Figure 7-1 Input and output information for the containment review process. 


\subsection{OPERATING PROCEDURES}

This chapter addresses the operating procedures to be used in preparation of and performance of processes for loading, transporing, and storing a DSC. It provides guidance for evaluating processes used to ensure that occupational radiation exposires are maintained as low as reasonably achievable (ALARA) as required by 10 CFR part 20 (Ref. 8.1). In addition, operating procedures that may affect the intemal environment of the DSC under storage conditions are assessed. Figure 8-1 shows the cypes of information required from other sections of the CSAR to perform the review.

\subsection{AREA OF REVIEW}

10 CFR Part 72 (a) (8) (Ref. 8.2) requires the applicant to submit "a plan for the conduct of operations including the planned managerial and controls system, and the applicant's organization and program for taining of personnel." While this provision applies, primarily to the ISFSI, the operations involved in loading, transporting, and storing of the spent fuel are closely associated with the design of the cask to the extent that design features are incorporated to facilitate the conduct of these operations. Consequently, the review of the operating procedures is limited to the specific operations of handling the cask from the time it is loaded in the storage pool until it is placed upon the storage pad. Managerial and administrative controls would only be relevant if the cask design were such that only administrative controls could ensure that the spent fuel could be safely handled and stored under conditions that would not pose a hazard to operating personnel or the public.

\subsection{ACCEPTANCE CRITERIA}

The CSAR should provide a detailed description of the procedures for loading, draining and drying the cask, creating an inert environment for the spent fuel. assuring the effectiveness of the seals at the bolied closure joints, transporing the loaded cask to the storage pad, and assuring that occupational radiation exposures are maintained ALARA as required by 10 CFR Pan 72.15 (a) (5), and furher defined in Chapter 10 of this guide.

\subsection{REVIEW PROCEDURE}

\subsubsection{General Description}

Verify that a detailed description of the operating procedures have been presented in the CSAR and that they are presented sequentially in the actuai order of performance. Verify that the 
operating procedures stress the importance of planning each operation carefully before any action is taken. Some specific areas of concem are the use of suitable equipment and ensuring that suitable environmental conditions (such as cleanliness) have been created and will be maintained. Verify that operations important to safety are identified.

\subsubsection{Procedures for Loading and Sealing the Cask}

Verify that inspection and cleaning procedures that are to be accomplished prior to loading the cask are specified and that controlled storage is planned for components such as lids, bolts, cover plates, " $O$ " rings etc. until they are needed. Ensure that cask sealing surfaces have been properly prepared and protected.

Verify that a description of any specialized equipment needed for cask loading operations are provided. This applies specifically to lifting yokes, drain and vent hoses, vacuum drying equipment, and inert gas leak detection equipment.

Verify that the procedures used for tightening the lid bolts after loading fuel in the pool minimizes the dose rate to operating persounel.

\subsubsection{Cask Draining and Drying Procedure}

Verify that the methods for draining the cask and subsequent operations for drydown to an acceptable moisture level are described. Of particular concem is the method for limiting the remperarure of the cladding if vacuum drying is part of the procedure.

\subsection{FINDINGS}

The reviewer verifies that sufficient and adequate information has been provided to satisfy the general requirements of the review plan for the DSC, and that the evaluation suppons the following conclusion, to be included in the SER:

"This secrion of the applicant's CSAR has been reviewed to determine that the DSC operating procedures have been designed in a manner that will assure compliance with the requirements of 10 CFR Parts 72.15 (a) (5), 72.15 (a) (8), and 20. The scope of the review covers the operating procedures for loading, sealing, draining, and drying of the DSC."

"The applicant has identified all operating procedures for loading, sealing, draining, and drying of the DSC. They are complete, explicit, and adequately justified by supporting arguments 
and are in general accordance with the requirements of 10 CFR Part 20 and the pertinent subsections of 10 CFR Par 72.15."

"Basis for acceptance in the review has been conformance with established guidelines and criteria. The evaluation of the DSC operating procedures provides reasonable assurance that, from the standpoint of general requirements on the DSC, it will be possible to load and store radioactive material in the DSC safely."

"The staff concludes that the protective features provided in the design of the DSC conform to applicable Regulations, Regulatory Guides, and industry standards, and are acceptable.

\subsection{REFERENCES}

1. Office of the Federal Register, Title 10. Code of Federal Regulations, Part 20, Office of The Federal Register, Washington, DC, January 1984.

2. Office of the Federal Register, Title 10, Code of Federal Requlations, Part 72, Office of the Federal Register, Washington, DC. Jaruary 1984. 


\subsection{ACCEPTANCE TESTS AND MAINTENANCE PROGRAM}

\subsection{GENERAL}

10 CFR Part 72.24 (p) (Ref. 9.1) requires the applicant to provide "a description of the program covering preoperational testing and initial operation." While this requirement applies to the entire ISFSI, it can also be interpreted to apply to the generic cask intended for the storage of spent fuel. The implication is that the loaded cask shail have been subjected to a series of acceptance tests prior to placement on the storage pad to assure that it will perform in accordance with design specifications. While not specifically stated, the regulacion can further be interpreted to require that the DSC be maintained throughout its specified life so that no degradation occurs that would reduce its performance below that stipulated in the design criteria. It is recognized that some of the tests will be performed by the applicant as part of a qualification program while some tests will be performed by plant personnel as part of its quality assurance program. Certainly all of the maintenance work will be performed by plant personnel. Neverheless, since testing requirements and maintenance procedures are closely tied to the design of the cask, it is incumbent upon the applicant to provide descriptions of such tests and maintenance procedures.

This section of the review verifies that appropriate acceptance tests and a maintenance program have been defined in sufficient detail in the the CSAR so that the fabrication and maintenance of the DSC can be ensured in compliance with regulatory requirements (Ref. 9.1 and 9.2).

Figure 10-1 shows the types of information required from other sections of the CSAR to perform the review. Information is required from most of the sections and include: pressure loads, heat loads, maximum temperatures for components, containment requirements, gamma and radiation shielding thickness, radiation limits and neutron absorber components. The loadings affecting the DSC acceptance testing and maintenance include temperature, pressure, source terms, and decay heat. The tests performed include visual, pressure, thermal, shielding, and materials (lot testing). The results of the acceptanice test and maintenance program assure the confinement of radioactive materials, subcriticality, the adequacy of shielding, the soundness of the fabrication, and the replacement of parts as required. 


\subsection{AREAS OF REVIEW}

\subsubsection{Acceptance Tests}

The acceptance iest that should be performed prior to the first use of the cask is reviewed. The acceptance tests include visual inspection, pressuse test, leak tests, component tests, shielding tests, thermal tests, and subcriticality tests.

\subsubsection{Maintenance Program}

The maintenance program used to ensure the continued safe performance of the DSC is reviewed. The maintenance program should describe all tests performed and their frequencies. The periodic replacement, if required, of parts such as seals and burst discs should be described by the applicant.

\subsection{ACCEPTANCE CRITERIA}

The specific criteria for judging the acceptability of the acceptance tests and maintenance program in the CSAR are provided in the following subsections.

\subsubsection{Acceptance Tests}

The acceptance tests should addiress the following:

\subsubsection{General}

a) There are no cracks, pinholes, uncontrolled voids, or other defects which could reduce the effectiveness of the DSC.

b) The cask is pressure tested at least 50\% higher than the maximum normal operating pressure when the maximum normal operation pressure exceeds 34.3 kilopascal ( $5 \mathrm{psi}$ ) gauge.

c) The cask is conspicuously and durably marked with its model number, gross weight, and serial or other identification number. 


\subsubsection{Confinement}

DSC should be leak tested per ANSI N 14.5 (Ref. 9.3).

\subsubsection{Gamma Shield}

Gamma scanning or probing may be used to demonstrate the soundness of the gamma shielding. Altematively, ultrasonic testing may be used. Whatever method is used, the following information should be provided in the acceptance test procedure:

1) Description of the measuring technique including the electronics.

2) The source type and strength used to measure the shield effectiveness.

3) The standards and methods used to calibrate the source, sensors, and other pertinent equipment.

4) The grid pattem used to check the shield.

5) The type of gamma sensor used to measure the shield effectiveness.

6) The specific test requirements and measurements.

7) The acceptance criteria.

\subsubsection{Neutron Shield}

The neutron shield effectiveness should be verified by test using a neutron source of adequate strength 10 verify the shielding effectiveness. Information should be provided in the test procedure which is similar to that specified for the gamma shield testing in 9.3.1.3.

\subsubsection{Subcriticality Assurance}

Casks designed to store spent fuel which contain neutron absorber material should be lested to demonstrate the presence of the neutron absorber material. The test description should include information similar to that requested for gamma shield testing 9.3.1.3. Fabrication records of the absorber material and its installation and testing should be maintained.

\subsubsection{Thermal}

Casks designed to store spent fuel should be tested to demonstrate their heat load capabilities unless such capability is orherwise justified. The test procedure should provide the following informacion: 
1) Test requirements and acceptance criteria.

2) Heat load testing at various levels including rated capacity.

3) Temperature gradients across all major materials and their interfaces.

4) Projected peak temperatures of the simulated contents.

5) Method used to simulate the decay heat.

6) Ambient environment conditions during the conduct of the test.

7) The test configuration, instrumentation, and recording equipment.

\subsubsection{Maintenance Program}

A maintenance program should be described in the CSAR that addresses the following items:

\subsubsection{Testing}

The DSC should undergo periodic testing to ensure the proper functioning of the components important to safety. The interval between such periodic testing should be provided by the applicant. In addition, the applicant should specify the nature of and procedure for conducting these tests.

\subsubsection{Parts Replacement}

All components important to safety must be qualified for their useful liferime of service. The replacement schedule for parts such as valves and closure seals must be justified based on testing or experience. Testing per 9.3 .1 is required following any parts replacement or repairs affecting the safety of the DSC.

\subsection{REVIEW PROCEDURES}

Verify that the applicant describes the acceptance tests and maintenance program to be used on the DSC.

\subsubsection{Acceptance Tests}

Verify that the CSAR adequately describes tests to be performed prior to the first use of the cask. As a minimum the test descriptions should contain the information described in the following paragraphs. 


\subsubsection{Visual Inspection}

Verify that sufficient visual inspections are performed and the intended purpose behind each inspection is discussed. Verify that the criteria for acceptance for each of these inspections are stated as well as the action to be taken if noncompliance is encountered.

\subsubsection{Structural and Pressure Tests}

Verify that structural and pressure tests to be performed are identified and described. The acceptance criteria for the test should be stated as well as the accion to be taken when the prescribed criteria are not met. The sensitivity of the tests should be provided in the CSAR.

\subsubsection{Leak Test}

Review the leak tests to be performed. The leak test should be performed on the containment vessel as well as on auxiliary equipment such as neutron shield tanks. The criteria for acceptance and the action to be taken if the criteria are not met should be stated. The sensitivity of the leak test should be given in the CSAR. Verify that the leak test requirements in 9.3.1.2 are met.

\subsubsection{Component Tests}

Verify that the subject of acceplance tests is addressed for all components imporant 10 safery. Acceptance criteria must be provided for each component. The action to be taken if the criteria are not met must also be stated.

\subsection{Valves and Rupture Discs}

Verify that these components are tested under the service conditions no less severe than those specified for the principal design criteria, Should the tests adversely affect the continued performance of a component, the results of tests on components of the same model may be substituted.

\subsection{Gaskets}

Verify that all gaskets are tested under conditions simulating the most severe service conditions under which the gaskets are to perform. Since these acceptance tests may degrade the performance of either the gasket under test or the cask into which it is assembled or both, the tests are not necessarily performed on gaskets or casks to be put into service. The simulation system, 
however, must ensure adequate representation of those conditions that would prevail if the actual system were used in the test. Verify that the gaskets are procured under a quality assurance program adequate to ensure that acceptance testing of a given gasketing device is equivalent to acceptance testing of all gaskets supplied and idenified by that manufacturer as that model gasket.

\subsection{Miscellaneous}

Verify that any other component whose failure would impair the effectiveness of the DSC is identified and tested under the most severe conditions for which it was designed. Since these acceptance tests may degrade the performance of either the component under test or the system into which it is assembled or both, the tests are not necessarily performed on components or systems to be put into service. The simulation system shculd ensure adequate representation of those conditions that would prevail if the actual system were used in the test. Furhermore, verify that the components are procured under a quality assurance program adequate to ensure that acceptance testing of a given coraponent device is equivalent to acceptance testing of the actual devices supplied by that manufacturer.

\subsubsection{Tests for Shielding Integrity}

Verify that tests to be performed to establish shielding for both gamma and neutron sources are identiffed and discussed. The discussion should include the dimensions of the grid pattem or a description of the scanning procedure that demonstrates the inspection of 100 percent of the cask surface area. Verify that the acceptance criteria as well as the action to be taken if the criteria are not met are described.

\subsubsection{Thermal Acceptance Tests}

Verify that tests are identified to show that the DSC performs, within sont derined variance, in accordanse with the results of the thermal analyses for nomal conditions of storage.

\subsection{Discussion of Test Setup}

Verify that the CSAR adequately describes the thermal acceptance tests. The description should include hear rource, instrumentation, and schematic showing thermocouple and heat source locations as weil as the placement of other test equipment. The test sensitivity based on instrumentation, test jtem, and environment variations should be provided and justified, 


\subsection{Test Procedure}

Verify that the procedures used in testing and data recording are discussed. The frequency of data recording during the test should be reported. The criseria used to define the steady-state (thermal equilibrium) condition of the test item should also be reviewed.

\subsection{Acceptance Criteria}

Verify that the thermal acceptance criteria and the method employed to compare the acceptance test results with predicted thermal performance are discussed. Review the action to be taken if the thermal acceptance criteria are not met by a cask component.

\subsubsection{Maintenance Program}

Verify that the maintenance program used to ensure continued perfomance of the DSC is described. The program should include periodic testing, inspection, and replacement schedules as well as criteria for replacement and repair of components and subsystems on an as-needed basis.

\subsubsection{Leak Tests}

Review the tests to be performed and the frequency of performance. Verify that the sensitivity of these tests is stated.

\subsubsection{Subsystem Maintenance}

Review the test and repiacement schedule to be used for DSC subsystems (e.g., auxiliary cooling systems and neuron shield tanks) whose inadequate performance could impair safety. Verify that the CSAR jusified the schedules established, using verifiable test or manufacturer's data.

\subsubsection{Valves and Rupture Discs}

Review the test and replacement schedule to be used for these components. Verify that the CiAR justified the schedules established, using verifiable test or manufacturer's data. For most systems. this would include as a minimum a visual inspection of the condition of these components. 


\subsubsection{Shielding}

Review the test and inspection schedules as well as the corrective action to be used to ensure adequate shielding performance. Verify that the CSAR considers both gamma and neutron sources.

\subsubsection{Thermal}

Review the tests proposed and the frequency of these tests that would be performed on the DSC. Verify that the CSAR establishes a frequency for the proposed tests that would detect degradation in the thermal performance of the DSC prior to any compromise of its safety.

\subsubsection{Miscellaneous}

Review any additional test not considered previously that should be performed periodically on components and subsystems.

\subsection{FINDINGS}

The reviewer verifies that sufficient and adequate information has been provided to satisfy the general requirements of the review plan for the DSC, and that the evaluation supports the following conclusion, to be included in the SER:

"This section of the applicant's CSAR has been reviewed to determine that the DSC acceptance test and maintenance program has been designed in a manner that will assure compliance with the requirements of 10 CFR Part 72.24 (p). The siope of the review covers DSC testing such as pressure, thermal and leakage, the replacement or repair of parts, and any supportive information or documentation."

"The applicant has identified all procedures in the acceptance test and maintenance program. They are complete, explicit, and adequately justified by supporting arguments and are in general accordance with the requirements of 10 CFR Part 72.24 (p)."

"Basis for acceptance in the review has been conformance with established guidelines and criteria. The evaluation of the DSC acceptarce test and maintenance program provides reasonable assurance that, from the standpoint of general requirements on the DSC, it will be possible to store radioactive material in the DSC safely." 
"The staff concludes that the protective features provided in the design of the DSC conform to applicable Regulations, Regulatory Guides, and industry standards, and are acceptable."

\subsection{REFERENCES}

1. Office of the Federal Register, Title 10. Code of Federal Regulations, Part 72, Office of the Federal Register, Washington, DC, January 1984.

2. U.S. Nuclear Regulatory Commission, Requlatory Guide CE-306-4: Standard Format and Content for a Topical Safery Analusis Report for a Dry Spent Fuel Casle, U.S. Nuclear Regulatory Commission, Office of Standards Development, Washington, DC.

3. American National Standards Institute, American National Standard for Leakage Tests on Packages for shipment of Radioactive Material, American National Standards Institute, New York, NY, ANSI N14.5-1985, (1985), Rev-1. 


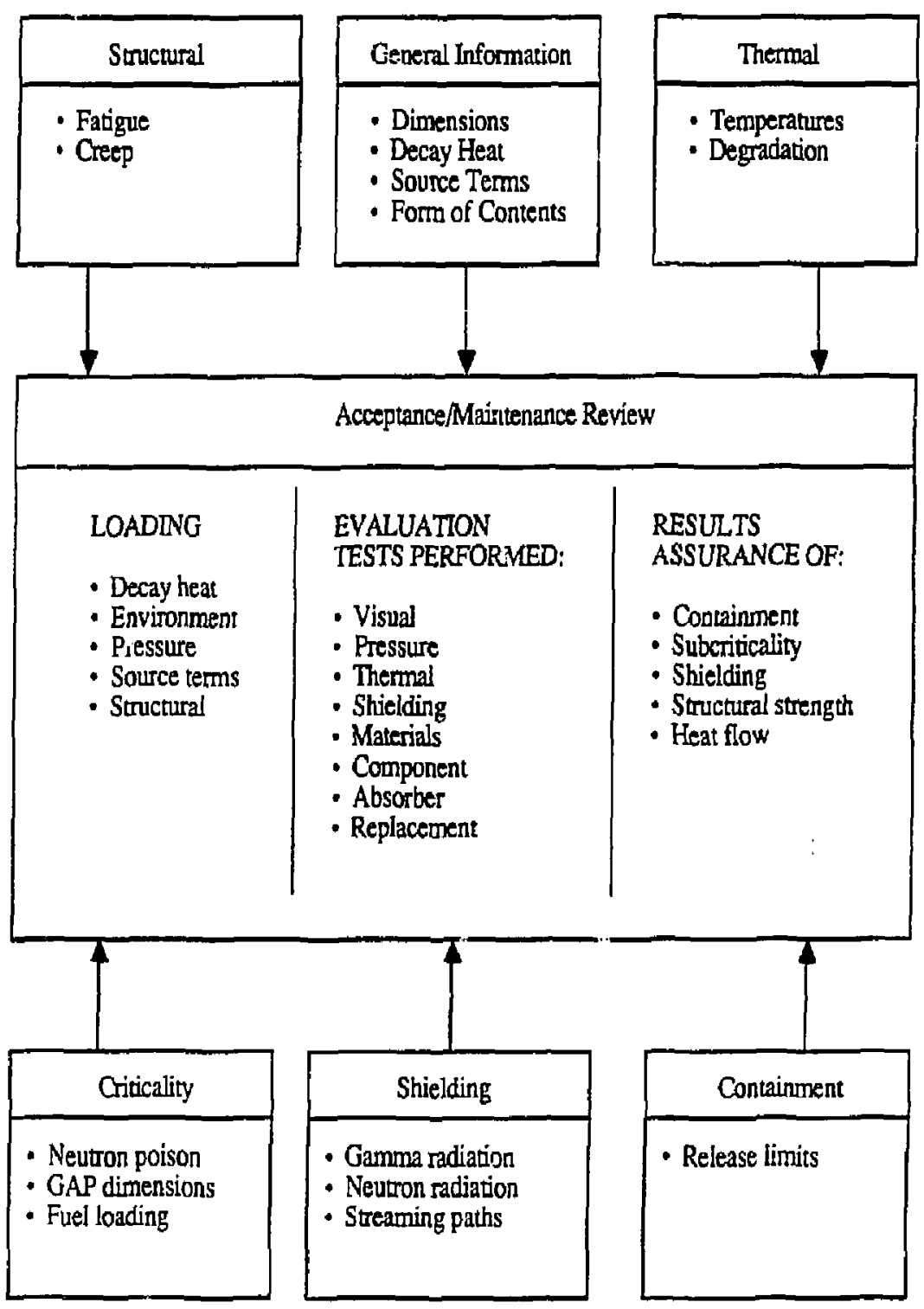

Figure 9-1 Input and ourput information for the review of the acceptance tests and maintenance program. 


\subsection{RADIATION PROTECTION}

\subsection{AREA OF REVIEW}

This chapter provides guidance for reviewing the information provided in the CSAR on methods for radiation protection and on estimated radiation exposures to operating personnel during nomal operation, and anticipated operational occurences such as maintenance, routine surveillance, jn-service inspection and calibration. This review shall also extend to assessing information relating to layout and equipment design planning and procedure programs and the techniques and practices employed by an applicant in meeting the standards of 10 CFR Part 20 (Ref. 10.1) for protection against radiation and the guidance given in associated regulatory guides. Radiation concems including estimates of radiation exposure as a result of off-normal occurnences and accidents are reviewed in Chapter 11 of this review guide.

\subsection{ACCEPTANCE CRITERIA}

The DSC submitted for review will be considered to provide an acceptable level of radiation protection if it conforms to the requirements of 10 CFR 72.15 (a) (5) (Ref. 10.2) which requires that the applicant demonstrate "the means for controlling and limiting occupational radiation exposures within the limis given in $10 \mathrm{CFR}$ Par 20 and for meeting the objectives of exposure as low as is reasontably achievable" (ALARA). The CSAR must show that the provisions of $10 \mathrm{CFR}$ Part 72.74 (a) are met with specific reference to:

A. The provision of radiation protection systems for all areas and operations where on-site personnel may be exposed to radiation or airborne radioactive materials.

B. Verification that the sunctures, systems and components for which operation, maintenance and required inspections may involve such exposure are designed, fabricated, located. shielded, controlled and tested so as to control external and internal radiation exposures to personnel.

\subsection{REVIEW PROCEDURES}

Topics for review that are necessary to assess confomance to the acceptance criteria are: ensuring that the occupational radiation exposures are ALARA, review of radiation protection design fearures, and on-site dose assessment. 


\subsubsection{Ensuring that Occupational Radiation Exposures are ALARA}

The principal documents that provide guidance for ensuring that occupational radiation exposures are ALARA are Regulatory Guide 8.8 (Ref. 10.3) and Regulatory Guide 8.10 (Ref. 10.4). Both documents serve to provide an interpretation of the provisions of 10 CFR Part 20.1 (c) which states that licensees should make every reasonable effort to maintain exposures to radiation as far below the limits specified in Par 20 as is reasonably achievable. Since Part 20 and the associated regulatory guides are primarily concerned with nuclear power plants, not all provisions of these documents are applicable to applicants for a cask license under the generic rule. It is recognized that all operations following receipt of the cask such as preconditioning, loading, sealing, ransporting, placing and routine maintenance and surveillance are performed by utility personnel under the direction of utility management. Consequently, the task of ensuring that occupacional doses are ALARA are primarily the responsibility of plant management and the policies adopted wouid be site specific for the paricular ISFSI. Nevertheless, it is also recoznized that the design of the DSC determines its inherent ability to limit occupacional exposure to radiation by its level of shielding, effectiveness of its seals and provision of appunenances that facilitate all the operations required to prepare the cask for the ISFSI and to maintain it. Therefore, the features of the cask that can influence the effectiveness of radiation protection are subject to considenation of whether or not they meet ALARA objectives. The design of the cask and the CSAR document, consequendy, must se evaluated for conformity to the acceptance criteria outlined in Par. 10.2 of this guide keeping in mind that they are primarily applicable to the cask.

\subsubsection{Policy Considerations}

Review the CSAR for the policy statement of the applicant that illustrates how the design of the cask is influenced by ALARA objectives. Review the policy statement not only for its influence upon design but also with respect to anticipated occurrences such as maintenance, repair and surveillance. Review the discussion of radiological protection with respect to its influence on cost, mass, strength, etc., for indications of the criteria that govern the distinction between reasonable and unreasonatle design features. The features considered should incinde, at least, those related to shielding, confinement, strucrural and surveillance systems.

\subsubsection{Design Considerations}

Review the design for those design features that ensure that occupational radiation exposures are ALARA. The CSAR should describe the design philosophy followed in minimizing exposure to radiation sources. Specifically, this wouid include the methods used to facilitue loading of the 
cask, minimize the necessity for maintenance and, in general, minimize the time spent to accomplish any of the operations requiring personnel to be exposed to radiation.

\subsubsection{Operational Considerations}

While the operations involved in loading the cask and preparing it for storage are performed by utity personnel, the procedure and methods will be guided by a sequence of operations dictuted by the cask design. Since the CSAR contains a chapter on operating procedures unique to the applicant's cask, consideration of how these procedures relats to ALARA objectives should be discussed.

\subsubsection{Radiation Protection Design Features \\ 10.3.2.1 Access Control of Radiation Areas}

With respect to facility and equipment design features Regulatory Guide 8.8 suggests that for avoidance of unnecessary and inadvertent exposure of personnel to radiation, the potential dose rate at all locarions within the station should be estimated during station design. The management team tesponsible for ALARA oversight must have detailed radiation dose rate estimates for the cask array on the storage pad as a funcrion of distance from the pad. Such information can only be provided by the applicant since it reflects the perfomance of the cask with the contents stipulated in the CSAR.

\subsubsection{Radiation Shields and Geometry}

Review the CSAR for infomation indicating how the design bases for the shielding against both gamma and neurron radiation ensure occupational radiation exposures to be ALARA. While temporary shielding may be necessary during some cask loading operations, these requirements are site specific so that only the shielding provided by the cask is relevant to the review. Guidance for the review of shielding is given in Chapter 5 of this guide.

\subsubsection{Process Instrumentation and Controls}

The policy with regard to the provision of instruments should be addressed from the point of view of their contribution toward sendering exposure to radiation ALARA. 


\subsubsection{Control of Airborne Contaminants or Gaseous Radiation Sources}

Review the methods used with regard to ensuring that exposure to radioactive gases or other airbome contaminants are maintained ALARA. Consideration should be given to the source terms for such contaminants and the design bases for seals at the bolted closures. Guidance for the review of confinement is given in Chapter 7 of this guide.

\subsubsection{Estimated Onsite Collective Dose Assessment}

Review the CSAR for information relating to the onsite collective dose assessment. This should include the dose rates associated with direct gamma and neutron radiation and gaseous activity release presented as a function of time and location around both a single cask and an array of casks. Furthermore, review information provided to show anticipated radiological occupacional exposure associated with loading, handling, transporting, maintaining, storage, repair, and surveillance operations of the DSC over its design lifetime. Sufficient information should be provided to allow the utility to evaluate the radiation levels at all locations within and surrounding the storage pad.

\subsubsection{Single Cask Dose Rates}

The dose from a single DSC 10 any individual from direct radiation and gaseous activity release during the nomal operations of loading, handling, transporting, maintaining, storage, repair, and surveillance should be documented in the CSAR. So too should the dose from a single DSC to any individual at 100 meters from direct radiation and gaseous activity release for 40 hours/week and 50 weeks/year.

\subsection{Doses From Direct Radiation}

Doses to any individual from direct radiation during the nomal operations of loading, handling, transporting, maintaining, storage, repair, and surveillance should be based upon the dose rate and exposure time associated with the most influential dose point for each significant cask operation. The bases for the various distances, exposure times, and dose rate as a function of distance must be adequately documented in the CSAR.

Doses to any individual at 100 meters from direct radiation should be based upon the most influential dose rate associated with the normal storage condition and an exposure time of 40 
hours/week and 50 weeks/year. Again, the basis for the dose rate as a funcrion of distance muse be adequately documented in the CSAR.

Critical to the review is the drop-off of the dose as a function distance. For verification, the reviewer should evaluate the dose as a function of distance. One suggested method of estimation is to use the product of the surface dose rate and the ratio of off-surface to surface dose as a function of distance that is appropriate for the cask operation or storage condition. The ratio of off-surface to surface dose may be computed in a number of ways. The simplest is derived from a point kernel code that considers scattering; the most precise is derived from a monte carlo analysis.

\subsection{Doses From Gaseous Activity Release}

Doses to any individual from gaseous activity release during the normal operations of loading, handling, transporting, maintaining, storage, repair, and surveillance should include the release of ${ }^{3} \mathrm{H}$ and ${ }^{85} \mathrm{Kr}$ and be computed under the following assumptions: (1) percent failure of fuel element cladding (generally taken at 1 percent for normal conditions of operation), (2) the release fractions of Regulatory Guide 1.25 (Ref. 10.5), (3) the maximum mechanical seal leakage rate, (4) the occuparional inhalation rate of Regulatory Guide 1.25, (5) the exposure time and cistance involved for each significant cask operation, (6) the inhalation dose and whole body dose factors of Regulatory Guide 1.109 (Ref. 10.6), and (7) a close-in box model for atmospheric diffusion with wind speed of 1 meter/sec.

Doses to any individual from gaseous activity at 100 meters from the DSC should include the release of ${ }^{3} \mathrm{H}$ and ${ }^{85} \mathrm{Kr}$ and be computed under the following assumptions: (1) percent failure of fuel element cladding (generally taken at 1 percent for normal conditions of operation), (2) the release fractions of Regulatory Guide 1.25, (3) the maximum meclanical seal leakage rate, (4) the occupational inhalation rate of Reguiatory Guide 1.25, (5) an exposure time of 40 hour /week and 50 weeks/year, (6) the inhalation dose and whole body dose factors of Regulatory Guide 1.109, and (7) F-stability atmospheric diffusion with wind speed of 1 meter/sec with plume meander from Regulatory Guide 1.145 (Ref. 10.7). 


\subsection{FINDINGS}

The reviewer verifies that sufficient and adequate information has been provided to satisfy the general requirements of the review plan for the DSC, and that the evaluation supports the following conclusion, to be included in the SER:

"This section of the applicant's CSAR has been reviewed to determine that the DSC has been designed in a manner that will assure compliance with the occupational radiation protection requirements of 10 CFR Part 72.15 (a) (5) and 10 CFR Part 20 under normal conditions of storage. The scope of the review covers the non site-specific policy, design, and operational considerations associated with ALARA occupational exposures, and the estimated on-site dose from direct radiazion and gaseous activity release during normal operations."

"A confirmatory analysis of dose from a single DSC to any individual from direct radiation and gaseous activity release during normal operarions is in substantial agrement with the dose reporter in the CSAR and is esimared to be less than mrem/year to the whole body."

"A confirmatory analysis of dose from a single DSC to any individual at 100 meters from direct radiation and gaseous activity release for 40 hours/week and 50 weeks/year is in substantial agreement with the dose reported in the CSAR and is estimated to be less than mirem/year to the whole body."

"Basis for acceptance in the review has been conformance with esrablished guidelines and criteria. The evaluation of the DSC provides reasonable assurance that, under normal conditions of storage, it will be possible to store radioactive material in the DSC safely."

"The staff concludes that the protective features provided in the design of the DSC conform to applicable Regulations, Regulatory Guides, and industry standards, and are acceptable."

\subsection{REFERENCES}

1. Office of the Federal Register, Title 10. Code of Federal Regulations, Part 20, Office of the Federal Register, Washington, DC, January 1984.

2. Office of the Federal Register, Title 10, Code of Federal Regulations, Part 72, Office of the Federal Register. Washington, DC. January 1984.

3. U.S. Nuclear Regulatory Commission, Regularory Guide 8.8: Infomation Relevant to Ensuring that Occupational Radiation Exposures at Nuclear Power Stations will be As Low 
As Reasonably Achievable, U.S. Nuclear Regulatory Commission, Office of Standards Development, Washington, DC, June 1978.

4. U.S. Nuclear Regulatory Commission, Regulatory Guide 8.10: Operating Philosophy for Maintaining Occupational Radiation Exposures As Low As Reasonably Achievable, U.S. Nuclear Regulatory Commission, Office of Standards Development, Washington, DC, September 1975.

5. U.S. Nuclear Regulatory Commission, Regulatory Guide 1.25: Assumptions Used for Evaluating the Potential Radiological Consequences of a Fuel Handline Accident in the Fuel Handling and Storape Facility for Boiling and Pressurized Water React Iss, U.S. Nuclear Regulatory Commission, Washington, DC, March 1972.

6. U.S. Nuclear Regulatory Commission, Regulatory Guide 1.109: Calculation of Annual Doses to Man from Routine Relenses of Reactor Effluents for the Purpose of Evaluating Compliance with 10 CFR Part 50, Appendix 1, U.S. Nuclear Regulatory Commission, Office of Standards Development, Washington, DC, October 1977.

7. U.S. Nuclear Regulatory Commission, Regulatory Guide 1.145: Amospheric Dispersion Models for Potential Accident Consequence.Assessments at Nuclear Power Plants, U.S. Nuclear Regulatory Commission, Office of Standards Development, Washington, LC, November 1982. 


\subsection{ACCIDENT ANALYSIS}

\subsection{AREA OF REVIEW}

This chapter provides guidance for reviewing the information provided in the CSAR relating to the consequence of accidents. 10 CFR Pan 72.15 (a) (13) (Ref. 11.1) requires that "the potential dose or dose commitment to an individual outside the controlled area from accidents or natural phenomena events that result in the release of radioactive material to the environment or direct radiation" be evaluated. "The calculations of individual dose or dose commitment shall be performed for direct exposure, inhalation, and ingestion occurring as a tesult of the design basis event."

These regulatory positions were also the basis for the guidance provided in Chapter 7 , "Confinement Evaluation." In Chapter 7 the emphasis was upon ensuring the effectiveness of sealing or other confinement systems while accident analysis is specifically concemed with the radiological consequences to personnel and the public that result from paricular accident scenarios.

While the regulation only refers to accidents, the practice has been to also consider offnormal events as distinct from anticipated occupational occurrences. Since no limits are provided for off-normal events, it is prudent to limit the radiological consequences of off-normal events to those for normal conditions of storage.

The purpose of the review, then, is to ensure that the CSAR identifies and analyzes a range of credible off-normal and accident occurrences emphasizing the causes and consequences. For each situation, reference should have been made to the appropriate chapter and section describing the design considerations to prevent or mitigate the accident. Fig. 11-1 shows the type of information required from other seccions of the CSAR to perform the accident analysis review.

\subsection{ACCEPTANCE CRITERIA}

\subsubsection{Radiological Consequences}

Acceptance criteria are governed by 10 CFR Part 72.68 (b) which requires that "any individual located on or beyond the nearest boundary of the controlled area shall not receive a dose greater than 5 rem to the whole body or any o:gan from any design basis accident." Since the distance of the nearest boundary to the controlled area is site-specific, the analysis should assume that this distance is the 100 meter minimum distance specified by the regulation. 


\subsubsection{Safety Analysis Report Requirements}

\section{1,2.2.1 Off-Normal Occurrences}

For off-normal occurrences the following information shall be provided:
A. Identification of the event and the portion of the cask involved.
B. A description of the type of failure or malfunction.
C. A description of the effects and consequences.
D. A descriprion of what corrective actions can be taken to retum to a normal situation.

\subsubsection{Accidents}

For accidents and the effect of extreme natural phencmena the following information shall have been provided.
A. A description of each accident scenario.
B. A dose calculapion for the condition of the cask after each accident.

\subsection{REVIEW PROCEDURES}

\subsubsection{Off-Normal Operation}

\subsubsection{Identification of Component or System Malfunction}

A dry spent fuel storage cask is a passive containment system that has relatively few operating systems for ensuring safety. Those systems or components that can malfunction are the sealing systems due to deterioration of the seal elements or the monitoring system that indicates the state of the iner internal atmosphere.

\subsubsection{Postulated Cause of the Event}

Review the discussion on postulated causes of the event. If, for example, deterioration of the seals is postulated, potential damage mechanisms such as thermal cycling or radiation effects may be possible causes. 


\subsubsection{Detection of the Event}

If the event has significant radiological consequences, means should have been provided for detecting the event. If seal leakage is such an event, then the method for detecting such leaks should he examined for effectiveness and reliability.

\subsubsection{Analysis of Effects and Consequences}

Again, as an example, if seal malfunction and leakage is the event, then the consequences should be analyzed using conservative values of internal pressure, leakage rates, and radioactive contents of effluents. Doses to any individual from gaseous activity release subsequent to an offnomal event involving seal malfuncion and leakage should include the release of ${ }^{3} \mathrm{H}$ and $85 \mathrm{Kr}$ and be compured under the following assumptions: (1) yercent failure of fuel element cladding (generally taken at 10 percent for off-normal conditions of operation), (2) the release fractions of Regulatory Guide 1.25 (Ref. 11.2), (3) the maximum mechanical seal leakage rate, (4) the population weighted inhalation rate of Regulatory Guide 1.109 (Ref. 11.3), (5) a worst case exposure time of one year and a distance equivalent to the CSAR specified site boundary limit, (6) the inhalation dose and whole body dose factors of Regulatory Guide 1.109, and (7) F-stability aumospheric diffusion with a wind speed of 1 meter/sec with plume meander from Regulatory Guide 1.145 (Ref. 11.4). The cumulative dose for such leakage should be compared with the limits established for the site boundary.

\subsubsection{Corrective Actions}

The corrective actions to be taken after the event is detected should be descrioed. If excessive leakage is the problem such corrective actions as replacing the seai or, if the design of the cask permits, welding the closures to the cask body should be described. For either of these operarions, plant personnel must work in the vicinity of the malfunctioning cask and the CSAR should describe the possible dose accumulation based upon an assessment of the duration of the repair activity and the proximity of the personnel to the source of radiation.

\subsubsection{Accidents}

This section of the review deals with high severity/low probability events that could occur over the design life of the ISFSI. These could include handling accidents resulting in a cask drop or the effects of extreme natural phenomena such as tornadoes, earthquakes, fire, explosion and flood. The CSAR should identify each accident, the portion of the cask involved and the type of 
accident. Each accident should be discussed sequentially covering, at least, (a) the cause of the accident, (b) analysis of the accident and (c) the accident dose calculations.

\subsubsection{Cask Drop}

Quite apart form the effect of extreme environmental conditions and nautal phenomena, casks may be dropped as a result of handling accidents. Since 10 CER Part 72 does not aliude to this type of event, it is prudent to assume that a loaded cask may drop from the greatest height to which it is lifted during transport to the storage site and that the surface upon which it falls is at least as hard and rigid as the reinforced concrete storage pad. Paragraph 3.3.1.3 of this guide requires that the drop height and orientation of the cask be specified. It should be recognized that the height assumed for the drop accident will constirute a cask operating limit that may affect the means for transporting a isaded cask to the storage site.

\section{(a) Cause oi the Accident}

The cause of a drop accident could be human error or failure of a component of the lifting/transporation system. Since there are no data on the frequency of such accidents it is difficult to estimate its probability of occurrence. Prudence dictates that it should be assumed cer a ain to happen at least once over the design lifeime of the ISFSI.

\section{(b) Analysis of the Accident}

The analysis performed for the cask drop accident should appear as part of the structural evaluation in Chapter 3 in accordance with paragraph 3.3.4.6.1 of this guide. The results of the analysis provide the basis for esimating tadiological consequences. It is permissibie to address structural failures that result in radiactive release or increased direct radiation. However, it is not permissible to evaluate the criticality consequences of an accident since damage to the basket that results from a drop accident must not be greater than local plastic deformation.

\section{(c) Accident Dose Calculations}

Dose colsequences from both direc: radiation and gaseous activity release depend upon the nature of the damage that results from ine accident. Gaseous activiviry release can result if the DSC seals are damaged or the primary concainment is breached. Increases in direct radiation can result from reduction of shielding either when complete or partial loss of an external neutron shield xccurs or in the case of deformed us cracked gamma shielding. An example of the latter is lead slump as a result of an end drop of a DSC with lend shielding between concentric steel shells. In 
the case of direct radiation, it is prudent to assume the worst case situation for each radiation type. For DSC with external neutron shields, neutron dose should be based upon the complete loss of the exiernal neutron shield and computed for the worst case accident configuration. For gaseous activity release, the following should be assumed: (1) 100 percent cladding failure with the consequence that the entire gaseous inventory is instantaneously seleased to the environment, (2) the release fractions of Regulatory Guide 1.25 , (3) the population weighted inhalation rate of Regulatory Guide 1.109, (4) the inhalation dose and whole body dose factors of Regulatory Guide 1.109, and (5) F-stability atmospheric diffusion with a wind speed of 1 meter/sec with plume meander from Regulatory Guide 1.145. With both direct radiation and gaseous activity release, a worst case condition of nc corrective action should be assumed for a period of at least one year. Moreover, the dose consequences should apply at the ISFSI site boundary specified by the CSAR. This site boundary will then constitute an operating limit. Altematively, the dose consequence could be estimated for the minimum site boundary distance of 100 meters.

\section{1!3.2.2 Cask Tipover}

The circumstances leading to tipping of a cask that has already been placed uneventfully on the storage pad are those arising from extreme environmental conditions or natural phenomena. The design basis criteria for these events are in Chapter 2 of this guide.

\section{(a) Cause of the Accident}

A cask tipover can result from either the direct force of lomado winds, heavy tomado generated missiles, seismic activity or floods.

\section{(b) Analysis of the Accident}

The analysis of this accident is the same as that described in Paragraph 11.3.2.1 (b) for cask drop.

\section{(c) Accident Dose Calculations}

The evaluation of dose consequences is the same as described in paragraph 11.3.2.1 (c) for the cask drop. However, in the case of extreme environmental condicions and natural phenomena, the entire array of casks is vulnerable to tipover. Since the number of casks in the array and their pattern are site specific, the CSAR need only provide sufficient information to allow the ISFSI applicant to evaluate the dose consequences of the entre array. 


\subsection{FINDINGS}

The reviewer verifies that sufficient and adequate information has been provided to satisfy the general requirements of the review plan for the DSC, and that the evaluation supports the following conclusion, to be included in the SER:

"This seccion of the applicant's CSAR has been reviewed to determine that the DSC has been designed in a manner that will assure compliance with the performance requirements of $10 \mathrm{CFR}$ Part 72.67 (a) under off-nomral conditions of storage and 10 CFR Part 72.68 (b) under accident conditions of storage. The scope of the review covers the identification of all credible off-nomal and accident events; the types of failures, consequences, and corrective actions; dose calculations for the condition of the DSC after each off-normal or accident event; and any supportive information or documentation."

"The dose consequences to any individual continuously present at the site boundary due to gaseous activity release from a single DSC following off-normal and accident events are less than mrem/year and mrme/year to the whole body, respectively. The dose consequence at the site boundary due to direct radiation for a single DSC subsequent to the worst case accident event is less than rem/year to the whole body."

"The total dose consequences to any individual continuously present at the site boundary due to gaseous activity release and direct radiation from a single DSC following off-normal and accident events are less than mrem/year and rem/year, respectively. Off-nomal consequerces are less than the is mrem limit established in 10 CFR 72.67 (a). Accident consequences are less than the $s$ rem limit established in 10 CFR 72.68 (b)."

"Sufficient information is provided for a single DSC to erable the ISFSI applicant to establish the total dose consequences at the site boundary for the site specific array."

"Basis for acceptance in the review has been conformance with established guidelines and criteria. The evaluation of the DSC provides reasonable assurance that, under off-normal and accident conditions of storage, it will be possible to store radioactive material in the DSC safely."

"The staff concludes that the protective features provided in the design of the DSC conform to applicable Regulation, Regulatory Guides, and industry standards, and are acceptable." 


\subsection{REFERENCES}

1. Office of the Federal Register, Title 12 Code of Federal Regulations. Part 72, Office of the Federal Register, Washington, DC, January 1984.

2. U.S. Nuclear Regulatory Commission, Regulatory Guide 1.25: Assumptions Used for Evaluating the Potential Radiological Consequences of a Fuel Handline Accident in the Fuel Handling and Storage Facility for Boiling and Pressurized Water Reactors, US. Nuclear Regulatory Commission, Washington, DC, March 1972.

3. U.S. Nuclear Regulatory Commission, Regulatory Guide 1.109: Calculation of Annual Doses to Man from Routine Releases of Reactor Effluents for the Purpose of Evaluating Compliance with 10 CFR Part 50, Appendix I U.S. Nuclear Regulatory Commission, Office of Standards Development, Washington, DC, October 1977.

4. U.S. Nuclear Regulatory Commission, Regulatory Guide 1.145: Atmospheric Dispersion Models for Potential Accident Consequence Assessments at Nuclear Power Plants. U.S. Nuclear Reguiatory Commission, Office of Standards Development, Washington, DC, November 1982. 


\subsection{DECOMMISSIONING}

\subsection{AREA OF REVIEW}

This chapter provides guidance for reviewing the information provided in the CSAR relating to decommissioning or the DSC. 10 CFR Part 72.18 (Ref. 12.1) requires that "each applicant include a proposed decommissioning plan that contains sufficient information on proposed practices and procedures for the decontamination of the site and facilities and for disposal of residual radioactive materials after all spent fuel has been removed." Under the generic rule, the requirement to provide a decommissioning plan applies only to the cask components. The necessity for such a plan reflects the regulatory position that it is required to provide reasonable assurance that the decontamination and decommissioning of the ISFSI at the end of its useful life will provide adequate protection to the health and safety of the public." Under the generic rule, this may be interpreted to require that reasonable assurance be provided to assure that decontamination and decommissioning of the DSC at the and of its useful life provide adequate protection to the health and safety of the public. Consequently, the area of review for decommissioning of a DSC encompass only the proposed practices and procedures for decontamination of the cask components to a level that does not present a hazard to the health and safety of the public.

\subsection{ACCEPTANCE CRITERIA}

\subsubsection{General}

The general acceptance criterion for the decommissioning plan is drawn from 10 CFR Part 72.18 which states, in part, that, "This plan stail identify and discuss those design features of the ISFSI that facilitate this decontamination and decommissioning at the end of its useful life." This acceptance criterion is furher amplified in 10 CFR Par 72.76 which states that, "The ISFSI shall be designed for decommissioning. Provisions shall be made to facilitate decontamination of structures and equipment, minimize the quantity of radioactive wastes and contaminated equipment, and faciliane the removal of radioacive wastes and contaminated materials at the time the ISFSI is permanently decommissioned." Under the generic rule, the provisions of 10 CFR Part 72 cited above are in the main applicable with the subsirution of DSC for ISFSI.

\subsubsection{Assurance of Public Safety}

The disposition of the decommissioned DSC is the responsibility of the ISFSI operator. The methods of disposal are constrained by other regulations such as; 49 CFR Parts 173.421, 173.423 and 173.435 (Ref. 12.2) which provide information on radionuclide activities that may be 
transported as limited quantity materials; 10 CFR Parts 30.14 and 30.70 (Ref. 12.5) that address radionuclide concentracions that are exempt from licensing requirements; 10 CFR Parts 30.18 and 30.71 that address radionuclide quantities that are exempt from licensing requirements; and 10 CFR Parts 61.55 and 61.56 (Ref. 12.4) that address radionuclide concentrations for class $A$ wastes and the characteristics of such waste.

Under the generic rule, the DSC applicant need not address the disposition of an irradiated DSC. However, it is important for the DSC applicant to provide sufficient infomation conceming the level to which the DSC may be decontaminated and the maximum level of activity remaining in the components due to activation after completion of the decommissioning process.

\subsection{REVIEW PROCEDURES}

To facilitate the review of the chapter on decommissioning within the bounds defined in the area of review and the acceptance criteria, the guidance presented in this section should be followed.

\subsection{Provisions to Facilitate Decontamination}

\subsubsection{Unloading the DSC}

Review the CSAR for information relating to the method for cask unloading in preparation for decommissioning. This subject may have bean addressed in Chapter 8 as part of operating procedures. If not, the operating procedures used to ensure safe removal of fission gases, contarninated coolant, and solid contaminants should be described. If altemative methods of cask unloading such as wet unloading in the reactor pool or dry unloading in a hol cell are suggested, it should be demonstrated that the cask is amenable to unloading in either mode. Specific features that should be described include connections for off-gas system venting and hookup of helium supply for flushing and lowering the stored fuel temperature.

\subsubsection{Decontamination}

Subsequent to the unloading, the ISFSI site may elect to remove internal cask cavity surface contaminants. The applicant should describe the features of the cask that facilitate such decontamination such as the nature of the intemal surfaces and the presence or absence of crannies where contaminants may lodge etc. 


\subsubsection{Decommissioning of Cask Components}

Under long term storage some elements in the DSC component materials may become activated. The level of activation is a function of the neutron flux, storage time, and the nature and quantity of the elements present. This information should be documented in the CSAR along with the procedure for computing elemental activation.

\subsubsection{Neutron Flux}

The source and strength of the neutron fluxes assumed in the activation calculations should be described.

\subsubsection{Activation Elements}

All elements present in the DSC components subject to activation should be listed together with their concentrations and weights. Of interest after a 20 year storage period is the level of activity in curies of each radionuclide in the cask body, basket, and closure lid(s). The applicant may also, for reference purposes, indicate the activity as a funccion of time following the unloading process.

\subsection{FINDINGS}

The reviewer verifies that sufficient and adequate information has been provided to satisfy the general requirements of the review plan for the DSC, and that the evaluation supports the following conclusion, to be included in the SER:

"This section of the applicant's CSAR has beer. reviewed to determine that the DSC has been designed in a manner that will assure compliance with the decommissioning requirements of 10 CFR Purts 72.18 and 72.76 . The scope of the review covers the various provisions to facilitate decontamination of the DSC arid decommissioning of the DSC components."

"The DSC design is consistent with the requirements of 10 CFR Part 72.76 requiring an ISFSI to be designed for decommissioning."

"The procedures described for cask unloading are consistent with the requirements of 10 CFR Par 72.18 to provide adequate protection to the health and safety of the public." 
"Sufficient information has been provided to ascertain the expected level of activation of the DSC components as a function of time following decommissioning."

"Basis for acceptance in the review has been conformance with established guidelines and criteria. The evaluation of the DSC and decommissioning procedures provides reasonable assurance that it will be possible to decommission the DSC safery."

"The staff concludes that the protective features provided in the design of the DSC conform to applicable Regulations, Regulatory Guides, and induscry standards, and are acceptable."

\subsection{REFERENCES}

1. Office of the Federal Register, Title 10, Code of Federal Regulations. Part 72, Office of the Federal Register, Washington, DC, January 1984.

2. Office of the Federal Register, Title 49. Code of Federal Regulations, Part 173, Office of the Federal Register, Washington, DC, January 1984.

3. Office of the Federal Register, Title 10. Code of Federal Regulations, Part 30, Office of the Federai Register, Washington, DC, January 1984.

4. Office of the Federal Register, Title 10, Code of Federal Regulation, Pan 61, Office of the Federal Register, Washington, DC, January 1984. 


\subsection{OPERATING CONTROLS AND LIMITS}

Licenses issued under 10 CFR Part 72 (Ref. 13.1) include license conditions that to a large extent are derived from the andyses and evaluations included in the CSAR. Consequently, in accoriance with 10 CFR Part 72.16, the applicant must include proposed technical specifications together with a summary statement of the bases and justification for the technical specifications.

The specific conditions under which a license is issued are detailed in 10 CFR Par 72.33. Not all of these conditions apply to a DSC for which a license is issued under the generic rule. Consequently, the review plan will concentrate on those aspects of the DSC for which controls and limits are necessary to safeguard the bealth and safety of the public and operating personnel.

\section{I AREA OF REVIEW}

The provisions of the Regulation pertinent to the review of a DSC under the generic rule is contained in secrions 72.33 (c) (1), 72.33 (c) (2), 72.33 (c) (3), and 72.33 (c) (4).

\subsubsection{Functional and Operating Limits}

This area of review is concemed with ensuring that functional and operaring limits are provided on fuel handling and storage conditions that are found necessary to:

A. Protect the integrity of the stored fuel

B. Protect operating personnel against occupational exposures $C$. Guard against the release of radioactive materials to the environment.

\subsubsection{Limiting Conditions}

This area of review is concerned with ensuring that the limiting conditions specified represent the lowest functional capabilities or performance levels of equipment required for safe operation of the DSC.

\subsubsection{Surveillance Requirements}

Surveillance requirements are reviewed witb respect to ensuring that the required systems and components for monitoring spent fuel in storage are maintained and to provide confimation that the operation of the DSC is within the required functional and operating limits. 


\subsubsection{Design Features}

Restrictions on design features are reviewed to assess the effect that alterations or modificadions either in materials of construction or geometric arrangements would have on safety.

\subsection{ACCEPTANCE CRITERIA}

The information contained in the CSAR will be deemed acceptable if it conforms to the requirements of 10 CFR Part 72.16 with respect to the inclusion of proposed technical specifications in accordance with the perinent sub-sactions of 10 CFR Part 72.33 and includes an adequate summary of the bases and justification of the technical specifications.

\subsection{REVIEW PROCEDURES}

\subsubsection{Proposed Operating Controls and Limits}

Verify that all operating limits and controls for the DSC have been identified and justified. These limits and controls may be based upon the design criteria for the DSC described in Chapter 2 of this SRP, reflect the safety assessment and evaluations that appear in the CSAR, or the independent safety analyses performed by the reviewers. They must also be complete to the fullest extent possible, explicit in the sense that numerical values or other pertinent data should be recorded, and adequately justified by supporting arguments. The format for operaring controls and limits should be as recommended in the regulatory guide for preparation of TSARS and is summarized here for convenience.

\section{A. Title}

Identification of the particulas conditions for which a control or limit is to be specified. The maximum radiation level at any surfce of the cask would be an exampie.

\section{B. Specification}

The limits within which the particular condition is to be constrained.

\section{Applicability}

This refers to the system or operation to which the control or limit applies and should be clearly defined. 
D. Action

This refers to specific recommendations as to what should be done if a particular control or limit is exceeded.

\section{E. Surveillance Requirements}

Surveillance requirements should be described if they are necessary for monitoring the performance of the DSC to ensure that the specified limits are not exceeded. This may include a description of maintenance functions and routine tests.

\subsubsection{Functional and Operating Limits}

Controls and limits in this area apply to safety related operaing variables that are observable and measurable. Control of such variables is directly related to the performance and integrity of the equipment and confinement barriers.

\subsubsection{Integrity of Stored Fuel}

The integrity of the stored fuel can be compromised either by long term deterioration under normal storage conditions or from impacts due to cask drop or tipover as a result of accident conditions. Under nomal conditions of operation the temperature and suress in the spent fuel rods combine synergistically to degrade the zircalloy cladding by the mechanism of diffusion controlled caviry growth (DCCG). The stress in the rod is generated by the pressure of the fill gas. There are no controls over the pressure in the spent fuel rods. The limiting pressure is usually taken to be the maximum initial pressure corrected for the operating temperature. On the other hand, the maximum temperature is controllable by the design of the DSC and, in fact, is limited to a value that will ensure no significant degradation of the cladding over the design life of the ISFSI. This subject has already been dealt with in Chapters 2,3 and 4 of this SRP where relevant references have been cited. For the purposes of this chapter, the maximum fuel rod temperature under normal conditions of operation is the significant limit that must be reported in the section of the CSAR on operating controls and limits. While the maximum tempernture of the fuel rods is controllable by the design, it is neither directly observable nor measurable in a DSC unless means for measuring temperature are installed. To date passive storage casks for spent fuel have not been furnished with such temperature monitoring instrumentation. Confidence in the claim that the maximum temperature recorded will not be exceeded lies in the credibility of the thermal analysis dealt with in Chapter 4. However, there are design features of the DSC that affect the maximum temperature 
attained by the cladding during storage. One such feature is the provision of an inerr gas internal environment which, in addition to preventing oxidation of the spent fuel, enhances the rate of heat transfer out of the cask. The presence of the inert gas is observable and measurable with appropriate pressure measuring instruments. Operating limits on the intemal pressure of the inert gas should be established, justified and documented in this chapter of the CSAR.

A second feature is the provision of seals at the interfaces of the bolted lids and other cover plates which limit the amount of leakage of the inert gas. The leak rate must be low enough to ensure that the inert environment is effective throughout the design life of the ISFSI. Consequently, maximum anticipated leak rates, which are observable and measurable, should be established, justified and documented in this chapter of the CSAR.

\subsubsection{Protection of Employees Against Occupational Exposures}

Here the performance and integrity of the equipment and confinement barriers determine the effectiveness of protection against occupational exposure. One of the hazards to personnel is the level of radiation at the surface and radiating from the cask. The maximum dose rate allowed by the design is observable and measurable and should be documented in this chapter of the CSAR. Another hazard to personnel is the possible loss of confinement following an accidental drop or tipover of the DSC. Since the integrity of the DCS is demonstrated by analysis for a drop from a specific height, it is imporant that this height not be exceeded during on-site transportation or handling of the loaded cask. Since the height to which the DSC is lifted is observable and measurable the appropriate limit should be established, justified and documented in this chapter of the CSAR.

\subsubsection{Guarding Against the Release of Radioactive Materials to the Environment}

The circumstances that could lead to a release of radioactive material to the environment are the same as those that would pose a hazard to operating personnel. The appropriate controls or limis are therefore the same as indicated in Par. 13.3.2.2.

\subsubsection{Limiting Conditions for Operation}

Limiting conditions are defined in 10 CFR 72.33 (c) (2) as the lowest functional capability or performance level of the equipment required for safe operation. Under the generic rule the "equipment" referred to in this section is interpreted to mean the storage cask and its appuntenances. The lowest functional capability or performance level is further interpreted to refer 
to the design bases that govem the design of the DSC. It cannot be assumed that the DSC can accommodate any increased demands upon its capability beyond those specified by the design bases. Consequently, the design bases themseives are limiting conditions. A distinction is made between limiting conditions as defined here and functional and operating limits insofar as the latter must be directly observable and measurable.

Limiting conditions for operation must be specified even though specific information in this regard may have appeared in previous chapters of the CSAR. Limiting conditions must be documented for, at least, the following rechnical conditions:

Fuel Type

Enrichment

Bumup Level

Specific Power of a Single Assembly

Heat Generation Rate of the Loaded DSC

Maximum Fuei Rod Temperature

Nuclear Criticality Margin

\subsubsection{Surveillance Requirements}

Major emphasis in surveillance specifications should be placed on operating controls and those DSC systems and components essential to safety during all modes of operation or necessary to prevent or mitigate the consequences of accidents. Tests, calibrarions or inspections should be described that verify performance or serve to detect incipient deficiencies. If surveillance is required periodically, the basis for frequency of the required action should be documented.

Verify that the applicant has described under surveillance requirements those operations necessary to ensure that the operation of the DSC is within the required functional and operating limits. An example would be a description of the system adopted to survey the status of the inert gas environment in the DSC.

\subsubsection{Design Features}

These operating concrols and limits cover design characteristics of special imponance to each of the physical barriers and to the maintenance of safety margins inherent in the design of the DSC. The principal objective of this cutegory is to control changes in the design of essential equipment. 
The applicant should be cognizant of those design features that may be altered either deliberately or inadvertently by the user. Some specific features of a DSC that may be vulnerable to change are the type of seals that are used to prevent leakage at the interface of bolted lids and cover plates or a fuel basket that features specific means for maintaining a nuclear criticality margin.

\subsection{FINDINGS}

The reviewer verifies that sufficient and adequate information has been provided to satisfy the general requirements of the review plan for the DSC and that the evaluation supports the following conclusion, to be included in the SEP:

"This section of the applicant's CSAR has been reviewed to determine that the DSC operating controls and limits have been designed in a manner that will assure compliance with the requirements of 10 CFR Parts 72.16 and 72.33. The scope of the review covers the functional and operating limits, limiting conditions, surveillance requirements, and design features of the DSC."

"The applicant has identified and justified all operating controls and limits for the DSC in an acceptable format. They are complete, explicit and adequately justified by supporting arguments and are in general accordance with the requirements of 10 CFR Par 72.16 and the pertinent subsections of 10 CFR Part 72.33."

"Basis for acceptance in the review has been conformance with established guidelines and criteria. The evaluation of the DSC operating controls and limits provides teasonable assurance that, under nomal and accident conditions of storage, it will be possible to store radioactive material in the DSC safely."

"The staff concludes that the protective features provided in the design of the DSC conform to applicable Regulations, Regulatory Guides, and industry standands, and are acceptable."

\subsection{REFERENCES}

1. Office of the Federal Register, Title 10. Code of Federal Regulations, Part 72, Office of the Federal Register, Washingion, DC, January 1984. 